\title{
Woods Hole Oceanographic Institution
}

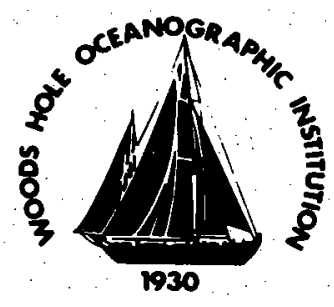

\section{The Arctic Environmental Drifting Buoy (AEDB)} Report of Field Operations and Results:

August 1987 - April 1988

by

Susumu Honjo, Richard Krishfield, Albert Plueddemann

\author{
January 1990 \\ Technical Report
}

Funding was provided by the Office of Naval Research, through grant Number N00014-87,88,89, J-1288.

Approved for public release; distribution unlimited.

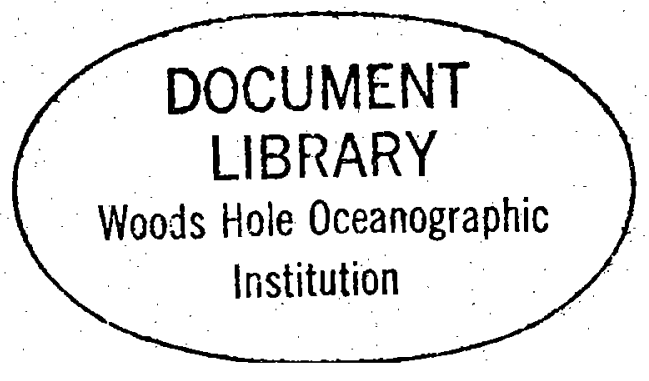




\title{
WHOI-90-02
}

\section{The Arctic Environmental Drifting Buoy (AEDB) \\ Report of Field Operations and Results: \\ August, 1987 - April 1988}

\author{
by \\ Susumu Honjo, Richard Krishfield, Albert Plueddemann
}

\begin{abstract}
Woods Hole Oceanographic Institution
Woods Hole, Massachusetts 02543
\end{abstract}

\author{
January 1990
}

\section{Technical Report}

Funding was provided by the Office of Naval Research, through grant Number N00014-87,88,89, J-1288.

Reproduction in whole or in part is permitted for any purpose of the United States Government. This report should be cited as: Woods Hole Oceanog. Inst. Tech. Rept., WHOI 90-02.

Approved for publication; distribution unlimited.

Approved for Distribution:

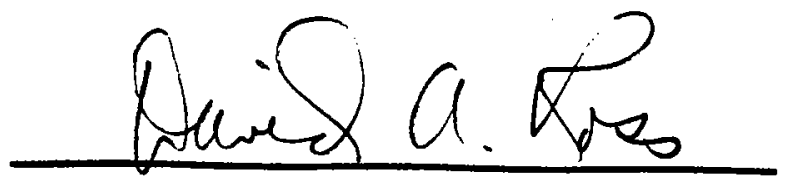

David A. Ross, Chairman

Deparment of Geology \& Geophysics 


\section{Highlights of the 1987-1988 AEDB Experiment}

- The desire to develop a multi-sensor automated station which could be deployed as an ice-tethered mooring system, survive in Marginal Ice Zone (MIZ) conditions, and also function as a surface float in the open ocean for a short period of time prior to retrieval, was realized in the Arctic Environmental Drifting Buoy (AEDB).

- The drift track of the AEDB closely followed the predicted track within the expected time, based on previous Transpolar Drift work and models.

- For deployment of the AEDB mooring line, a method was devised using a CRREL hot water drill ring to drill a $1 \mathrm{~m}$ diameter hole in a $4 \mathrm{~m}$ thick multiyear ice island. While the bow crane of the FS Polarstern was used for removal of the ice plug in this instance, other means could be used in other circumstances.

- The ARGOS location system was used not only to determine the position of the buoy during the experiment, but also to telemeter essential engineering data. Due to the polar orbits of the ARGOS satellites, $94 \%$ of the received transmissions were spaced less than 105 minutes apart. Characteristics of the drift, including speed, were calculated from the locations.

- The temperature, strain gauge and battery information telemetered from the surface sphere was necessary for the near real-time determination of the physical condition of the surface float in the ice and ocean. Furthermore, these observations are being used to improve the design of the surface float as part of the 1991 Ice-Ocean Environmental Buoy Project (IOEB).

- Data from ice thermistor chains was collected by a logger in the surface float until the icefloe broke apart. Upon retrieval, this information was used in the calculation of oceanic heat flux between the ocean and ice (Perovich et al., 1989).

- Nearly $500 \mathrm{~kg}$ of internally recording mooring instrumentation hung below the AEDB sphere. Valid data was retrieved from two fluorometers and an Acoustic Doppler Current Profiler (ADCP), but not from a $C / T$ recorder and a seawater thermistor logger which both malfunctioned. The ADCP results will be used to investigate the climatology and dynamics of internal waves under the sea ice.

- The deepest segment of the AEDB mooring system was lost during the dritt, consequently data from those instruments were not recovered. In the IOEB experiment, almost all of the instruments on the mooring line will be configured to transmit their data via ARGOS. 


\section{Table of Contents}

List of Figures and Tables ii

Acknowledgements iii

Abstract 1

1. Introduction 2

2. Description of the AEDB 10

$\begin{array}{ll}\text { a. Overview } & 10\end{array}$

b. ARGOS Platform Transmit Terminals (PTTs) 14

c. Temperature and Conductivity Measurements 16

d. Ice Thermistor Chains $\quad 19$

e. Fluorometer Packages 21

f. Current Measurements 22

g. Sediment Trap / Micro-filter Pump / Transmissometer 24

3. Deployment, Drift, and Recovery 27

a. Deployment operation 27

b. Drift summary 28

c. Recovery operation 33

4. Results $\quad 35$

Appendix A: Campbell data logger program 122

Appendix B: Fluorometer and data logger tests 124

Appendix C: Schedules for sediment trap and micro-filter pump 125

$\begin{array}{ll}\text { References } & 126\end{array}$ 


\section{List of Figures and Tables}

Fig. 1 - General ice flow pattern in the Arctic Basin 3

Fig. 2 - Drifts of the buoys in the Arctic Ocean Buoy Network for 1979

Fig. 3 - AEDB schematic $\quad 11$

Table 1 - Deployment parameters 13

Fig. 4 - Sensor positioning on buoy sphere 15

Fig. 5 - PTT sensor wiring diagram $\quad 17$

Fig. 6 - Temperature and conductivity sensors / lce thermistor chains 18

Fig. 7 - Wiring diagram for Campbell data logger 20

Fig. 8 - AEDB drift track 29

Table 2 - AEDB drift regions 30

Fig. 9 - January temperature, speed, and strain 32

Table 3 - AEDB section data 36

Fig. 10 - Histogram of number of ARGOS location fixes versus time difference between consecutive fixes 38

Fig. 11 - Azimuth stereographic projection plots of drift track 40-44

Fig. 12 - AEDB speed and East and North velocity time series $\quad 46-50$

Fig. 13 - AEDB sphere temperature times series 52

Fig. 14 - PTT battery voltage time series $\quad 54-55$

Fig. 15 - AEDB sphere strain gauge time series 57-61

Fig. 16 - Speed of AEDB and ice and water temperature time series 63

Fig. 17 - AEDB fluorometry time series 65-66

Fig. 18 - ADCP temperature, tilt, and heading time series 68-71

Fig. 19 - ADCP battery voltage and transmit current time series 73-76

Fig. 20 - ADCP echo amplitude data for beam $1 \quad 78-81$

Fig. 21 - ADCP echo amplitude data for beam 2

Fig. 22 - ADCP echo amplitude data for beam $3 \quad 88-91$

Fig. 23 - ADCP echo amplitude data for beam $4 \quad 93-96$

Fig. 24- ADCP absolute velocity time series for the east direction 98-101

Fig. 25- ADCP absolute velocity time series for the north direction 103-106

Fig. 26 - ADCP velocity time series with depth average removed, east direction

108-111

Fig. 27 - ADCP velocity time series with depth average removed, north direction

Fig. 28 - ADCP vertical velocity time series 


\section{Acknowledgements}

Without valuable advice and assistance from a large number of engineers and scientists at the Woods Hole Oceanographic Institution, the AEDB project would never have been completed. These individuals include $K$. W. Doherty who designed the surface buoy, A. Gordon who coordinated the construction of the buoy, P. Clay and S. Manganini who designed and helped construct the underwater array, E. Mellinger who assisted in the design of the satellite communication system for the AEDB, Dr. A. J. Williams who provided underwater electronic loggers, Dr. R. Koehler and A. Sharp who designed and assisted in the installation of the strain gauge circuitry in the interior of the sphere, $\mathrm{K}$. von der Heydt who provided us with valuable advice on the expected ice conditions in the Transpolar Drift, and E. Evans who assisted with the collection of the satellite data. We thank all our colleagues cited above.

We are grateful for our research partners at the U. S. Cold Regions Research and Engineering Laboratory, Hanover, New Hampshire, in particular Dr. D. Perovich, Dr. W. B. Tucker III, and Dr. J. Govoni whose help and advice were most crucial for our successful field operation. They furnished a large diameter pressurized hot water auger, making it possible to drill a large diameter hole through the multi-year ice with unprecedented efficiency.

Without the FS Polarstern, which successfully brought the AEDB as far north as $86^{\circ} \mathrm{N}$ by breaking up the ice-filled Arctic Ocean, this program would never have gotten off the ground. We thank Dr. Jörn Thiede, Chief Scientist of the Arktis IV Expedition, Leg 3, cruise coordinator Dr. S. Pfirman, logistics officer R. A. Krause, and the Master, officers, and crew of the Polarstern and the Alfred Wegener Institute of Polar and Marine Research. Co-author R. Krishfield, AEDB project coordinator, extends his gratitude to the many scientists and crew on board the Polarstern who volunteered to assist him in deploying the AEDB on the pack ice.

The most crucial help was provided by the Marine Research Institute, Reykjavik. Dr. J. Olafsson coordinated the recovery operation of the AEDB with the cooperation of the Icelandic Coast Guard aircraft. MRI dispatched the R/S Arni Fridriksson with Chief Scientist Dr. S. Kristmansson to cooperate with R. Krishfield in pursuing the recovery of the AEDB under rough sea conditions. Without the skill and enthusiasm of the captain, crew and scientists of MRI, the AEDB could not have been recovered. Our most sincere gratitude is dedicated to them. 
We received a great deal of encouragement and support from international colleagues before, during, and after the experiment; in particular, Dr. H. Hoeber, Meteorological Institute, University of Hamburg, who provided us with wind and temperature data from his drifting buoy. We thank Dr. P. Wadhams, Scott Polar Research Institute, Cambridge, Dr. K-P. Koltermann, German Hydrographic Institute, Hamburg, and Dr. E. Hartwig, ONR, Arlington for valuable encouragement and suggestions.

This study was supported by the Office of Naval Research, Code 1125AR, Arlington, VA, under the grant N00014-87, 88, 89-J-1288. It was Dr. G. L. Johnson who encouraged pursuit of this ambitious program in 1987 and guided us to the successful completion. Dr. T. B. Curtin, who succeeded as manager of ONR's Arctic Programs after Dr. Johnson, also gave us very valuable advice and participated in the interpretation of all phases of the physical oceanographic data gathered by the AEDB. We are most grateful to these two colleagues.

This report is dedicated to the two founding fathers of the science of the Transpolar Drift, Fridtjof Nansen and Ivan Papanin. Their courage and insight inspired modern Arctic oceanography, 100 and 50 years ago, respectively. 


\title{
The Arctic Environmental Drifting Buoy (AEDB)
}

\author{
Report of Field Operations and Results:
}

August, 1987 - April 1988

by

Susumu Honjo, Richard Krishfield, Albert Plueddemann

Woods Hole Oceanographic Institution

Woods Hole, Massachusetts 02543

January 1990

\begin{abstract}
There are strong reasons to gather data on polar oceanography and climatology in real time using fully automated, unattended instrumentation systems for long periods; particularly during the inaccessible winter months when moving ice is extremely hazardous. We deployed an Arctic Environmental Drifting Buoy (AEDB) on 4 August 1987 at $86^{\circ} 7{ }^{\prime} \mathrm{N}, 22^{\circ} 3^{\prime} \mathrm{E}$ off of the FS Polarstern on a large $3.7 \mathrm{~m}$ thick ice island. The AEDB consisted of 2 major components: a $147 \mathrm{~cm}$ diameter surface float housing ARGOS transmitters and a data logger for ice-profiling thermistors, and a $125 \mathrm{~m}$ long mooring line attached to the sphere and fed through a $1 \mathrm{~m}$ diameter ice hole. Along the mooring were deployed 2 fluorometers, conductivity and temperature loggers, an Acoustic Doppler Current Profiler (ADCP), a current meter, and a timeseries sediment trap/micro-filter pump/transmissometer unit. The AEDB proceeded southwesterly with the Transpolar Drift at an average speed of $15.3 \mathrm{~km} /$ day, with a maximum speed of $88.8 \mathrm{~km} /$ day. On 2 January 1988, the AEDB dropped into the water while passing through the Fram Strait and for the remaining drift period was either free-floating on the water surface or underneath the sea ice. Throughout this period, the transmitters onboard successfully transmitted position, temperature, and strain caused by ice on the sphere. Although the sediment trap package was lost during the drift, valuable data was collected by the other instruments throughout the experiment. The ice thermistor data was used to determine oceanic heat flux, while continuous ADCP observations over the Yermak Plateau provided a wealth of information for understanding internal waves in the ice-covered ocean. The buoy was recovered by the Icelandic ship R/S Arni Fridriksson on 15 April 1988 at $65^{\circ} 17^{\prime} \mathrm{N}, 31^{\circ}$ $38^{\prime}$ 'W, off southeastern Greenland, completing $3,900 \mathrm{~km}$ of drift in 255 days. We are in the process of constructing the next automated stations which are planned for deployment in both the north and south polar regions in 1991-92.
\end{abstract}




\section{Introduction}

Environmental investigation of the Arctic has never been more important than it is now with respect to global change and many aspects of world security. Strong justification for further studying the oceanography of Arctic sea ice includes the following reasons: First, sea ice insulates the latent heat of the water, thus the properties of the Arctic sea in the packed and mixed ice zone decisively influence the present climate dynamics of the northern hemisphere. Both the extent and the thickness of the polar sea ice covers are sensitive to the transfer of heat from the ocean to the underside of the ice (Untersteiner, 1986; Maykut, 1982). Second, the Arctic is the precursor of global environmental change because of the unique characteristics of the physical phases of water (Andrews, 1988). Scientific observation of sea ice provides us with the first signs of long-range climatic change caused by anthropogenetic forcing, such as the green house effect and the reduction of reverine discharge in the Arctic basin.

Among many important ice-covered ocean areas of the Arctic, the Transpolar Drift has gathered the most attention from multidisciplinary studies. Essentially, the ice formed in the Arctic basin flows in a clockwise gyre in the northweștern basin and straight southward through the pole, then exits the Arctic Ocean through the Fram Strait, and continues to drift along the east coast of Greenland while dissipating volume by mixing southern Norwegian and Icelandic Currents. This linear southward portion of the drift, from offshore East Siberia Island to its extinction southeast of Greenland, is called the Transpolar Drift (Figure 1). The Transpolar Drift is the largest single drift of sea ice $(0.2$ Sverdrups at the Fram Strait; Wadhams, 1986), which provides an enormous negative heat flux to the Nordic Seas and also to the North Atlantic Ocean.

In addition to its importance in relation to its physical and climatological setting, the Transpolar Drift appears to contribute an important role in the biogeochemical cycles of the North Atlantic. For example, recent biogeochemical studies of ocean stations in the extreme north and south of the Atlantic Ocean have revealed many conspicuous differences in their ocean processes of carbon cycling (e.g. Honjo, 1990). First, the magnitude of particulated carbon (and nitrogen) brought into the Greenland and Norwegian Seas is several times greater than the amount brought into their Antarctic counterpart, the central Weddell Sea. Second, against expectations, the Nordic Seas comprise a "carbonate ocean" where the calcium carbonate flux exceeds that of biogenic silica, while the pelagic Southern Ocean is a "silica ocean" where a very small 
Figure 1

\section{General ice flow pattern in the Arctic Basin}

(Gorshkov, 1983)

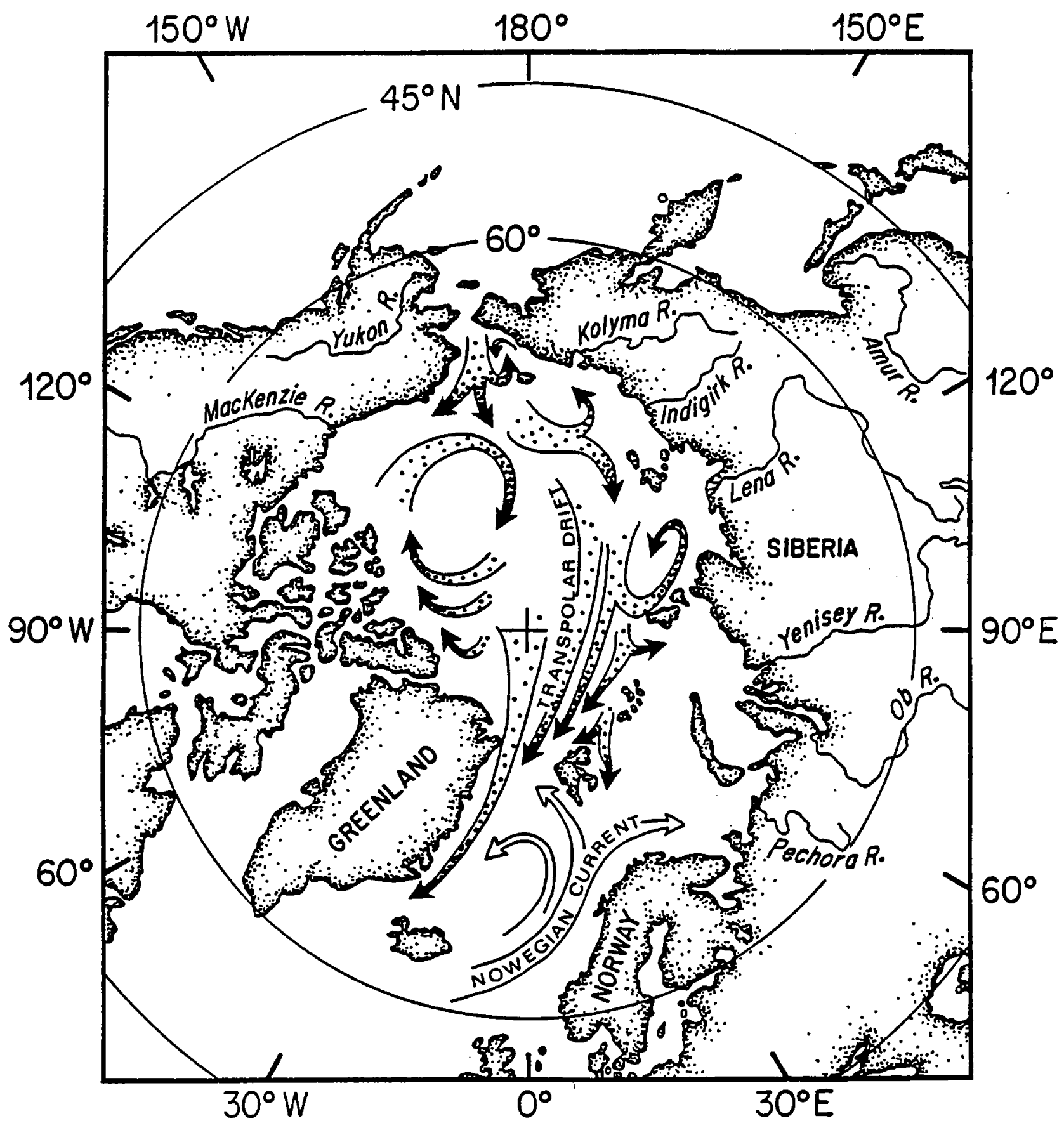


amount of calcium carbonate is produced by primary producers. Third, a relatively high carbon and nitrogen flux, close to the annual average, is maintained in the Fram Strait-Greenland Sea area during mid-winter. In contrast, under the pelagic Southern Ocean ice sheet phytoplankton production decreases to almost zero during the austral winter.

Explanations for these biogeochemical characteristics of the Transpolar Drift area are not readily available. One hypothesis is that the Transpolar Drift is more correctly defined as a conduit system which transports the Arctic river discharge through the Arctic mediterranean, thus making the Fram Strait the true combined estuary of all Arctic-basin rivers. Consequently, the Drift carries significant river elements and compounds which strongly influence the biogeochemical setting of the southern area of the Drift and the Nordic Seas (Honjo, 1990).

Our long-term objective is to clarify the global role of the sea ice that moves through the Arctic Basin and overflows into the northern Atlantic Ocean by depicting its physical, energetic and biogeochemical characteristics; particularly those characteristics of the southern Transpolar Drift, where the melting process is more significant than new ice formation. In pursuit of this objective, a number of significant contributions made in the last decade can be cited, including the modeling of Arctic ice motion (e.g., Hibler and Walsh, 1982), glaciology (e.g., Weeks and Ackely, 1982), marine chemistry (e.g., Öslund and Hut, 1984: Jones et al., 1990), the Marginal Ice Zone studies (many international MIZEX related publications: Johannessen et al., 1983), and particle flux/biogeochemistry (e.g., Honjo, 1990).

From a more historical perspective, Transpolar Drift research has developed through a number of glorious benchmarks of adventure and scientific accomplishment. It was the ingenious idea of Fridtjof Nansen to freeze a specially-built ship, the Fram, into the ice of the East Siberian Sea and allow it to drift; expecting that the current would bring the ship to the North Pole. Nansen was convinced that the wind-driven polar current was the agent responsible for transporting the wreckage of the Jeannett from the East Siberian Sea through the passage between Svalbard and Greenland; this current is now known as the Transpolar Drift. This Norwegian North Pole expedition, which travelled with the pack ice from 1893 to 1896 (Nansen, 1897), not only returned with a wealth of information about Arctic sea ice in the basin, but also strongly impressed polar researchers with the value of long-term scientific camp-research. 
In 1937, Ivan Papanin and his colleagues set up a scientific station on an ice floe which drifted south through the Fram Strait and along the west coast of Greenland. This expedition acquired an enormous volume of high-quality sea ice (as well as oceanographic) data which spanned all disciplines and established the foundation of Transpolar Drift research practiced today. Since then, more than 35 long-term drifting ice camp expeditions have been attempted all over the ice covered Arctic Ocean, including Alpha (Canada), long-standing "North Pole" expeditions (Soviet), and the most recent Coordinated Eastern Arctic Research Experiment (CEAREX).

The Soviets began to deploy unmanned radio stations to understand the variability of the trajectories of the Transpolar Drift in 1953 and maintained the program into the 1960s (the Drifting Automatic Radio-Meteorological Station program). However, as Dr. R. Colony noted, very little data from these experiments has been published (Colony, 1990). Since the late 1970's, the Arctic Buoy Program (Untersteiner and Thorndike, 1982) has simultaneously placed up to 20 automated buoys over the entire Arctic Basin; each of which was linked to a land laboratory through the ARGOS satellite. These air-dropped buoys have collected data on ice motion, surface atmospheric pressure, and surface temperatures for more than 100 station-years up to the present (Figure 2, Thorndike and Colony, 1980). Using similar technology, the Norwegian programs also contributed to an understanding of the ice motion, particularly in the southern Arctic area (Vinje and Finnekasa, 1986). These data are the foundation of the modern observational understanding of sea ice motion in the Arctic Basin.

The highly successful Arctic Buoy Program mentioned above should be continued in order to cover yet unexplored areas of the Arctic and to gather more information on the inter- and intra-seasonal variabilities of ice movement in the Arctic Ocean and elsewhere. However, we realize that the Arctic Buoy Program is still only a small fraction of what is required in Arctic environmental research for understanding its critical role in the changing earth. In particular, we need more year-round observational oceanographic information from underneath the sea ice (Aagaard, 1989). Specific examples of what is required are measurements of the variability of temperature, salinity, primary productivity, and other critical criteria in the upper oceans with reference to the thermal properties of sea ice and its thickness, thermal structure and its variability of holocline water, details of the current structure and its relation to pack-ice movements. Time-series observations of particle fluxes and associated biogeochemical information are 
Figure 2

Drifts of the buoys in the Arctic Ocean Buoy Network for 1979

(Thorndike and Colony, 1980)

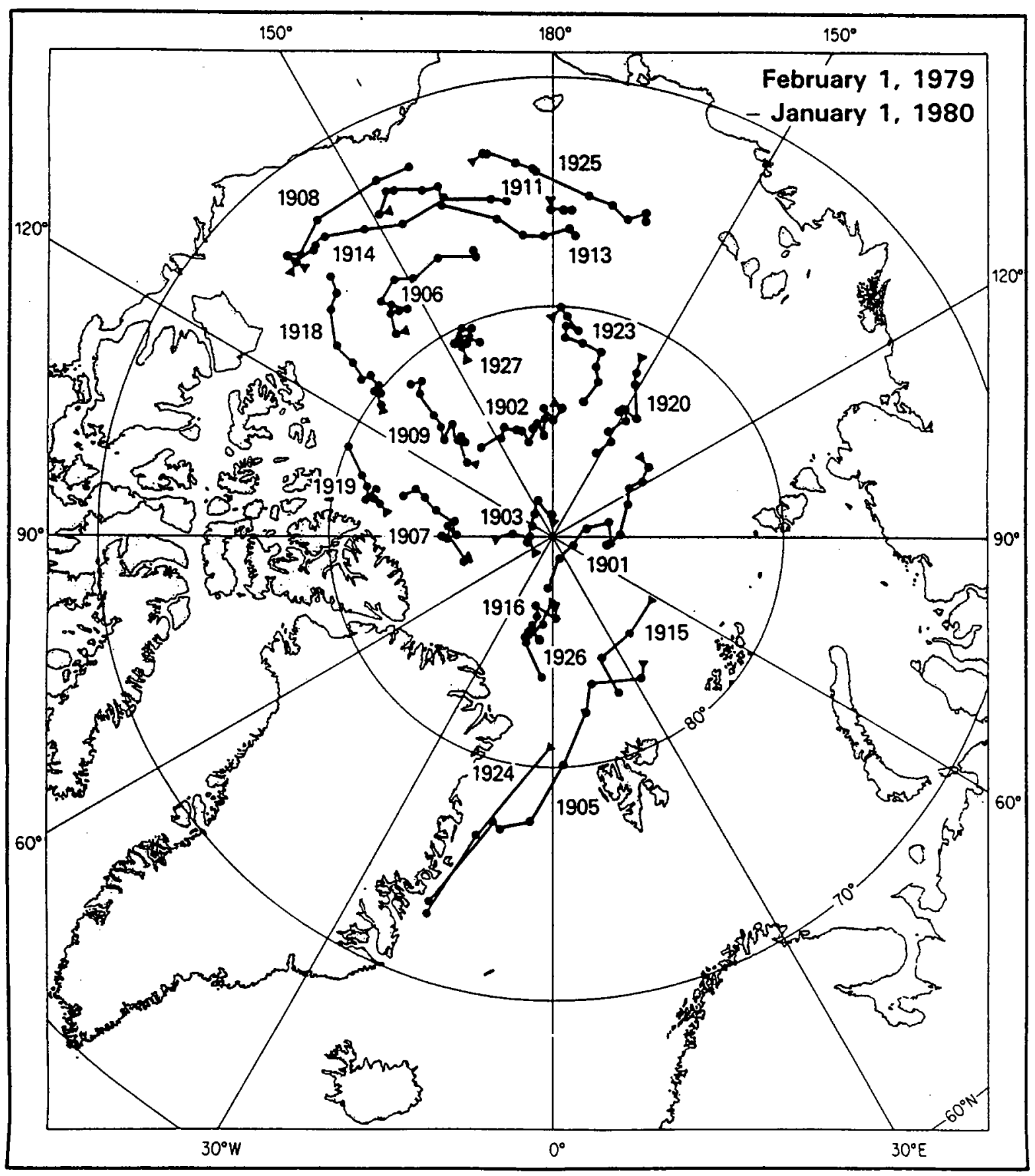


vital to understand the biogeochemical processes in the Arctic Ocean and to make paleoceanography more useful for the prediction of environmental changes taking place in the Northern Hemisphere.

Frequent, synchronous measurements of a variety of parameters must be made using tightly controlled coherent methods, so that an investigator can cross reference between multifaceted data sets in order to gain a more comprehensive understanding of the environment. The advancement of recent sensor technology, in-situ data processing, and satellite data transmission led us to design an automated, extremely durable, self-sustaining, multi-sensor environmental data collecting station which could function independently for more than one year. We designed and produced a prototype model of an ice-tethered mooring array, called an Arctic Environmental Drifting Buoy (or AEDB), with the support of the Office of Naval Research, Arlington, Virginia in 1987. A detailed description and review of the design of the AEDB, its procedure of deployment and recovery, and the scientific results from this prototype experiment are presented in this technical report.

The AEDB experiment was primarily designed to study the feasibility of developing and operating a multi-sensor automated station which could be deployed as an ice-tethered mooring system, but also survive as a surface float when released into the water. In particular, the buoy had to be able to withstand extremely harsh conditions while it was in a mixed ice zone. The survivability of any conventionally designed buoy with a long and heavy underwater mooring array is considered to be very slim under dynamic mixed ice zone conditions where ice floes crush and pile up on any floating object.

The prototype automated station consisted of an ice-ocean surface float and a $125 \mathrm{~m}$ taut line mooring array with many sensors. The spherical buoy was $147 \mathrm{~cm}$ in diameter and served as the surface flotation device. On the outside of this buoy, two pancake antennae for satellite transmission were mounted. Inside, dual ARGOS communication electronics (Platform Transmit Terminals) and an electronic logger for ice profiling thermistor chains were housed in a watertight cylinder. Against the inner steel skin of the buoy, 6 thermistors and 8 strain gauges were attached. The skin itself was galvanized, $5 \mathrm{~mm}$ thick, soft steel which recorded the major crushing events as dents, while measurements from the strain gauges were simultaneously broadcast. Eight-word data packages from each $\mathrm{PTT}$, including pressure on the sphere, temperature, and operating voltage, were transmitted via the ARGOS system and received at the Woods Hole Oceanographic Institution approximately 20 times a day. The remaining 
space in the sphere was filled with non-permeable closed-cell polyurethane foam.

The array was joined to the bottom of the sphere via a gimbal mechanism. Along the $125 \mathrm{~m}$ of taut line, 15 sensors, including an Acoustic Doppler Current Profiler, conductivity and fluoresence loggers, and a sediment trap/micro-filter pump package with transmissometer, were deployed as illustrated in Figure 3. In this prototype station, the technology to transfer the signals from the underwater sensor packages to the satellite transmitters was not established. (This design has recently been completed and will be applied to the 1991 IOEB experiment.) Therefore, four large capacity, solid-state electronic loggers were deployed at 3 depths. A $300 \mathrm{~kg}$ anchor at the bottom of the line completed the array.

The AEDB was settled on a multi-year ice floe with an estimated size of several square kilometers at $86^{\circ} 7 \mathrm{~N}, 22^{\circ} 3^{\prime} \mathrm{E}$, on August 4,1987 off of the FS Polarstern, Alfred Wegener Institute of Polar and Marine Research, Bremerhaven, FRG, Dr. Jörn Thiede, Chief Scientist. After drifting southward with the Transpolar Drift for approximately $3,900 \mathrm{~km}$ through the Fram Strait and along the east coast of Greenland, the AEDB was recovered on April 15, 1988 at $65^{\circ} 17^{\prime} \mathrm{N}, 31^{\circ} 38^{\prime} \mathrm{W}$ (west of Iceland) by the R/S Arni Fridriksson, Marine Research Institute, Reykjavik, Iceland.

We were successful in recovering most of the underwater sensors except for the sediment trap-transmissometer package which was lost during the drift. As seen in this report, the quality of much of the retrieved data from the scientific sensors, particularly drift speed/direction and subsurface current profiles, is excellent and useful. Publication of scientific results of the 1987-88 AEDB experiment has already begun (e.g., Perovich et al., 1989).

In conclusion, we have found that an automated ice-ocean observation station, such as an AEDB, can be deployed in an energetic environment such as the Transpolar Drift and will retrieve a large amount of useful high quality data from many sophisticated sensors; although we found that some aspects of the individual data collection devices need improvement. It is obvious that automated ice-ocean observation systems are worthwhile in overcoming the extremely adverse conditions of polar oceans; especially during the winter. Recent technology indicates that the quality and quantity of data acquired by an automated station can exceed that of a manned station, which tends to be considerably riskier and more expensive. Still, an automated station is not feasible for some types of research, such as bottom coring. While it was once impossible to do synchronous measurements of critical parameters in vastly remote areas like the northern and southern Arctic, or even in the Antarctic. 
Ocean, now it is technically feasible.

Based upon the experience from the successful (prototype) AEDB experiment, we have designed and are in the process of constructing a more sophisticated version of an automated polar ice-ocean research station: the IceOcean Environmental Buoy (IOEB). The major difference in an IOEB from an $A E D B$ is that the majority of measured signals from sensors, including those from an $A D C P$, will be transmitted via satellite. Using a new material for the surface float, based on the results from the AEDB's strain gauge information, the IOEB is far more lightweight and therefore portable by helicopter. In 1991, a group of international scientists plans to deploy a number of IOEBs, not only in the Transpolar Drift (USA), but also in the northern Arctic's Canadian Basin (Japan), as well as in the Southern Ocean's Weddell Sea (UK-Norway). Instant, direct and synchronized comparisons of those extremely remote but ordinarily sea icecovered areas should provide us with more valuable information needed to understand the polar environment and should enable us to produce more realistic prediction models. 


\section{Description of the AEDB}

\section{a. Overview}

The AEDB had two major components: a 5-foot diameter steel surface float and a mooring line of self-contained oceanographic instruments extending through a $1 \mathrm{~m}$ diameter icehole (Fig. 3). The foam-filled surface sphere housed the ARGOS telemetry systems required for determining the location of the buoy and provided triple the buoyancy required to maintain the $500 \mathrm{~kg}$ of mooring instrumentation.

The surface float was constructed from a $147 \mathrm{~cm}$ O.D. Navy surplus steel sphere, of the type used during World War II to cordon off harborways. The thickness of the steel skin varied between 5 and $7 \mathrm{~mm}$, amounting to an air weight of $300 \mathrm{~kg}$ when empty. The original surface had attachment points at either pole and a single fill/vent plug. At WHOI, the sphere was cut open and a $53 \mathrm{~cm}$ diameter cylindrical tube segment was added, providing interior access from the top. Fifty $\mathrm{kg}$ of lead was added to the floor to increase the vertical stability of the float. Strain and temperature sensors were positioned on the inside wall of the sphere, while on the outer surface, two patch antenna mounts were fixed at $34^{\circ}$ angles from the vertical.

Accessible from the top of the sphere, a cylindrical watertight aluminum compartment housed a rack of electronics for ARGOS telemetry, sensor conditioning, and data logging operations. The temperature and strain sensors mounted on the inside wall of the sphere were interrogated by the two ARGOS transmitters inside the housing. Two thermistor chains installed in the ice surrounding the buoy were attached to the sphere at a watertight bulkhead along its equator. Linking the thermistor chain connector on the sphere with the bulkhead on the inner housing lid was a 36-wire pressure resistant extension cable. Watertight bulkhead connectors and cables were used between the external devices and the inner housing lid to ensure isolation from external moisture at pressures up to $150 \mathrm{PSI}$. With all the cables and the housing installed, the space between the inner package and outer steel shell was filled with a cellular insulating foam to provide backup buoyancy if the steel shell cracked under ice pressure.

Flat patch antennas were used on the AEDB to physically transmit the signals to the ARGOS satellite. These durable antennas do not protrude above the surface of the sphere which makes them optimal for a hostile Arctic environment. Furthermore, each antenna radiates a $180^{\circ}$ pattern which, between 


\section{Arctic Environmental Drifting Buoy}

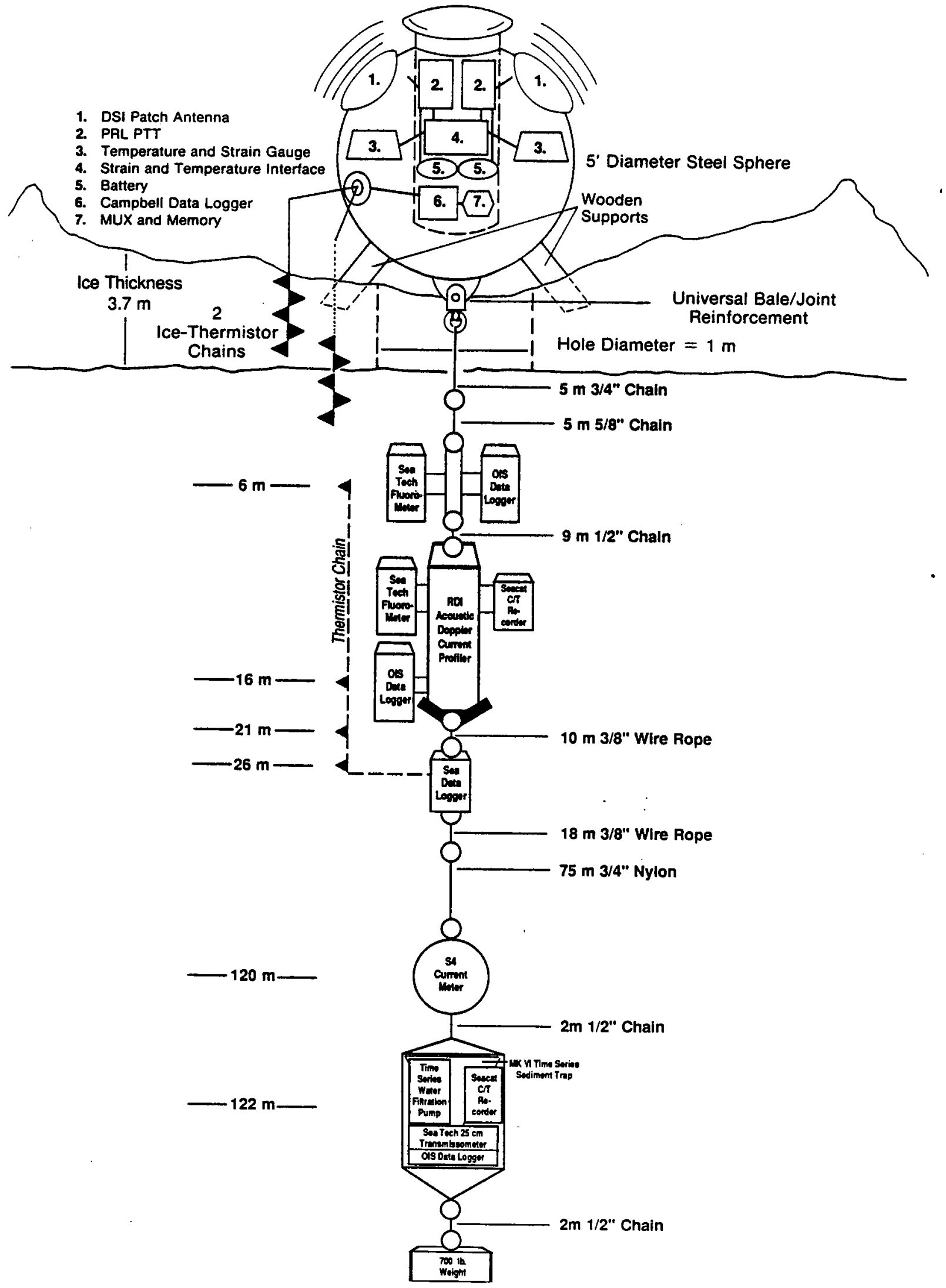


the two units, makes signals to the satellite visible from virtually any angle the sphere may be at in relation to vertical.

The mooring line which extended through the ice to a depth of $125 \mathrm{~m}$ below the surface of the water was deployed with the following instrumentation:

-two fluorometer packages;

-a temperature thermistor chain and micrologger;

-an Acoustic Doppler Current Profiler (ADCP);

-an electromagnetically induced current meter;

-an instrument package consisting of a time-series sediment trap, a time-series water casting/filtration pump, and a precision

transmissometer with data logger;

-two conductivity/temperature $(\mathrm{C} / \mathrm{T})$ recorders.

All instruments were synchronized to take readings at the beginning of the hour, respective to their individual scanning intervals. A summary of the deployed operating parameters and specifications is given in Table 1. A detailed discussion of the functions and placements of each of these instruments on the mooring line follows.

The two major concerns in the design of the mooring system of the AEDB were the survivability of the buoy in the ice, and the survivability of the mooring line once the buoy is in the open ocean. In the ice, the surface sphere has to withstand destruction by colliding ice floes, as well as damage by aggressive polar bears or other outside forces. Out of the ice, the buoy must remain afloat in whatever sea conditions exist, in order to be located and recovered.

Furthermore, the mooring line must not be ripped from the sphere in either situation, else the majority of the internally recorded or collected scientific information will be lost.

Three sizes of galvanized chain (1/2", 5/8", and 3/4"), 3/8 " wire rope, and $3 / 4$ " nylon connected the instruments, or instrument frames together. While the shallow fluorometer package was attached to the mooring on a stainless steel strongback, the deeper fluorometer package was mounted in an electropolished stainless steel frame with the $A D C P$ and one $C / T$ unit. These units were mounted together to eliminate interference in front of the downward facing sensors of the ADCP. For the same reason, the fluorometer located below this package was mounted in an in-line stainless steel cage to prevent it from protruding out from the mooring line. The $\$ 4$ current meter was located in-line, while the sediment trap, pump, and transmissometer were mounted with the second $\mathrm{C} / \mathrm{T}$ unit in a galvanized aluminum frame. At the end of the line hung a 
Table 1

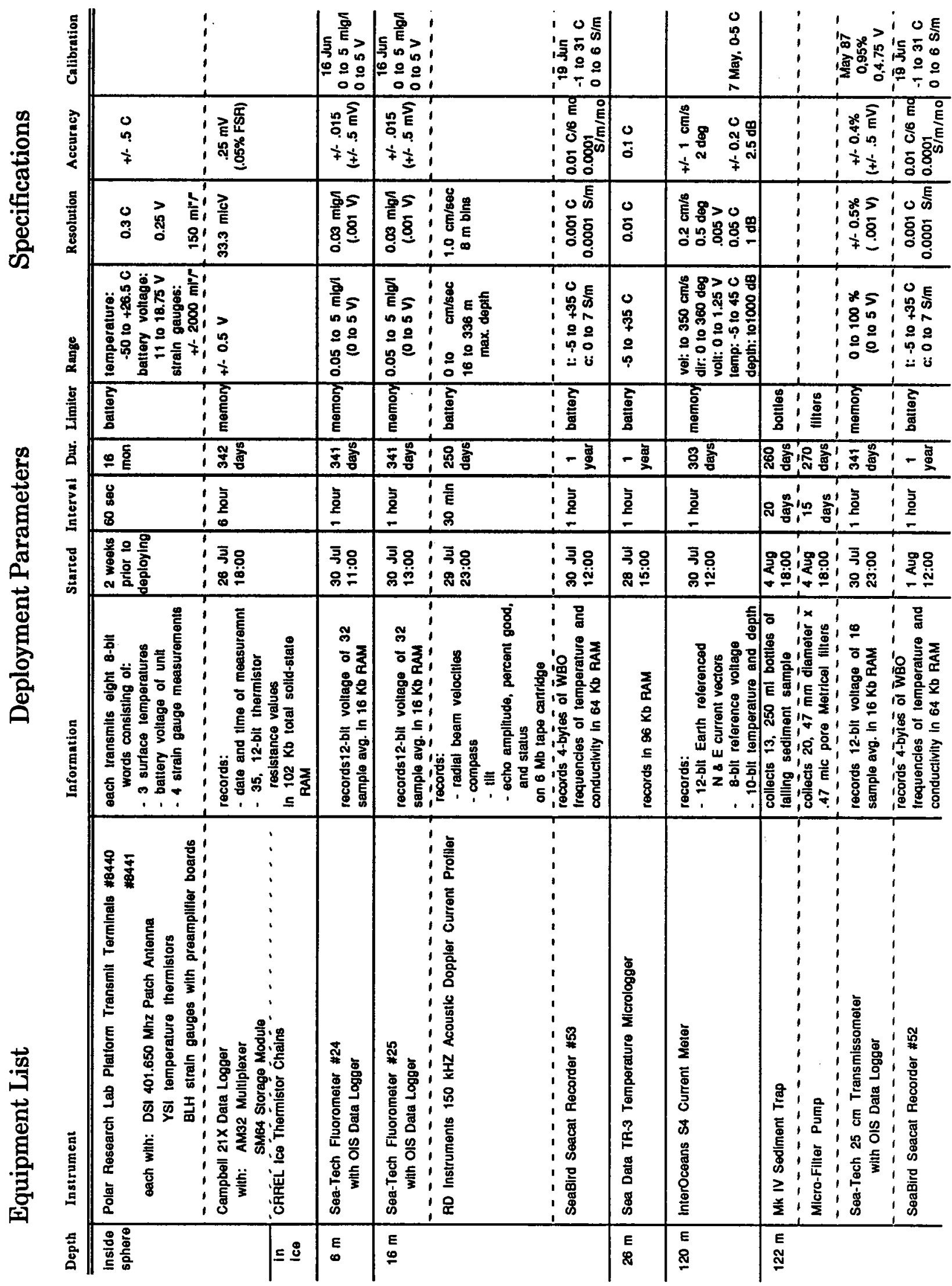


railroad wheel, providing ballast for the mooring. Throughout the line, no link was rated at less than $5,000 \mathrm{~kg}$ maximum load.

Anticipating that the buoy would spend a portion of its time in the open ocean, a $75 \mathrm{~m}$ length of nylon and $350 \mathrm{~kg}$ depressor weight at the bottom of the mooring line was incorporated to allow the sediment trap to be dynamically decoupled from the sphere in moderately rough seas. The nylon was to reduce the sea anchor effect of the sediment trap, while the weight would maintain a positive mooring line tension in most fair weather sea conditions. Furthermore, a steel universal/bale joint attached the mooring line to the sphere with the purpose of reducing friction at that critical juncture.

\section{b. ARGOS Platform Transmit Terminals (PTTS)}

The Polar Research Laboratory PTTs each transmitted eight words of sensor information via ARGOS satellite to ground stations where the position of the buoy was determined by the Doppler effect on receive frequencies. The buoy was monitored daily for its position in (or out of) the sea ice. While this information was essential for recovery, it also provided ice drift vectors which have been incorporated into the ADCP current measurements made below the surface.

Each PTT transmitted three temperature readings from temperature sensors positioned along vertical lines on opposite sides of the sphere (Fig. 4). Each set had one sensor mounted on the equator, and one near either pole of the sphere. The intention was to analyze the temperature differences at six locations of the float and determine characteristics of the environment surrounding the sphere. Due to the thermal conduction of the steel shell and inaccuracy of the measurements, however, the differences between the separate sensors were insignificant.

Strain gauges mounted along the sphere's equator were used to indicate the presence of ice pressure surrounding the buoy, while strain gauges mounted on the floor of the sphere were intended to observe excessive force in the direction of the mooring line (Fig. 4). Each PTT transmitted data from four strain gauges representing one half of the float, divided vertically.

Altogether, each ARGOS transmission contained 3 words of temperature, followed by the lithium battery voltage of the PTT unit, followed by 4 strain gauge readings. For positioning purposes, the PTTs transmitted a new message every 
Sensor Positioning on Buoy Sphere

Figure 4

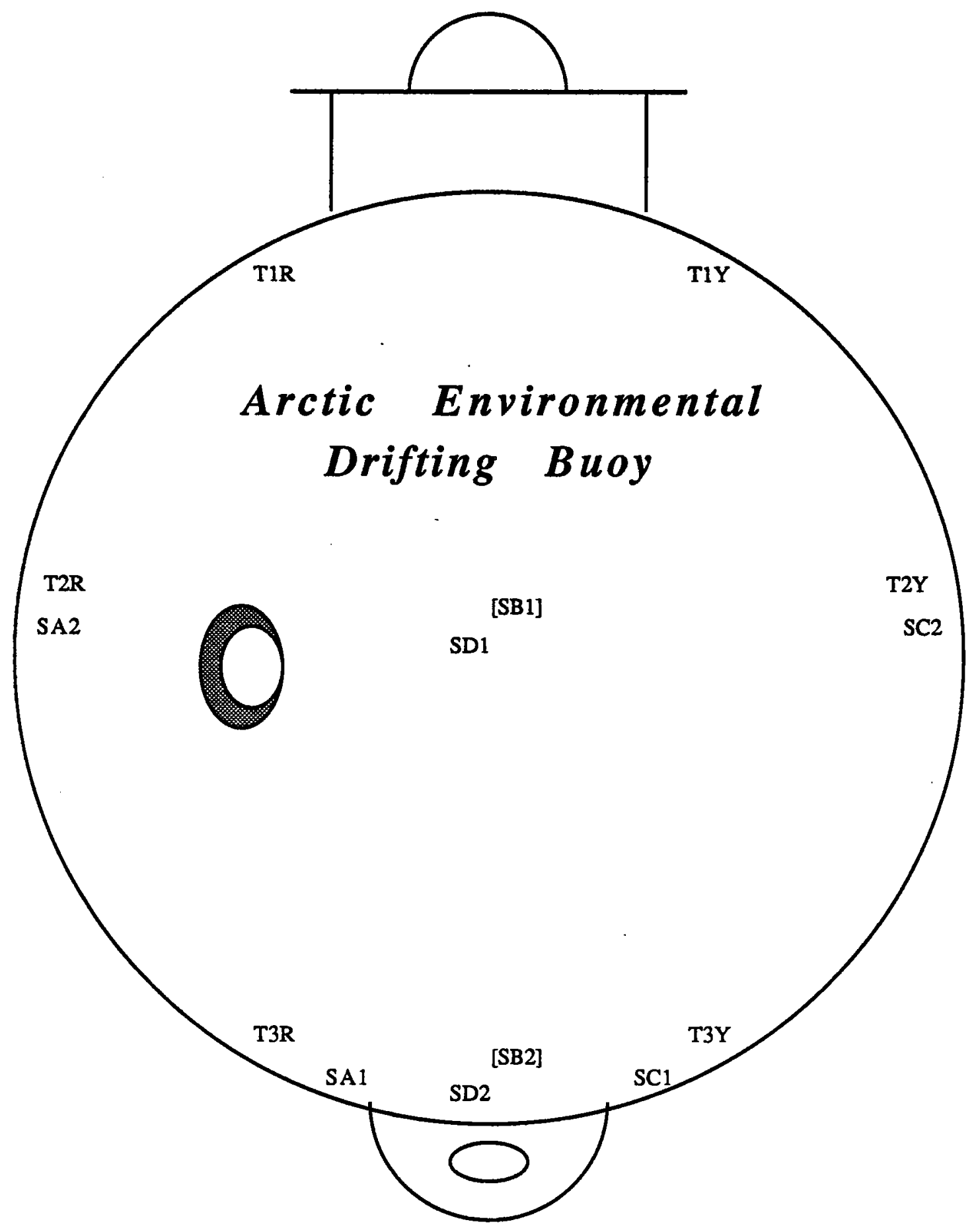

PTT 8440 transmits: T1Y, T2Y, T3Y, battery voltage, SC1, SC2, SD1, SD2

PTT 8441 transmits: T1R, T2R, T3R, battery voltage, SA1, SA2, SB1, SB2 
sixty seconds. Due to the path of the ARGOS satellites around the Earth, however, data was only acquired from the AEDB float a maximum number of 28 ten-minute periods per day. The wiring diagram for the PTT system is shown in Figure 5.

Temperature requirements of the Arctic winter dictated that the PTTs be provided with lithium battery power to ensure an operating range down to $-40^{\circ} \mathrm{C}$, and a duration of at least 16 months. Two completely redundant ARGOS systems were incorporated in the event that one should fail.

\section{c. Temperature and Conductivity Measurements}

The AEDB was outfitted with a total of 48 thermistors in order to provide a temperature profile of the air, ice, and upper $122 \mathrm{~m}$ of water with respect to space and time (Fig. 6). The ice thermistor chains are described in detail the next section. Conductivity was recorded along with temperature at two locations (15 and $122 \mathrm{~m}$ ), with the intention of providing a two point salinity curve below the ice floe.

The six temperature sensors mounted inside the surface sphere are influenced by the large time constant of the sphere and resolve only $0.3^{\circ} \mathrm{C}$. The sphere temperature provides a rough indication of the temperature of the surrounding environment, but is not exactly the air temperature. Only this information was transmitted in real-time; all other temperature data was internally recorded with varying degrees of success.

The Campbell data logger was configured to acquire high resolution data from the 36 ice thermistors, four times each day. Approximately 12 of these sensors extended below the ice floe to a depth of $1.8 \mathrm{~m}$ into the seawater.

The Sea Data Micrologger was incorporated with four temperature thermistors attached to the mooring line at depths $6,16,21$, and $26 \mathrm{~m}$ below the icefloe. These depths were chosen with respect to the fluorometer packages in order to monitor the changing temperature maximum with respect to the fluorescence readings. The memory capacity of the micrologger is such that it could record data for over 400 days, although alkaline battery life limits the acquisition period to one year.

At 15 and $122 \mathrm{~m}$ below the ice floe, Sea-Bird SeaCats were configured to record high resolution temperature and conductivity. Every hour, the SeaCats would store precision readings of the temperature (resolution $=0.001^{\circ} \mathrm{C}$ ) and 
Figure 5

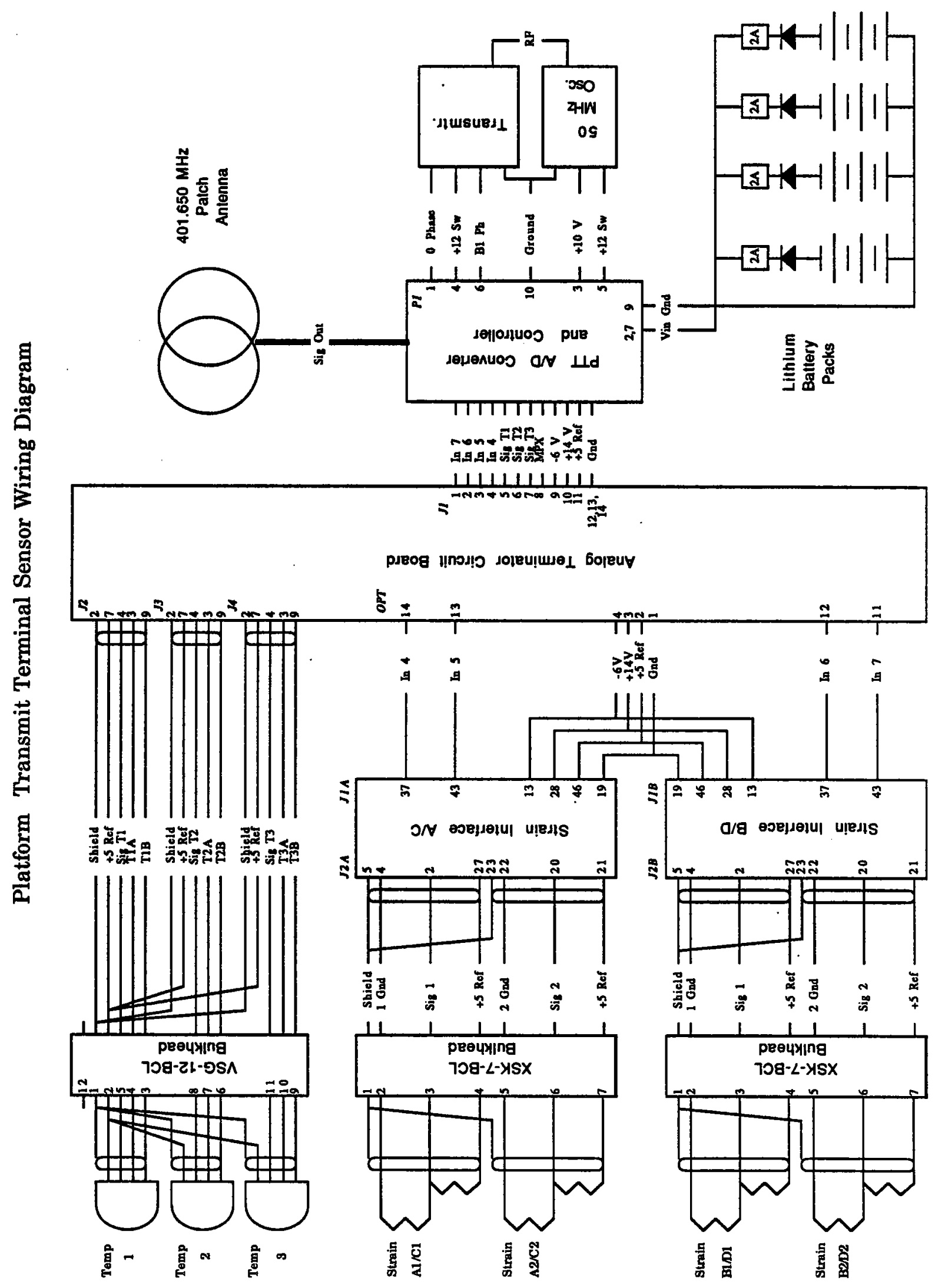




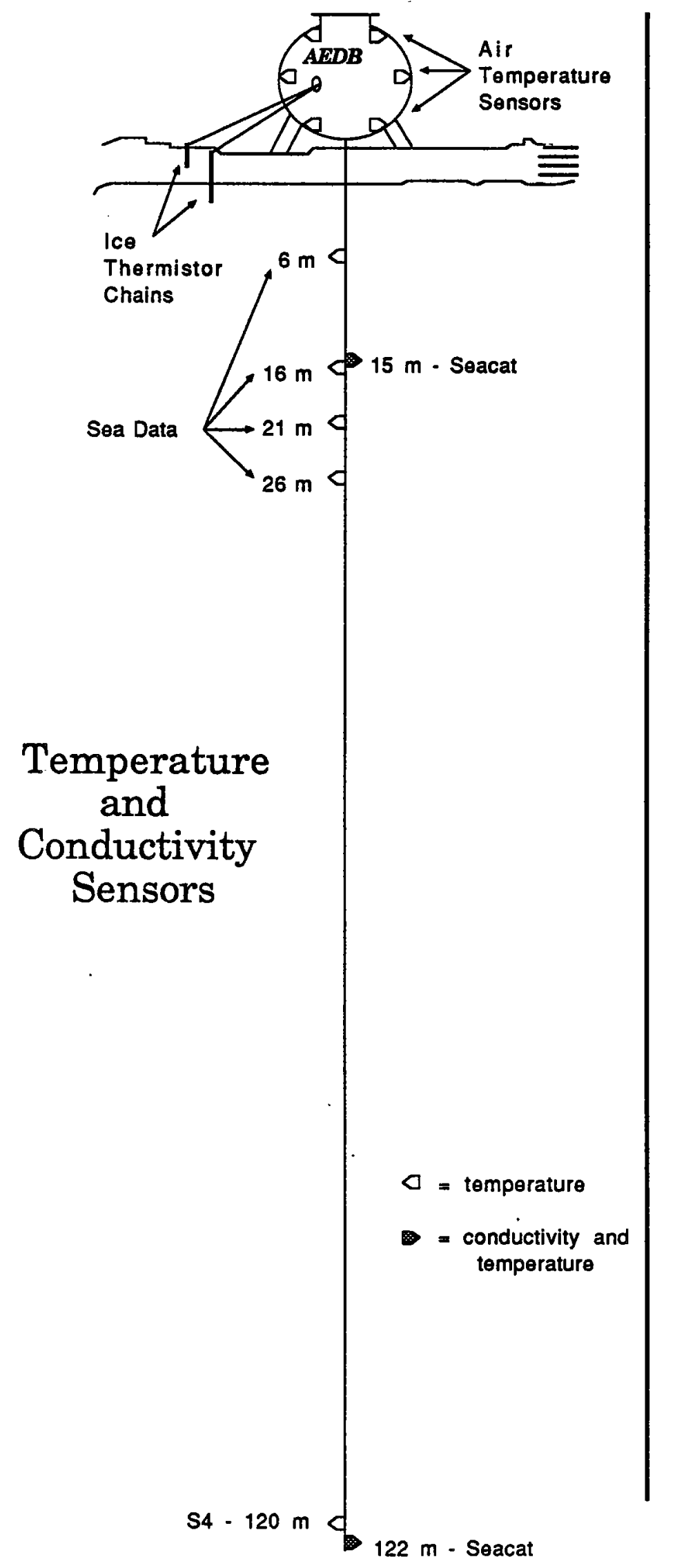

Figure 6

Ice

Thermistor

Chains

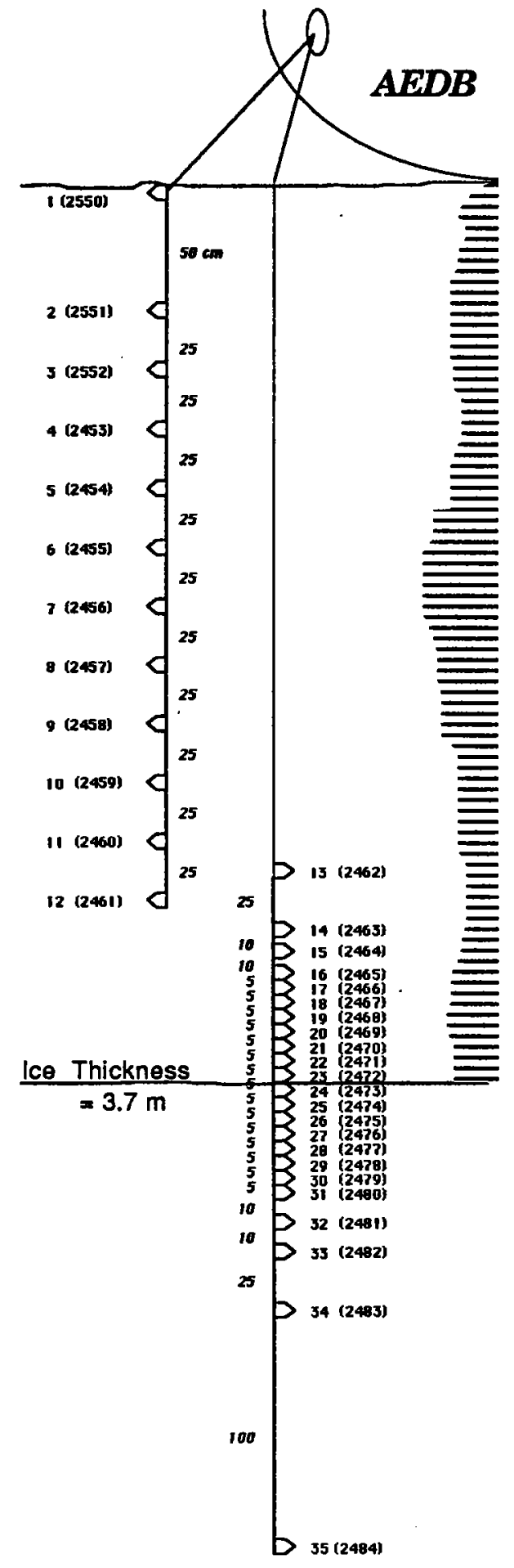


conductivity (resolution $=0.0001 \mathrm{~S} / \mathrm{m}$ ) of the surrounding seawater. The conductivity sensor was provided with anti-fouling devices to prevent drifting of the sensor over the duration of the buoy deployment. Alkaline batteries are sufficient to power these data loggers for approximately one year.

\section{d. Ice Thermistor Chains}

The U.S. Cold Regions Research and Engineering Laboratory (CRREL) provided the AEDB with two ice thermistor chains which were installed in the 3.7 $m$ ice surrounding the sphere (Fig. 6). The data from these was stored inside the sphere in the Campbell electronics package. By measuring ice temperatures, the heat flux between the ocean and the sea ice can be determined from the changing ice thickness.

One string had twelve thermistors extending from the surface of the ice to a depth of $3 \mathrm{~m}$. Half a meter below the surface thermistor, the remaining eleven thermistors were spaced at $25 \mathrm{~cm}$ intervals. Silicon cement bonded the thermistor wires to a sectioned wooden dowel.

Placed in the same four inch ice hole, the second string consisted of 23 thermistors, with $5 \mathrm{~cm}$ spacing between those surrounding the bottom of the ice floe. The deepest two thermistors hung below the string's dowel framework at approximately 75 and $175 \mathrm{~cm}$ distance from the bottom of the floe. The two strings overlap for a total length of $4.5 \mathrm{~m}$. The plastic attachment sleeve of the connector to the sphere was designed to separate when the icefloe breakup pulled the thermistor chains away from the float; ensuring that previously recorded data would not be affected when this occurred.

The combination of a Campbell 32 channel Multiplexer and 21X Data Logger was used to interrogate the thermistors and feed the calculated resistance value to the 64 kbyte Storage Module every 6 hours (Fig. 7). The computations performed in the $21 \mathrm{X}$ use 4 bytes for floating point arithmetic. The storage resolution decreases as the value increases, but the thermistors exhibit logarithmic increase in impedance with increasing temperature over the range -40 to $+40^{\circ} \mathrm{C}$. The thermistors were calibrated at three temperatures at CRREL to provide an accuracy of $0.01^{\circ} \mathrm{C}$.

At the selected sampling rate, the storage module would be filled in 215 days. The $21 X$ contains enough memory to collect an additional 127 days of information, for a maximum of 342 days of data collection. The $21 X$ provided 
Figure 7

Wiring Diagram for Campbell Data Logger

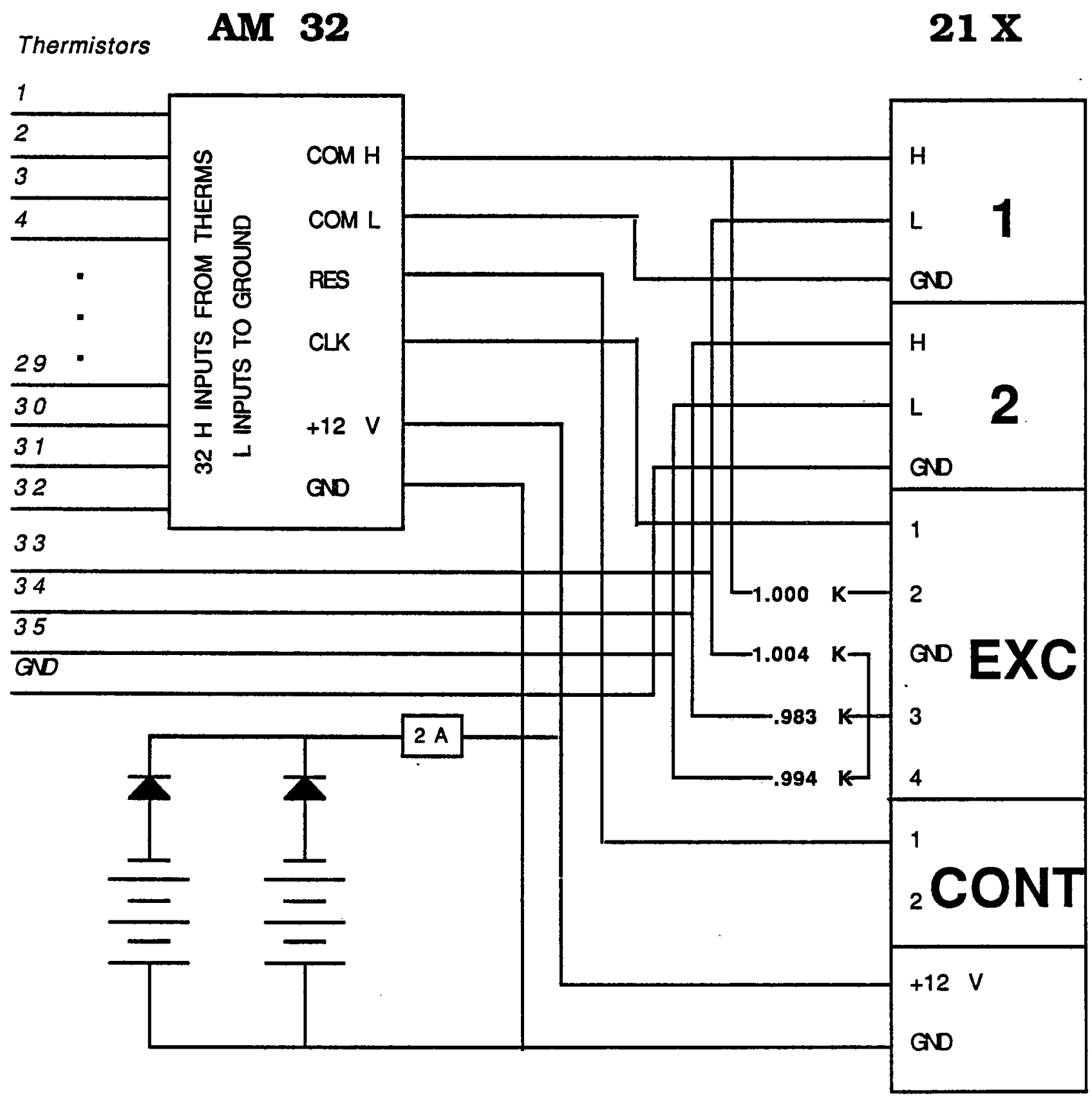


power from fused lithium " $D$ " cells to itself, the multiplexer and the storage module. For 342 days of operation, the system would require 9.5 Ah of power, which is only two thirds of the temperature derated capacity of the cells. The storage module had a separate backup lithium battery to retain its information should the main power to the data logger become depleted.

\section{e. Fluorometer Packages}

Information on the variability of phytoplankton pigments under and near the sea ice will provide a key to understanding the productivity of polar and high latitude ocean environments. Two high-sensitivity fluorometers with data storage modules were incorporated on the AEDB to monitor this activity.

The Sea Tech fluorometers are designed for in-situ measurement of fluorescence in seawater. Excitation is accomplished by the emission of bright blue light from a Xenon flash lamp. The optical components have been selected to be almost completely insensitive to ambient light below the water surface, while optimizing emission detection of chlorophyll a. At the high sensitivity setting, the fluorometer detects concentration levels from 0.05 to as much as 5 $\mathrm{ug} / \mathrm{l}$ with a resolution on the order of $0.03 \mathrm{ug} / \mathrm{l}$. The signal gain was set to high sensitivity and the amplifier time constant to $1 \mathrm{~s}$.

The fluorometer must be both powered and controlled externally. Separate OIS Data Loggers were used to control, digitize, average, and store the output from the fluorometers. Each logger has programmable sampling rate, delayed starting, sensor warmup time, and sample averaging. The units communicates with external terminals via RS-232 serial protocol. During this project an HP 85 Personal Computer was used for initialization and a Toshiba 1100 laptop for data retrieval.

The sampling rate of the logger is selectable from $20 \mathrm{~s}$ to $85 \mathrm{~min}$. At the sampling period, power is applied to the external sensor; in this case, the fluorometer. After an appropriate number of half seconds (determined by the setup of the warmup variable), the first measurement is made. The 0 to $5 \mathrm{~V}$ analog input is converted by successive approximation to a 12-bit value between 0 and 4095. Every next tenth of a second a new value is calculated until the selected number of samples to be averaged is acquired. The averaged value is then stored in 2 bytes of 16 kbytes total RAM. Up to 8,192 measurements may thus be stored before the memory of the unit is exhausted. With a one hour 
interval between readings, the memory of the data logger would fill in 341 days at which time no more information will be recorded. A backup battery ensured that no data would be destroyed should the main battery pack have been depleted.

The fluorometer draws approximately $1 \mathrm{amp}$ of current with each flash. The battery capacity to power this unit and the data logger (taking into account temperature degradation at $5^{\circ} \mathrm{C}$ ) exceeds that provided by conventional NiCad batteries. Consequently, fused lithium power cells had to be used with the fluorometer packages, and a large 10,000 microfarad capacitor provided to prevent passivation of the lithium cells due to the large instantaneous current drawn by the fluorometer when flashing. In this manner the fluorometers were safely provided with over 15 Ah of power; enough to last over one year.

The shallow fluorometer was deployed $10 \mathrm{~m}$ below the sphere, or approximately $6 \mathrm{~m}$ below the bottom of the ice floe. The other was deployed 16 $\mathrm{m}$ below the ice. Temperature thermistors located at each fluorometer depth, were to be recorded by the Sea Data Micrologger synchronous with the fluorometer readings.

\section{f. Current Measurements}

An Acoustic Doppler Current Profiler (ADCP) manufactured by RD Instruments was deployed in a load cage that also provided the mounting point for the fluorometer package and shallow $\mathrm{C} / \mathrm{T}$ recorder. The objective of the ADCP deployment was to observe the sub-ice horizontal velocity field as a function of depth and horizontal position (latitude) as the buoy drifted through the Arctic Ocean. The ADCP uses the Doppler principle to produce a profile of the seawater flow velocity. It operates by transmitting $150 \mathrm{kHz}$ pulses along lines of position defined by the beam patterns of four transducers. Backscattered echoes from plankton and micronekton in the water are received by each transducer with a frequency shift proportional to the relative velocity between the scatterers and the transducer. This frequency shift, or Doppler shift, is converted into a radial velocity for each beam.

The instrument was fixed at a depth of $16 \mathrm{~m}$, transducers facing downwards, and configured to record an ensemble of 40 profiles every $30 \mathrm{~min}$. Each profile consisted of 40 eight-meter bins giving a profiling range of $320 \mathrm{~m}$. Since a transmit interval corresponding to $16 \mathrm{~m}$ in depth was selected, the $8 \mathrm{~m}$ bins actually oversampled in range by a factor of two. The 40 profiles in each 
sample were not equally spaced over the half-hour ensemble interval. Instead, the instrument was operated in a "burst sampling" mode with the $\mathbf{4 0}$ profiles collected at $1 \mathrm{~s}$ intervals immediately following the start of the half-hour data collection cycle and averaged together to form the ensemble. The expected accuracy of the horizontal velocity measurements for each ensemble is $+/-1.0$ $\mathrm{cm} / \mathrm{s}$.

The ADCP also contained a thermistor, a flux-gate compass, and a twoaxis tilt meter. The thermistor produces a linear change in resistance with temperature over the range -5 to $45^{\circ} \mathrm{C}$ and is digitized to $0.01^{\circ} \mathrm{C}$ resolution. The accuracy of the temperature measurement is $0.10^{\circ} \mathrm{C}$. The calibrated flux-gate compass is accurate to $+/-2^{\circ}$ and the tilt measurements are accurate to $+1-1^{\circ}$ up to a $20^{\circ}$ threshold. The compass and tilt measurements are used to transform the radial beam velocities measured by the ADCP into earth coordinates.

A 60 Mbyte tape drive stores data records consisting of a header block with time, compass, tilt, and thermistor values plus a data block containing the radial beam velocities, the backscattered intensity, and certain data quality information. Battery life depends principally on the number of pings, the number of depth cells, the time between ensembles, and the amount of data recorded. For the parameters used here the lithium battery supply of the ADCP is rated to 250 days.

\begin{tabular}{|c|c|}
\hline \multicolumn{2}{|c|}{ Selected ADCP Parameter Settings * } \\
\hline Parameter/Value & Description \\
\hline 116 & $16 \mathrm{~m}$ transmit interval \\
\hline J 080 & $8 \mathrm{~m}$ delay after transmit \\
\hline L3 & $8 \mathrm{~m}$ bin length \\
\hline 0029 & $\begin{array}{l}\text { record radial beam velocities, echo amplitude, } \\
\text { percent good pings, and status bits }\end{array}$ \\
\hline P 00040 & 40 pings per ensemble \\
\hline Q 40 & 40 bins per ping \\
\hline R 00300000 & 30 min between ensembles \\
\hline U 0729230000 & first ping at $23: 00 \mathrm{Z}, 07-29-87$ \\
\hline V 000100 & $1 \mathrm{~s}$ between pings \\
\hline
\end{tabular}


A second current meter was attached to the mooring line $120 \mathrm{~m}$ below the ice bottom. The InterOceans $S 4$ Current Meter hung just above the sediment trap package and was programmed to provide Earth referenced current vectors and low resolution temperature and pressure values at the mouth of the trap. The S4 measures horizontal current by sensing the induction created by the motion of water through a magnetic field created by its flush mounted sensors. Sampling every hour, the solid state memory of the $\$ 4$ fills with data 300 days after deployment.

\section{g. Sediment Trap / Micro-filter Pump / Transmissometer}

The combination of a time-series oceanic sediment trap, a time-series micro-filter pump, and a precision light transmissometer in a single frame $122 \mathrm{~m}$ below the bottom of the ice, were to provide comprehensive particle data along the track of the buoy. Included in this frame was a second $\mathrm{C} / \mathrm{T}$ recorder measuring the physical properties of the seawater at this depth.

The key component of the sediment trap is a set of sequentially rotating samplers which is driven by a microprocessor-controlled stepping motor. Thirteen $250 \mathrm{ml}$ polyethylene sample bottles are sequentially placed under the $0.5 \mathrm{~m}^{2}$ aperture of the trap; each for a 20 day interval during this experiment (Appendix C). A spring gasket positively seals each of the bottles from ambient water prior to, and after acquiring its sample. An Epix MPC electronic controller triggers the rotator and independently records execution of each sampling event.

The MPC is programmed using an Epson HX-20 portable computer for the date and time at which each event is to occur. When an event time is reached, the MPC pulses the rotator stepping motor until the next sample bottle is in place of the last. A microswitch in the stepping motor assembly signals when the rotator has turned the proper distance. Concurrently, the MPC records the time when the event occurred (which should be within seconds of the programmed time) and the number of executed steps (which during proper operation equals 90) in RAM. Upon retrieval, this information verifies proper operation of the rotator/controller, or can be used for analysis of any broken events. A lithium battery provides backup power to sustain the original program and memory should the main battery pack of the MPC be depleted.

A similar Epix controller rotates a similar stepping motor on the microfilter pump. Twenty .47 micron Metricel filters were to collect suspended particle 
samples via the pumping action, which passes approximately $100 \mathrm{ml}$ of seawater per minute of operation. Every 15 days, the controller was configured to step the pump valve to a blank filter and pump for a maximum of 3 hours, although the pump would cease when the filter clogged with particle materials.

Nucleopore filter holders were fitted between check valves, to enclose the filters in a sealed unit. When pumping, these filter holder assemblies introduce only a small friction. When they are removed from the pump, these units act to prevent contamination of the filters from stray particles.

Like the sediment trap controller, this MPC is programmable for date and time of each event, but includes other programmable parameters for the pumping action. An event for this system comprises the pumping of a filter followed by 9 steps to the next filter, to await the next event. The pump controller will discontinue pumping at a programmed time limit, at a minimum flow rate, or when a maximum volume of seawater has passed through the filter. Each of these parameters (like date and time) is determined by the user and relayed to the MPC via an Epson HX-20.

The controller determines flow and volume by keeping a running count of the number of revolutions of the pumping motor. Each revolution passes $.044 \mathrm{ml}$ of seawater. The pump is current limited to cause it to slow as the filter clogs. Every minute, it checks to see that the pump is not below the minimum flow or above the maximum volume settings. For this experiment, the minimum flow was set at $35 \mathrm{ml} / \mathrm{min}$, and the maximum volume at 14.4 liters (which is the maximum programmable value). Every $5 \mathrm{~min}$ it records the volume that has been pumped during that period. This information is retrievable from the controller, as are the total volume for pumped through each filter, the time of the event, and the number of steps between each event.

A Sea Tech Transmissometer was located just below the sediment trap sample bottles, whose function it was to measure beam transmission in its $25 \mathrm{~cm}$ water path. In studying suspendoid dynamics, it has been shown that particle size, shape and roughness affect beam attenuation. Thus the transmissometer can detect particle concentration changes in clear water of $100 \mathrm{ug} / \mathrm{l}$, but needs samples collected along with its measurements to determine accurate concentrations of particle mass or volume.

On the transmissometer, a modulated LED and synchronous detector measures transmission, while remaining insensitive to ambient light. It outputs a linear 0 to 5 volt analog signal corresponding to 0 to $100 \%$ transmission in water. The LED light output can decrease slightly over time, requiring calibration of the 
instrument during use. Comparison of a factory measured air value (approximately $95 \%$ equivalent transmission) to a present air value corresponds to a proportional change in LED degradation. From this a corrected output voltage can be computed.

The transmissometer was controlled by an OIS Data Logger functionally identical to those used for the fluorometers. As the transmissometer requires less stabilizing time for its electronics, and outputs less noise than the fluorometers, this data logger was programmed with different parameters than the others. In this application, the logger provides $3 \mathrm{~s}$ of warmup and averages only 16 samples. There is no impedance mismatching between the transmissometer and logger providing a linear 12-bit conversion through zero. The transmissometer draws less power than the fluorometers, consequently, this system was powered with alkaline cells and required no capacitor. At an hourly sampling rate, the memory of the data logger would be filled in 341 days, after which no further sampling would occur. 


\section{Deployment, Drift, and Recovery \\ a. Deployment operation}

The AEDB was deployed on 4 August 1987 at the northernmost point achieved by the FS Polarstern during the third leg of the Arktis IV Expedition. By 1031 UTC, the buoy was resting on four wooden posts at position $86^{\circ} 7.4^{\prime} \mathrm{N}$ latitude, and $22^{\circ} 3.3^{\prime}$ E longitude. Below the sphere lay $3.7 \mathrm{~m}$ of sea ice and 3937 $\mathrm{m}$ of seawater. Preliminary work was performed the previous day to accelerate the deployment procedure on this day, which took slightly more than two hours to complete.

Leg 3 of the Arktis IV Expedition began in Tromso, Norway on 4 July 1987, ended in Hamburg, F.R. Germany on 2 September 1987, and included 57 scientists and technicians from 19 institutions in 8 European and North American countries (Krause et al., 1989). The primary objectives were to investigate the modern depositional and oceanographic environment and the paleoceanographic and tectonic development of the eastern Arctic Basin (Augstein, 1987). The Polarstern succeeded in penetrating the Arctic ice as far north as $86^{\circ} 11^{\prime} \mathrm{N}$; further that any previous multidisciplinary research vessel.

On 3 August, an ice party of four surveyed a large multi-year ice island while the Polarstern maneuvered through the surrounding leads. Large ridges confirmed the strength of this floe; indicating that it had previously withstood collisions with other floes. Cores were drilled along the perimeter in order to determine thickness, which was on the order of 4 to $6 \mathrm{~m}$. After three hours of coring, a site was chosen near a well ridged edge, in an area accessible to the. Polarstern. This decision was based on the expectation that the preformed ridges would prevent cracking of the ice and act as barriers between the deployed float and neighboring ice floes.

Shortly thereafter, work was begun in removing a $1 \mathrm{~m}$ diameter ice core approximately $16 \mathrm{~m}$ away from the edge, but within range of the cranes aboard the ship. A hot water drill ring developed by U.S. CRREL was used to melt a circle through the ice with hot water provided by a pressurized pump on board the ship (Tucker et al., 1987). Hydraulic hoses carried the hot water from the bow of the ship to the ice ring while other station work was being performed off of the stern. Drilling the ice core took over two hours, while the bow crane of the Polarstern removed the 2.5 ton ice plug in one motion.

At 0820 UTC the following day, the actual deployment of the AEDB began. The Polarstern positioned its stern so that the work could be performed 
within the maximum extension of the rear crane. On the ice, the mooring system was assembled in five $25 \mathrm{~m}$ segments. Beginning with the anchor, each section was lowered through the ice hole, secured, and attached to the next section. Finally, the surface float was attached to the last segment and lowered onto four wooden posts positioned in the ice. As a precaution to prevent the yellow metal sphere from absorbing solar radiation in the summer and melting through the floe, the posts would drift away from the buoy without causing damage once the icefloe broke apart. The operation proceeded smoothly, the ice thermistors were subsequently installed within a few meters of the float, and the deployment was complete.

\section{b. Drift summary}

The AEDB travelled over $3900 \mathrm{~km}$ through three distinct ocean regions in 255 days (Fig. 8). During the first four and a half months, it drifted south with the Transpolar Drift pack ice to the Fram Strait, whereupon the buoy's velocity tripled as it entered the East Greenland Current. Later, west of Jan Mayen Island, locations became sporadic for 21 consecutive days when the surface float was forced under the sea ice. Upon resurfacing, the buoy was rapidly transported through the Denmark Strait where it was recovered west of Iceland.

From 4 August to 21 December 1987, the mooring system was carried by the pack ice from 86.1 to $80.9^{\circ} \mathrm{N}$ (Table 2). Because of the congestion of the sea ice, over half of the AEDB's journey was spent here, traversing only one-third of the total drift distance. This period was characterized by an average speed of almost $11 \mathrm{~cm} / \mathrm{s}$ and a maximum speed of $44.8 \mathrm{~cm} / \mathrm{s}$. Throughout, the ice island supporting the buoy remained intact, protecting the surface sphere from damaging ice collisions.

In accordance with historical ice drift data, the buoy proceeded in a generally southwesterly direction during the first seven weeks after deployment. In September and October, however, winds forced the drift southeast; toward the islands of Svalbard. Fortunately, the system avoided running aground when the course reverted back to the southwest late in October. Just north of $81^{\circ}$, in an area where all the polar pack ice begins to squeeze through the Fram Strait, the drift track became increasingly irregular. The buoy came nearly to a stop on 21 December then immediately accelerated through the narrows.

Between the Fram Strait and the Denmark Strait, the AEDB was 
Figure 8

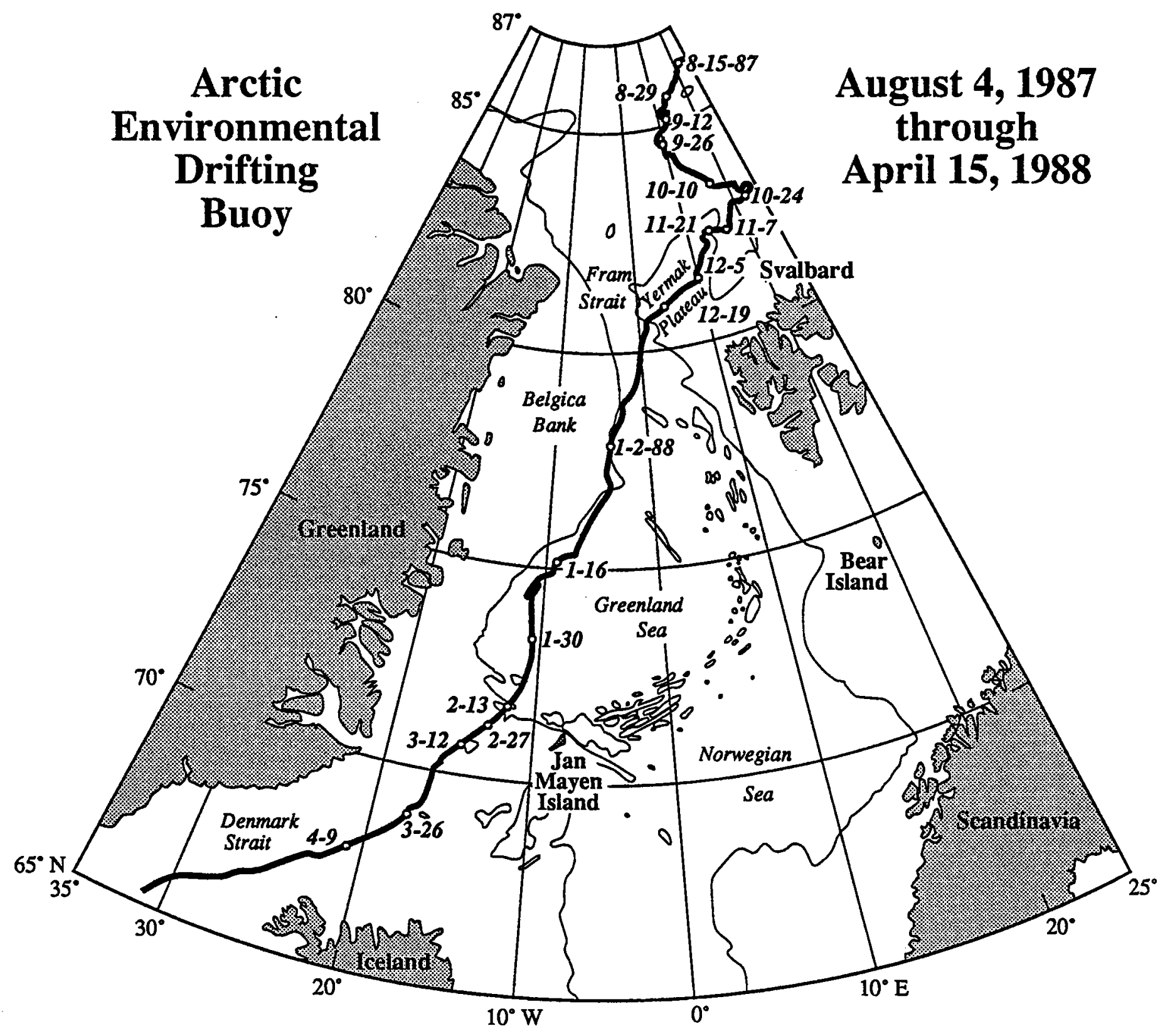

with $2000 \mathrm{~m}$ bathymetry contours 
Table 2

AEDB Drift Regions

\begin{tabular}{c|ccc|c} 
& & $\begin{array}{c}\text { Pack } \\
\text { lce }\end{array}$ & $\begin{array}{c}\text { East } \\
\text { Greenland }\end{array}$ & \multicolumn{2}{c}{$\begin{array}{c}\text { Denmark } \\
\text { Strait }\end{array}$} & TOTAL \\
\hline Start date & 4ug 87 & 21 Dec 87 & 21 Mar 88 & 4 Aug 87 \\
latitude (N) & 86.122 & 80.910 & 68.684 & 86.122 \\
longitude (E) & 22.047 & 3.660 & -18.150 & 22.047 \\
& & & & \\
End date & 21 Dec 87 & 21 Mar 88 & 15 Apr 88 & 15 Apr 88 \\
latitude (N) & 80.908 & 68.684 & 65.305 & 65.305 \\
longitude (E) & 3.669 & -18.153 & -31.613 & -31.613 \\
& & & & \\
Total time (days) & 139.3 & 90.7 & 25.2 & 255.2 \\
distance (km) & 1321 & 1763 & 823 & 3907 \\
& & & & \\
Speed (cm/s) & & & & \\
minimum & 0.12 & 0.38 & 1.77 & 0.12 \\
maximum & 44.84 & 98.00 & 101.96 & 101.96 \\
average & 10.97 & 22.51 & 37.76 & 17.72 \\
std. dev. & 6.5 & 20.8 & 19.5 & 16.9 \\
\hline
\end{tabular}

transported by the ice and ocean currents along the east coast of Greenland. Four times in four weeks, the speed of the buoy steadily increased to over 70 $\mathrm{cm} / \mathrm{s}$ then suddenly decreased to less than $25 \mathrm{~cm} / \mathrm{s}$.

For 5 days after 21 December, the buoy steadily gained speed, attaining a peak velocity of $98.0 \mathrm{~cm} / \mathrm{sec}$. Over a sea cliff east of Belgica Bank where the ocean depth soars from 2000 to $400 \mathrm{~m}$ across less than $40 \mathrm{~km}$, the system began slowing, but accelerated again upon reaching the deeper water.

On 2 January 1988, the ice floe containing the float apparently broke up releasing the buoy into the seawater. When this occurred, the ice thermistor chains were torn from the sphere at the same time as the temperature readings being transmitted from the sphere increased from $-18^{\circ} \mathrm{C}$ (air temperature) to $-2{ }^{\circ} \mathrm{C}$ (water temperature). Post recovery calculations showed that the oceanic heat flux had increased to $128 \mathrm{~W} / \mathrm{m}^{2}$, and that over $1 \mathrm{~m}$ of the icefloe bottom had melted away in the warmer water since deployment (Perovich et al., 1989). 
After entering the seawater, the AEDB continued speeding up to 96.6 $\mathrm{cm} / \mathrm{s}$. In a three hour period on 4 January, the speed dropped from $91 \mathrm{~cm} / \mathrm{s}$ down to $32 \mathrm{~cm} / \mathrm{s}$ concurrent with huge increases in the strain gauge readings (Fig. 9). In some places on the surface sphere, the sensors indicated calculated pressures in excess of $40,000 \mathrm{PSI}$, suggesting that it had been compressed by ice floes. The condition of the sphere upon recovery confirmed that substantial deformation had occurred. The ARGOS transmitting equipment was not significantly damaged by the collision and still functioned properly afterwards (at only a slightly diminished reliability). On the other hand, readings from the transmitted sphere temperature sensors were no longer reasonable. On the following day, the system reduced its speed to nearly $5 \mathrm{~cm} / \mathrm{s}$.

By 10 January, the velocity again exceeded $93 \mathrm{~cm} / \mathrm{s}$, just prior to plunging down to $31 \mathrm{~cm} / \mathrm{sec}$ in another three hour period. The ice pressure effects on the surface float could not be observed at this time, since most of the strain gauge circuits had already reached their full scale limits. The AEDB continued to slow, reversed course five days later, and started heading northeast. The speed of the buoy while heading north peaked at $40.8 \mathrm{~cm} / \mathrm{s}$ during the three days it drifted in that direction.

After resuming a southwesterly course on 18 January, the AEDB once again sharply accelerated to over $70 \mathrm{~cm} / \mathrm{s}$ and then reduced speed. From 21 December to 21 January, the mooring system had travelled over $1000 \mathrm{~km}$ in the East Greenland Current, at a pace four times faster than in the pack ice drift. By then it was located at $74^{\circ} \mathrm{N}$ latitude, having migrated from nearly $81^{\circ} \mathrm{N}$.

After 21 January, the location of the float could not be accurately determined for 11 consecutive days. The number of transmissions from the AEDB patch antennas that were received by the ARGOS satellites on a single pass were not enough for accurate location determinations. The only remaining useful information that was being transmitted was the battery voltages of the PTTs, and that data was being received infrequently.

For four successive days in February the signals transmitted by the buoy improved and it was positively relocated. Later, no transmissions at all were received for 6 days, and only one low quality location in 21 days. The surface float may have been pushed below the ice for a portion of this time. After recovery ice was discovered in the sealed hatch designed to protect the watertight connections from stray moisture. Water had to have been forced by pressure past the gasket seal and frozen. Furthermore, in late February and early March only a small distance was covered by the mooring system; the 
Sphere Temperature and Speed of AEDB

Figure 9

December 31, 1987 thru January 7, 1988

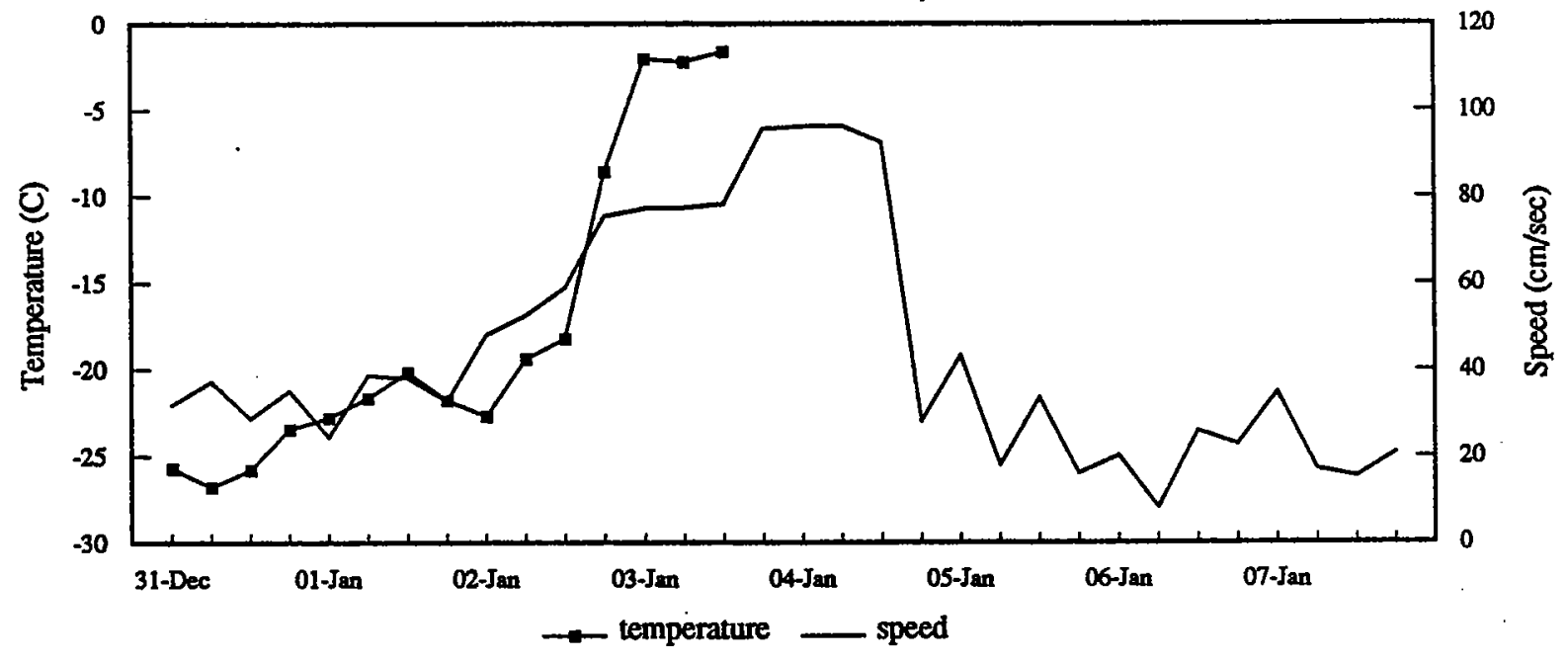

Strain on AEDB Sphere

Strain around equator. December 31, 1987 thru January 7, 1988

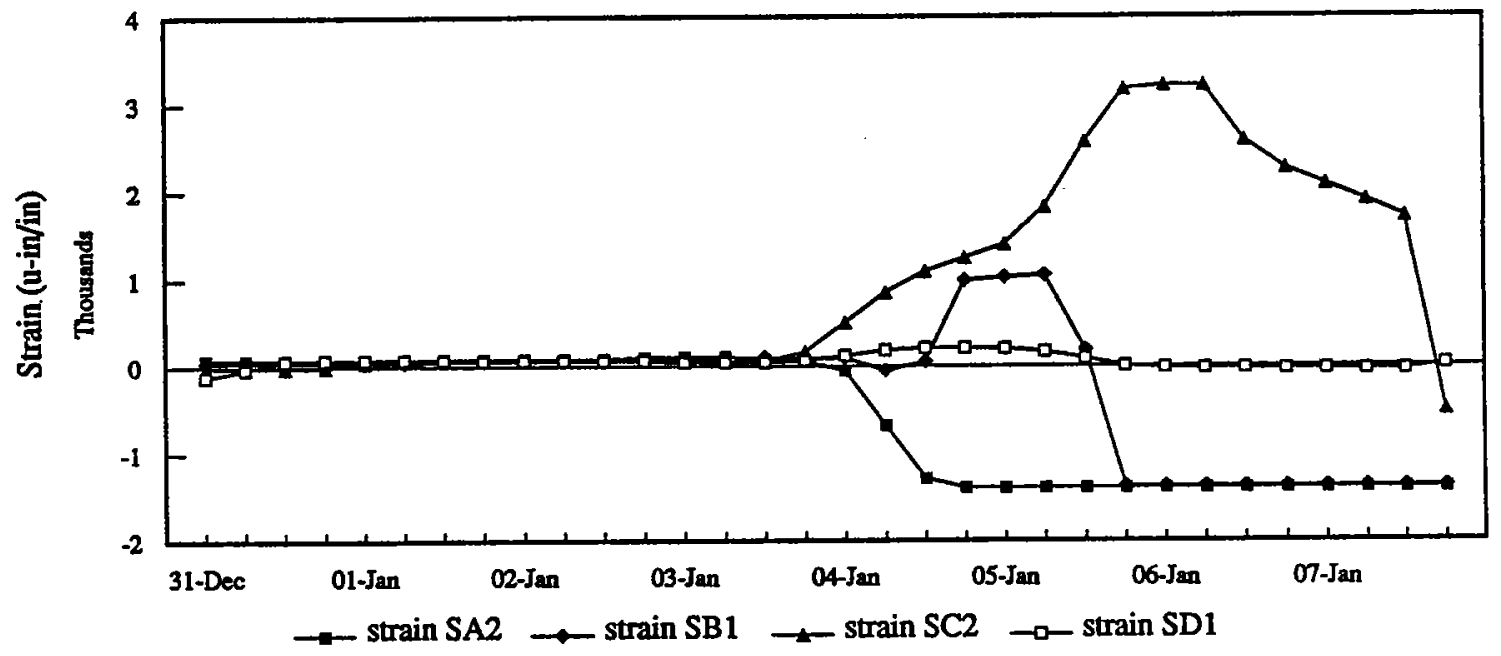

Strain around bottom: December 31, 1987 thru January 7, 1988

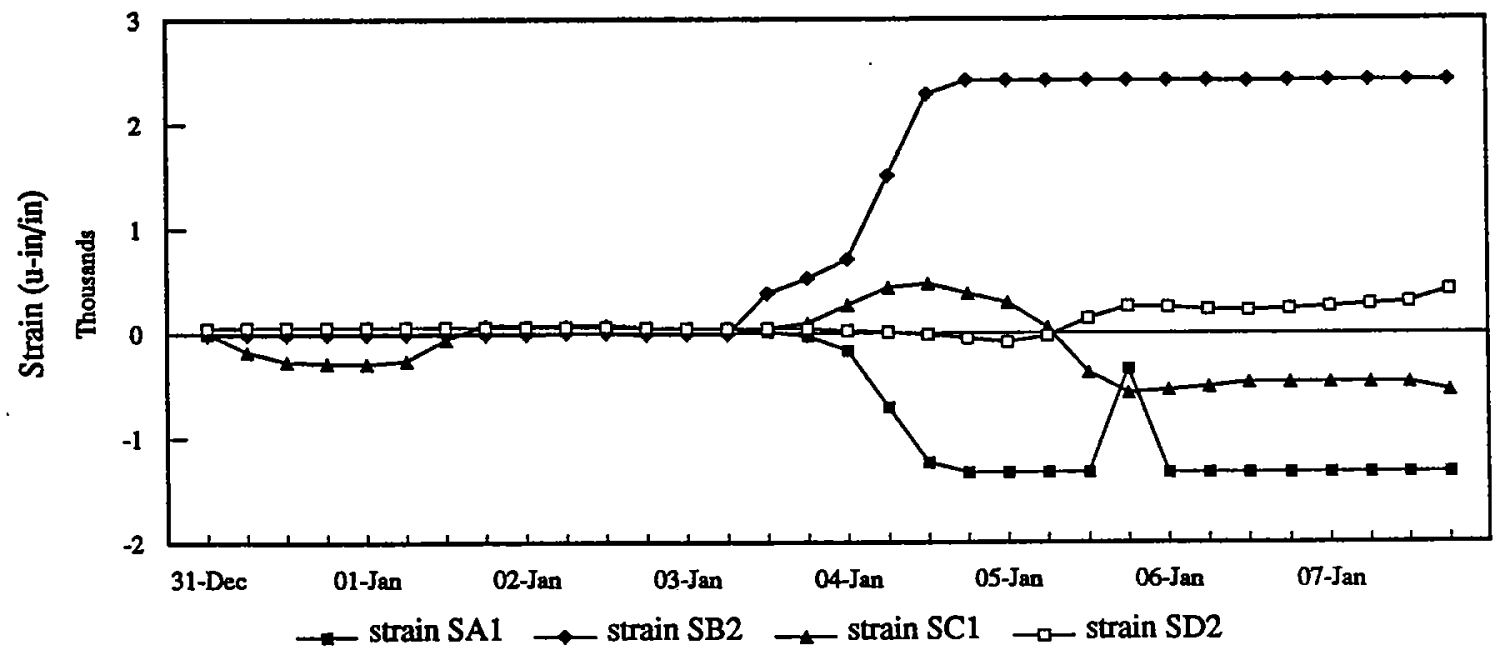


volcanic topography below the ocean surface west of Jan Mayen Island may have impeded its progress.

Abruptly during the first week of March, the transmission difficulties pervading the AEDB cleared, and quality locations were received throughout the remainder of the deployment. Initially drifting south toward Iceland, the float nearly stopped on 21 March, and then turned to the southwest as it moved into the Denmark Strait. Between Iceland and Greenland the drift track circled over itself, and shortly thereafter the buoy's speed began increasing greatly.

The buoy travelled at the fastest pace throughout its journey in April; reaching its maximum speed on 9 April. Again, large deviations in the speed were evident; the buoy attained its maximum speed of $102 \mathrm{~cm} / \mathrm{s}$ after drifting at only $0.4 \mathrm{~cm} / \mathrm{s}$ two days earlier. Only a few miles inside the ice edge, attempts were made by the Icelandic Coast Guard to visually spot the surface float from low flying aircraft, but without success.

\section{c. Recovery operation}

The AEDB was successfully retrieved on 15 April at position $65^{\circ} 17^{\prime} \mathrm{N}, 31^{\circ}$ $38^{\prime} \mathrm{W}$ in severe weather conditions. An exceptional effort was made by the Captain, crew, and scientists of Marine Research Institute, Iceland and R/S Arni Fridriksson to locate and recover the buoy in such difficult surroundings.

Arriving at the approximate position of the AEDB on 14 April, the ice edge was scanned that evening, and most of the next day for the AEDB sphere. By noon on the 15th, it was determined that the buoy was located on the far side of a large strip of ice. Fortunately, the ice strip broke apart shortly thereafter, allowing the ship to approach a second strip of ice in which the buoy was located. Ten minutes later, the ice had drifted by the sphere, requiring the ship to circle the ice strip, and retrieve the buoy between ice strips. In 30 knot winds and 3 to $4 \mathrm{~m}$ seas, the recovery was difficult but well executed.

The recovered mooring system was intact from the sphere down to the SeaData Micrologger. Unfortunately, the recovery terminated at the thimble to which the nylon segment of the mooring was spliced. Consequently, everything below this segment, including the sediment trap, pump, transmissometer, and S4 current meter were lost at sea. The motion of the sphere bobbing in the water prior to deployment indicated that the equipment was missing before the retrieval operation had begun. 
The sphere was dented in on all sides, and the handle on top was bent over. Yellow paint remained only on the very top and bottom of the sphere. Several inches of ice was discovered inside the hatch where watertight connectors interfaced between the cylinder and sphere components, but the watertight compartment housing the electronics was intact and undamaged. The antennas were undamaged in their protective housings mounted on the surface of the sphere. None of the retrieved mooring hardware exhibited abnormal wear or corrosion.

Inside the inner electronics compartment, the PTTs were still transmitting. The Campbell $21 \times$ Data Logger was still collecting data, but the valid information ended on January 2, when the ice floe broke up and the thermistor chain separated from the sphere.

Retrieved from the mooring line, both fluorometers were still flashing. Over 6000 points of hourly data were retrieved from each. The SeaData Micrologger recorded 25,000 samples, but that data was corrupted shortly after deployment by the infiltration of seawater in the bulkhead connection to the sensors. The ADCP recorded data over 7 Mbytes of half-hourly data until March 7 and stopped due to a low battery. The SeaCat unit flooded and collected no data. New from the factory, this unit had not been opened prior to deployment. 


\section{Results}

Results for each sensor on the AEDB that returned data are presented in graphical form. Full or partial records over the drift period were recovered from the ARGOS PTT's (giving the buoy position), the sphere temperature and strain gauges, the fluorometer packages, the ice thermistor chains, and the ADCP. To facilitate plotting, the drift period of the AEDB was divided into 5 sections of roughly equal duration (Table 3). The start and end dates for each section include a six day overlap with the next section. The first two sections contain data from the portion of the drift in the pack ice. The third section includes the transition from pack ice to the East Greenland Current through the Fram Strait. The fourth section is primarily in the East Greenland Current, and the last section includes the passage through the Denmark Strait. 
Table 3

\section{AEDB Section Data}

\begin{tabular}{lrrrrrrr} 
& & & & & \\
& Date & Time & Lat(N) & Lon(E) & $U$ & (cm/s) & Speed \\
\hline Start & 870804 & 1000 & 86.122 & 22.047 & & & \\
End & 870927 & 2330 & 84.283 & 10.802 & & & \\
Minimum & & & 84.277 & 8.059 & -23.895 & -24.536 & 0.205 \\
Maximum & & & 86.214 & 23.844 & 21.400 & 14.686 & 28.817 \\
Average & & & 85.310 & 13.695 & -1.982 & -4.371 & 8.946 \\
STD & & & & & 6.905 & 5.722 & 4.839
\end{tabular}

SECTION 1 Total Distance $=421.9 \mathrm{~km}$

Time $=54.6$ days

\begin{tabular}{lrrrrrrr}
\hline Start & 870928 & 0 & 84.283 & 10.816 & & & \\
End & 871121 & 2330 & 82.283 & 12.426 & & & \\
Minimum & & & 82.283 & 10.816 & -35.753 & -39.389 & 0.286 \\
Maximum & & & 84.283 & 23.279 & 30.936 & 16.357 & 39.765 \\
Average & & & 83.055 & 17.386 & 0.048 & -4.625 & 11.789 \\
STD & & & & & 9.990 & 7.998 & 6.795
\end{tabular}

SECTION 2 .Total Distance $=560.2 \mathrm{~km}$

Time $=\mathbf{5} 5$ days

\begin{tabular}{lrrrrrrr}
\hline Start & 871122 & 0 & 82.279 & 12.423 & & & \\
End & 880115 & 2330 & 74.426 & -11.341 & & & \\
Minimum & & & 74.270 & -11.965 & -70.955 & -92.540 & 0.116 \\
Maximum & & & 82.279 & 13.064 & 24.332 & 26.988 & 97.997 \\
Average & & & 79.349 & 2.109 & -10.466 & -18.476 & 26.680 \\
STD & & & & & 14.997 & 24.093 & 23.334
\end{tabular}

SECTION 3 Total Distance $=1267.8 \mathrm{~km}$

Time $=\mathbf{5 5}$ days

\begin{tabular}{|c|c|c|c|c|c|c|c|}
\hline $\begin{array}{l}\text { Start } \\
\text { End } \\
\text { Minimum } \\
\text { Maximum } \\
\text { Average } \\
\text { STD }\end{array}$ & $\begin{array}{l}880116 \\
880310\end{array}$ & $\begin{array}{r}0 \\
2330\end{array}$ & $\begin{array}{l}74.430 \\
70.055 \\
70.055 \\
74.672 \\
71.916\end{array}$ & $\begin{array}{l}-11.326 \\
-16.852 \\
-16.870 \\
-10.505 \\
-13.203\end{array}$ & $\begin{array}{r}-38.446 \\
34.286 \\
-4.182 \\
7.578\end{array}$ & $\begin{array}{r}-71.745 \\
38.487 \\
-10.315 \\
11.959\end{array}$ & $\begin{array}{r}0.979 \\
72.413 \\
13.857 \\
11.502\end{array}$ \\
\hline
\end{tabular}

SECTION 4 Total Distance $=658.5 \mathrm{~km}$

Time $=\mathbf{5} 5$ days

\begin{tabular}{lrrrrrrr}
\hline Start & 880311 & 0 & 70.051 & -16.852 & & & \\
End & 880415 & 1500 & 65.305 & -31.613 & & & \\
Minimum & & & 65.305 & -31.708 & -94.790 & -65.643 & 0.376 \\
Maximum & & & 70.051 & -16.836 & 56.073 & 28.271 & 101.959 \\
Average & & & 67.831 & -22.046 & -20.705 & -17.264 & 32.423 \\
STD & & & & & 21.520 & 14.990 & 19.061
\end{tabular}

SECTION 5 Total Distance $=998.6 \mathrm{~km} \quad$ Time $=35.6$ days 
Fig. 10. A histogram giving the number of ARGOS location fixes versus the time difference between consecutive fixes from 0 to $225 \mathrm{~min}$ in $1 \mathrm{~min}$ intervals is shown. Data includes all 4414 fixes from PTT 8441 , over the entire duration of the AEDB drift. The orbital characteristics of the dual satellite system cause the locations to be variable in positioning accuracy and unevenly spaced in time. The data from PTT 8440 is not analyzed here as it amounted to only one-tenth of the information as PTT 8441 and typically was of poorer quality.

Service ARGOS provides a quality indication from 0 to 3 with each position determination; quality 3 indicates fixes with one-standard-deviation accuracy of $150 \mathrm{~m}$, quality 2 gives accuracy of $350 \mathrm{~m}$, quality 1 of $1000 \mathrm{~m}$, and quality 0 of greater than $1000 \mathrm{~m}$. Out of the total 4414 locations obtained from PTT 8441, 3928 were of a quality 2 or 3; only 486 fixes were of quality 0 or 1.

It can be seen that a roughly equal number of fixes are obtained for time differences between 0 and $97 \mathrm{~min}$. This distribution is due to the different orbital altitudes of the two satellites, which cause the period of one satellite's orbit to be approximately one minute longer than the period of the other. The largest proportion (nearly 20\%) of fixes have time differences between 98 and $104 \mathrm{~min}$; a time interval that represents the transit interval for a single satelite (101 min). The number of fixes drops off dramatically for time differences greater than 105 min, amounting to only $6 \%$ of the total. The secondary peak at about $200 \mathrm{~min}$ results from data obtained between two passes of a single satellite. 
Figure 10

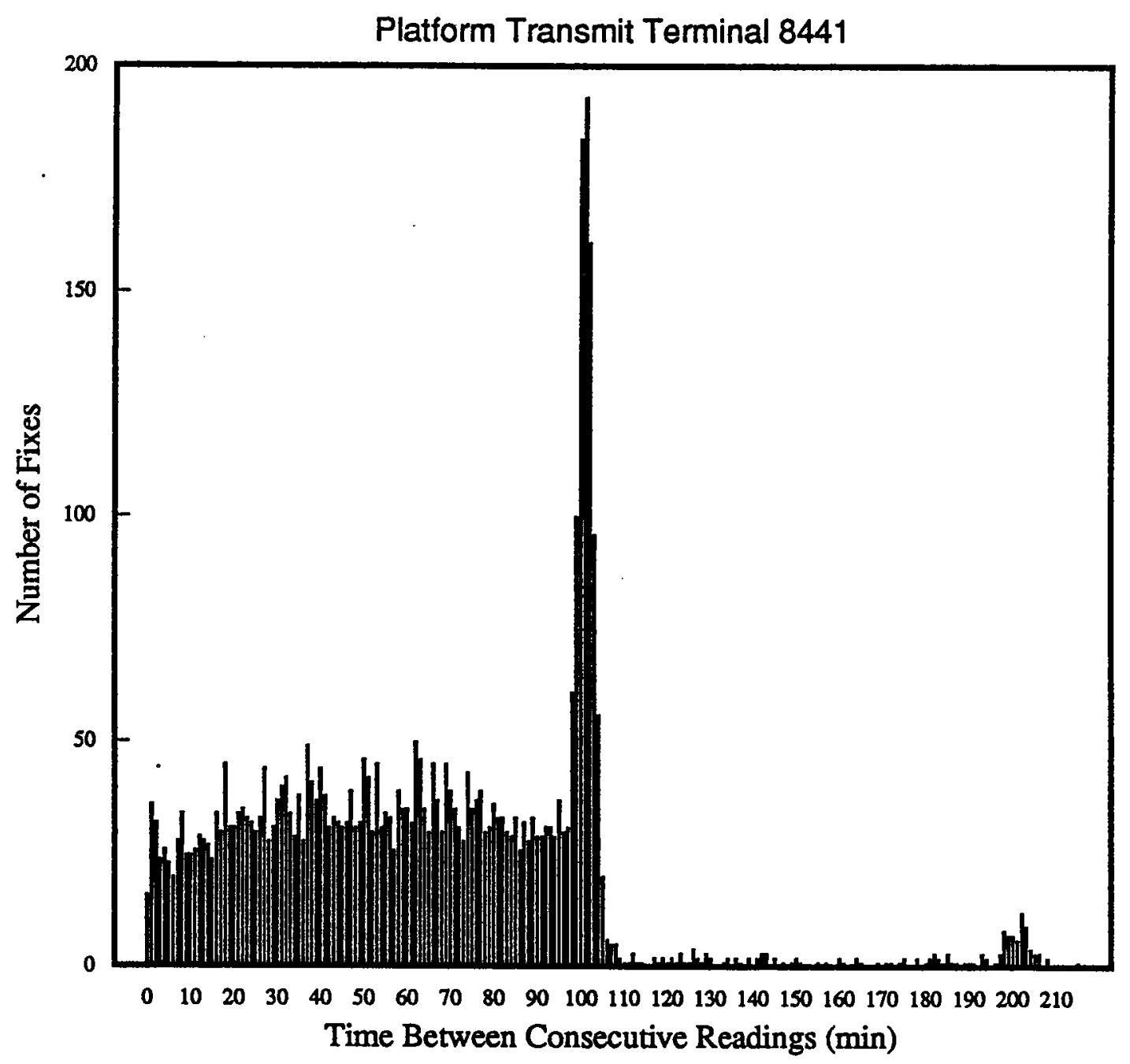


Fig. 11. Azimuth stereographic projection plots of the drift track of the AEDB: a) section 1, b) section 2, c) section 3, d) section $4, \theta$ ) section 5 . Locations are plotted every half-hour and connected by line segments. Crosses mark every 96th point (equal to a two day interval), while only every other cross is date labeled.

The raw data is from PTT 8441 , and is primarily composed of location fixes possessing an ARGOS quality indication of either 3 (150 m accuracy) or 2 (350 $\mathrm{m}$ accuracy). During certain periods, however, lower quality locations were used to fill in large gaps of time without higher quality positions. From 30 January thru 15 March 1988 (in section 4), locations with qualities of 1 (1000 m accuracy) and 0 (greater than $1000 \mathrm{~m}$ ), were used in the absence of any quality 2 or 3 fixes. In fact, no locations were obtained between 21 and 30 January, and only one location between 8 February and 3 March; consequently, these portions of the drift track are entirely straight-line interpolations. From 16 March thru 1 April (in section 5), quality 1 fixes were used in addition to quality 2 and 3 locations, to add detail to an otherwise rough plot.

The raw data generated an unequally-spaced time series of locations. Taking into account the curvature of the Earth, a second time sequence was derived by computing the speed of the buoy from the locations. The speed sequence was divided into subsections and the standard deviation of each was calculated. Locations that corresponded to speed points that exceeded 3 times the standard deviation for each section, were removed from the original time series. In this manner, 363 questionable locations were eliminated and the resulting series interpolated using a straight-line method to produce a smooth, equally spaced location time series with a half-hour interval. 
Figure 11a

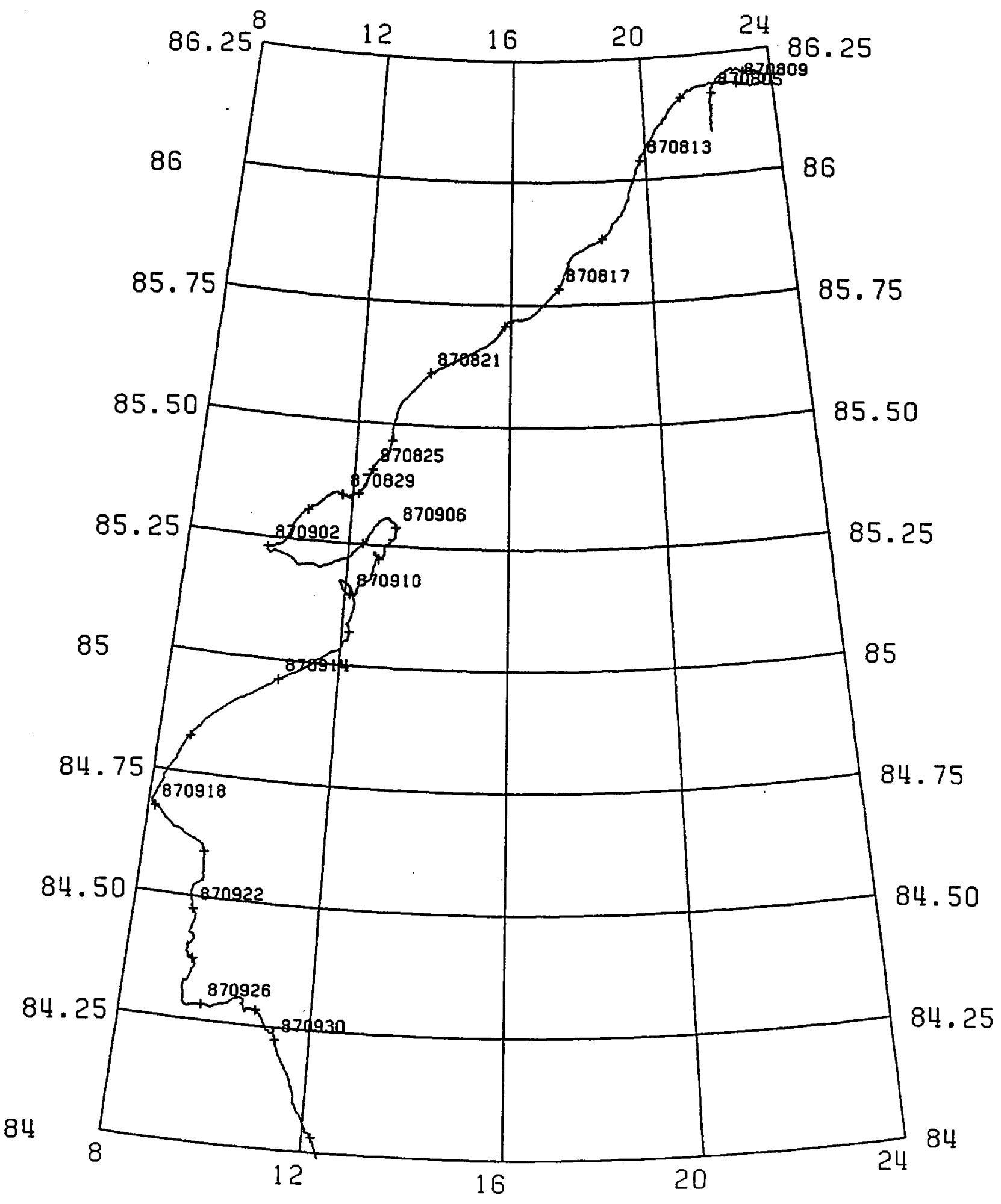


Figure 11b

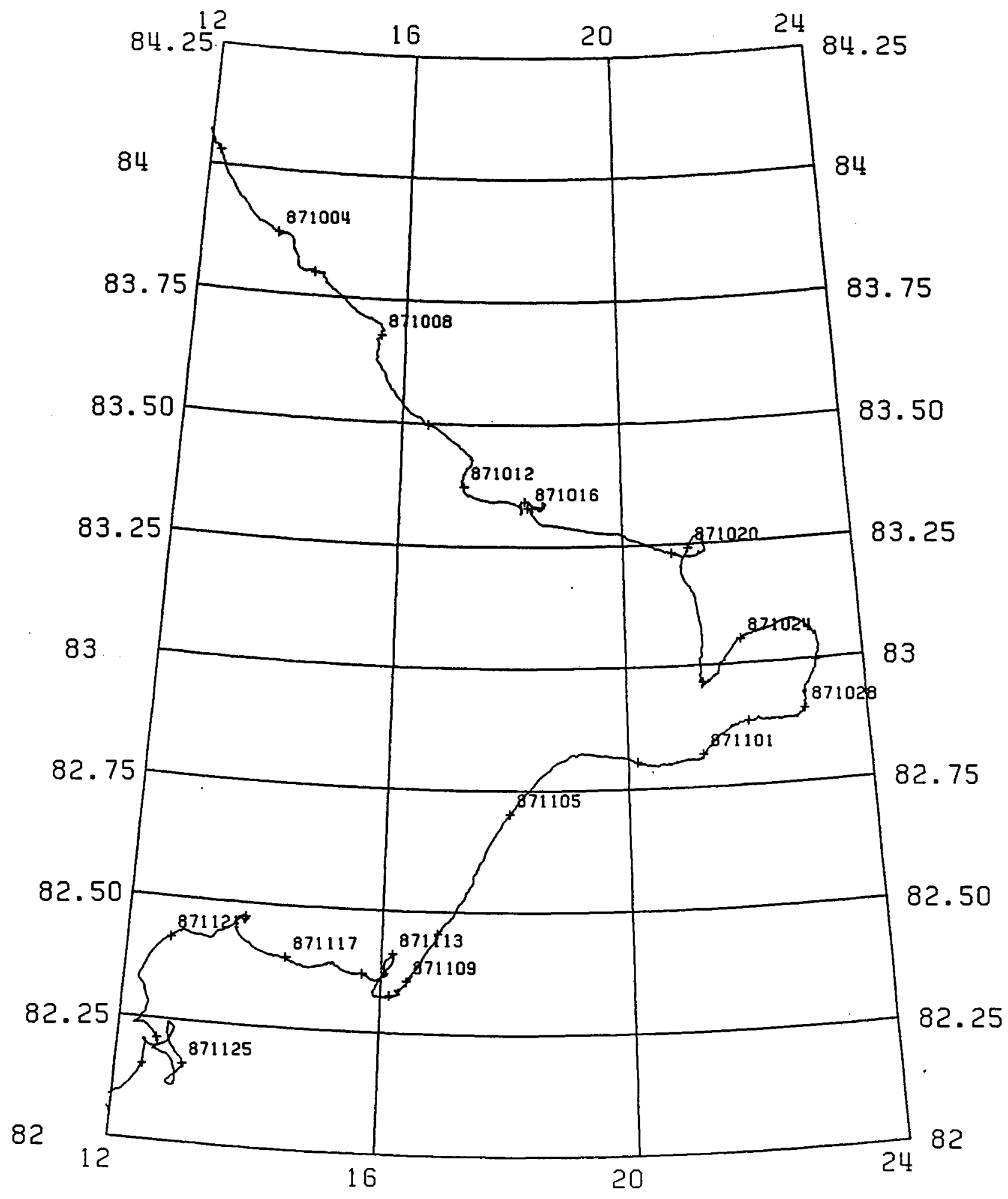


Figure 11c

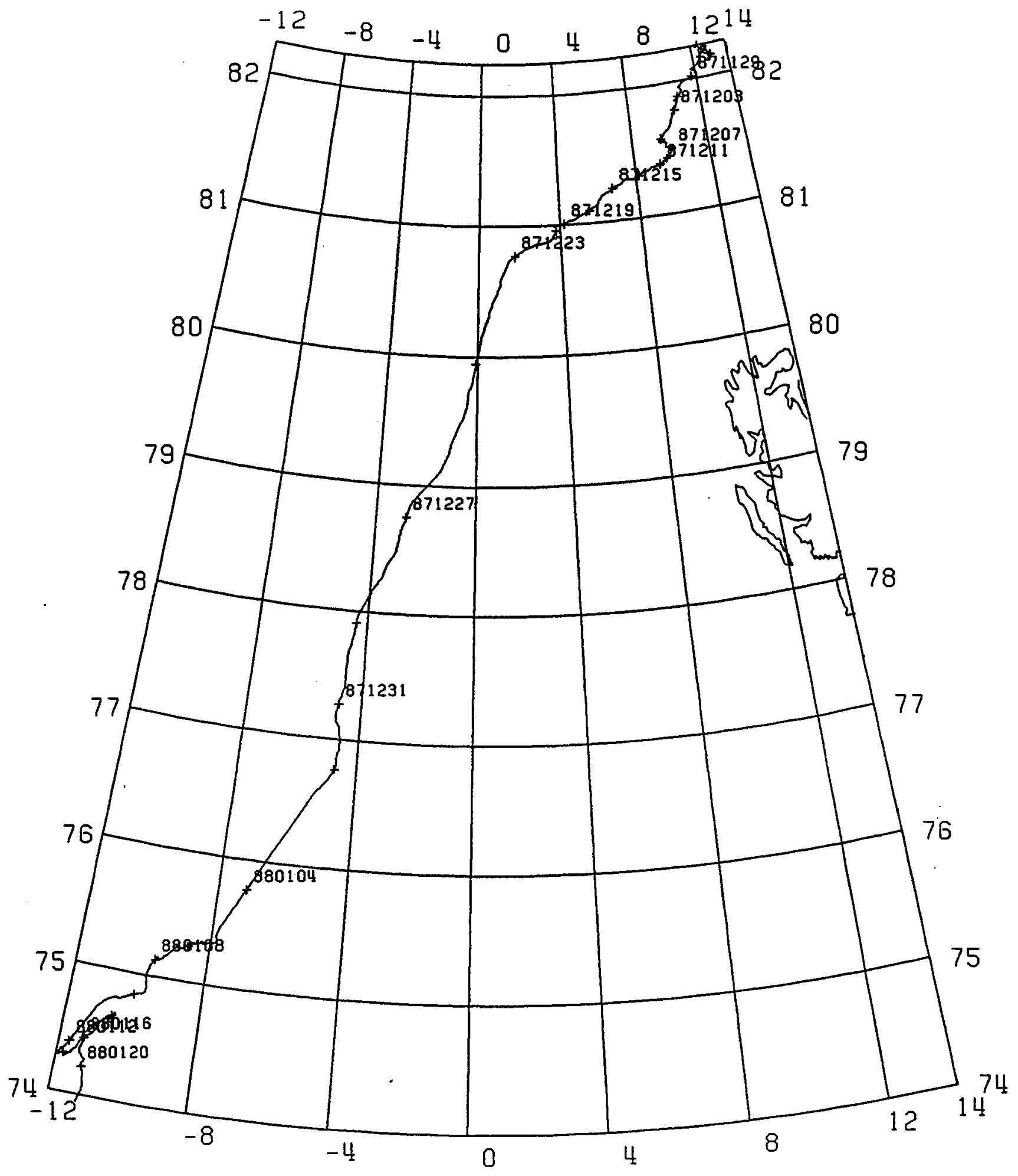


Figure 11d

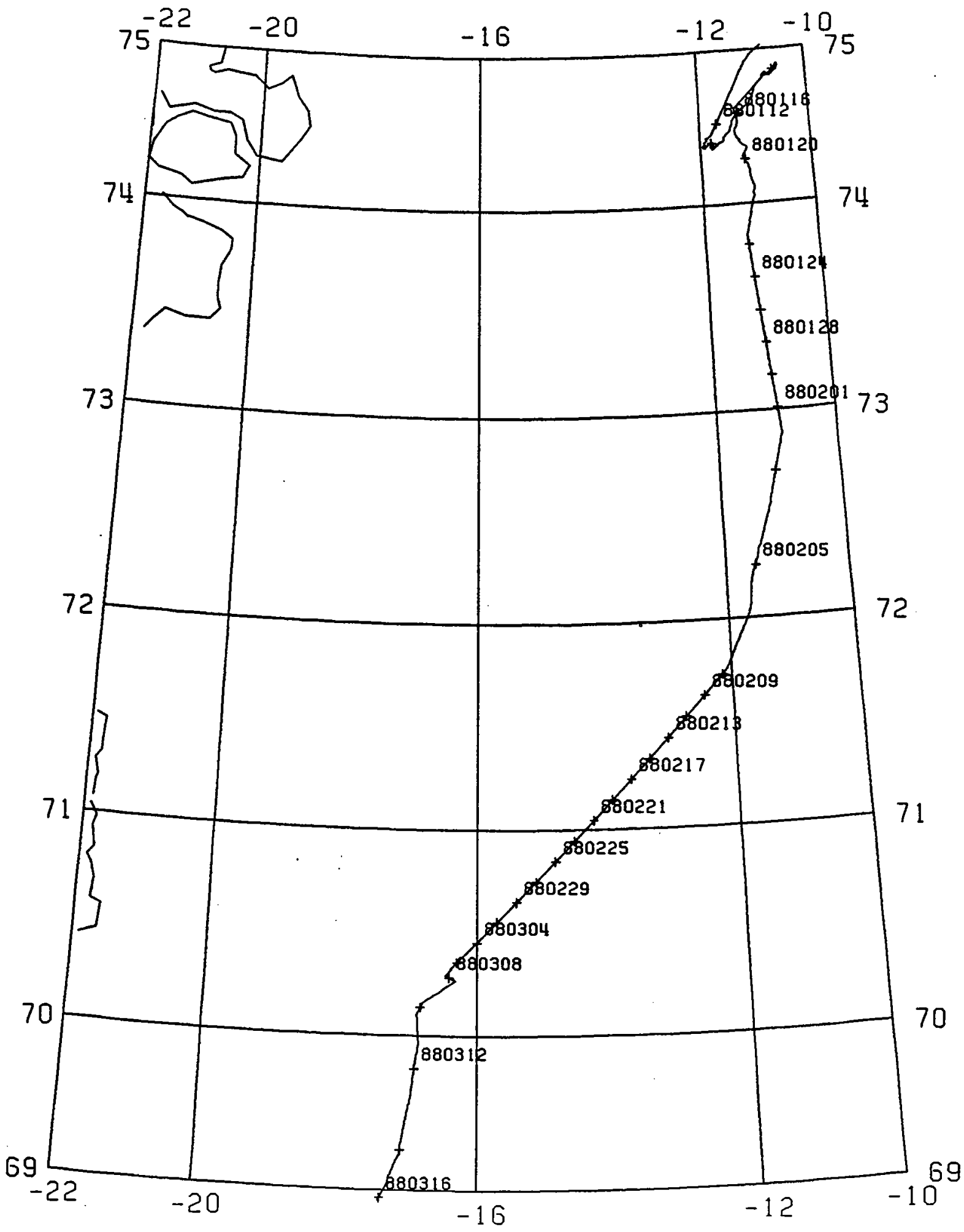


Figure 11e

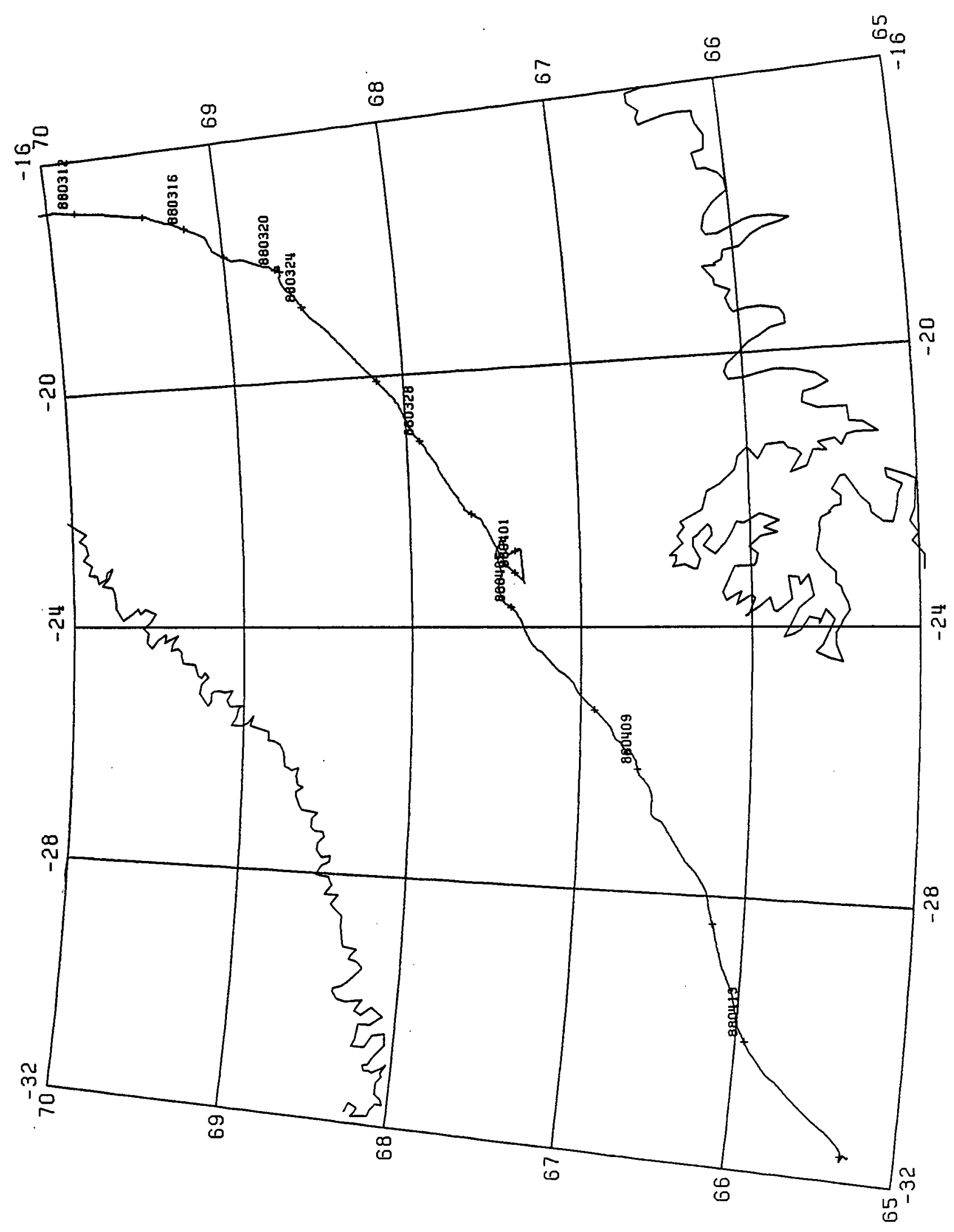


Fig. 12. AEDB speed and East and North velocity time series in $\mathrm{cm} / \mathrm{s}$ : a) section 1, b) section 2, c) section 3, d) section $4, e$ ) section 5 . A positive $U$ represents easterly displacement, while a positive $V$ represents northerly displacement. The $\mathrm{U}$ and $\mathrm{V}$ time series are the scaled first differences of the location time series calculated as per Figure 11, and filtered through a 7 point triangular filter. The speed time series is the magnitude of the vector formed from $U$ and $V$. In section 4 , extended periods of missing locations generate long segments of constant velocity interpolations. 
Figure $12 a$

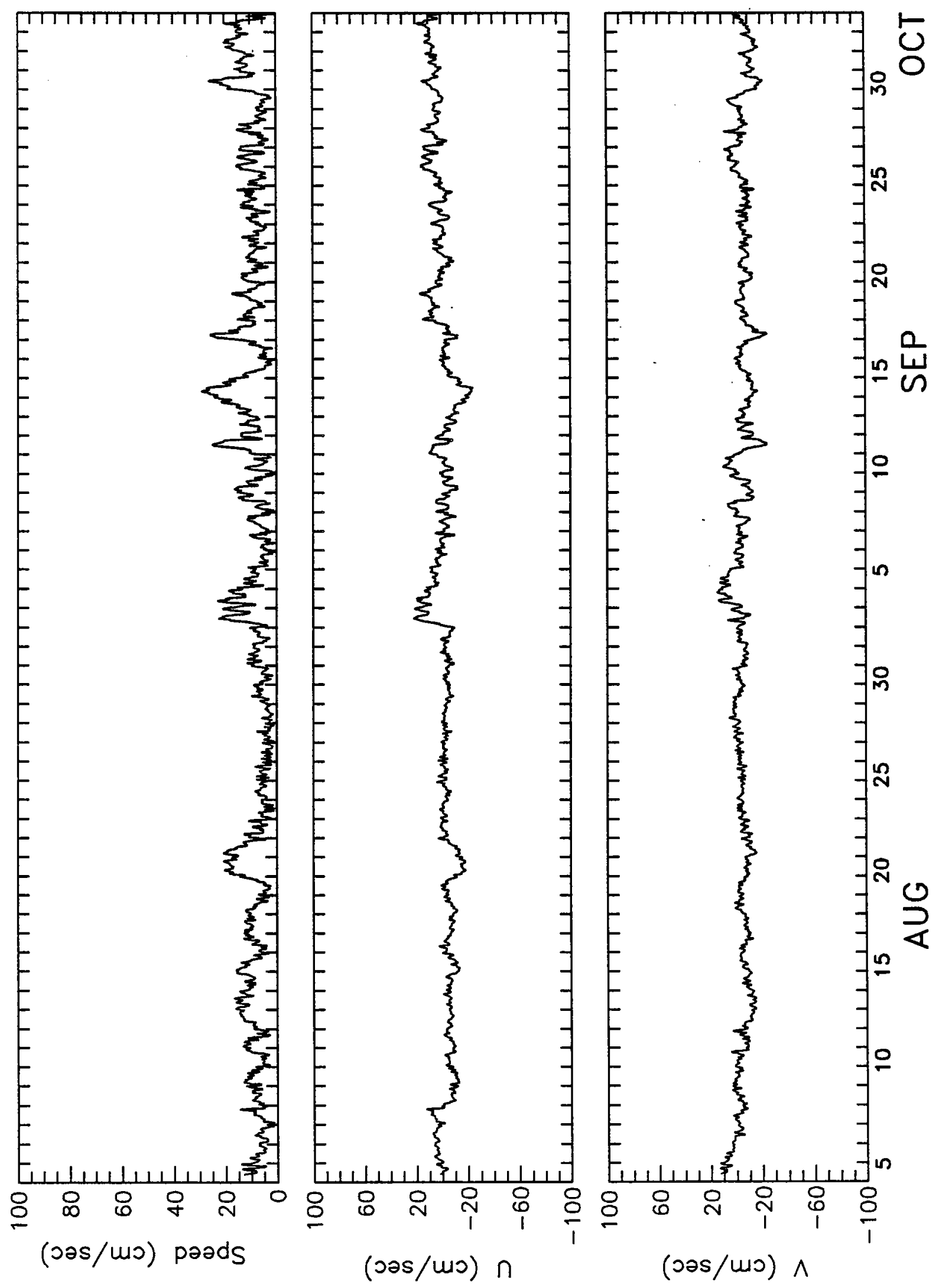


Figure $12 b$

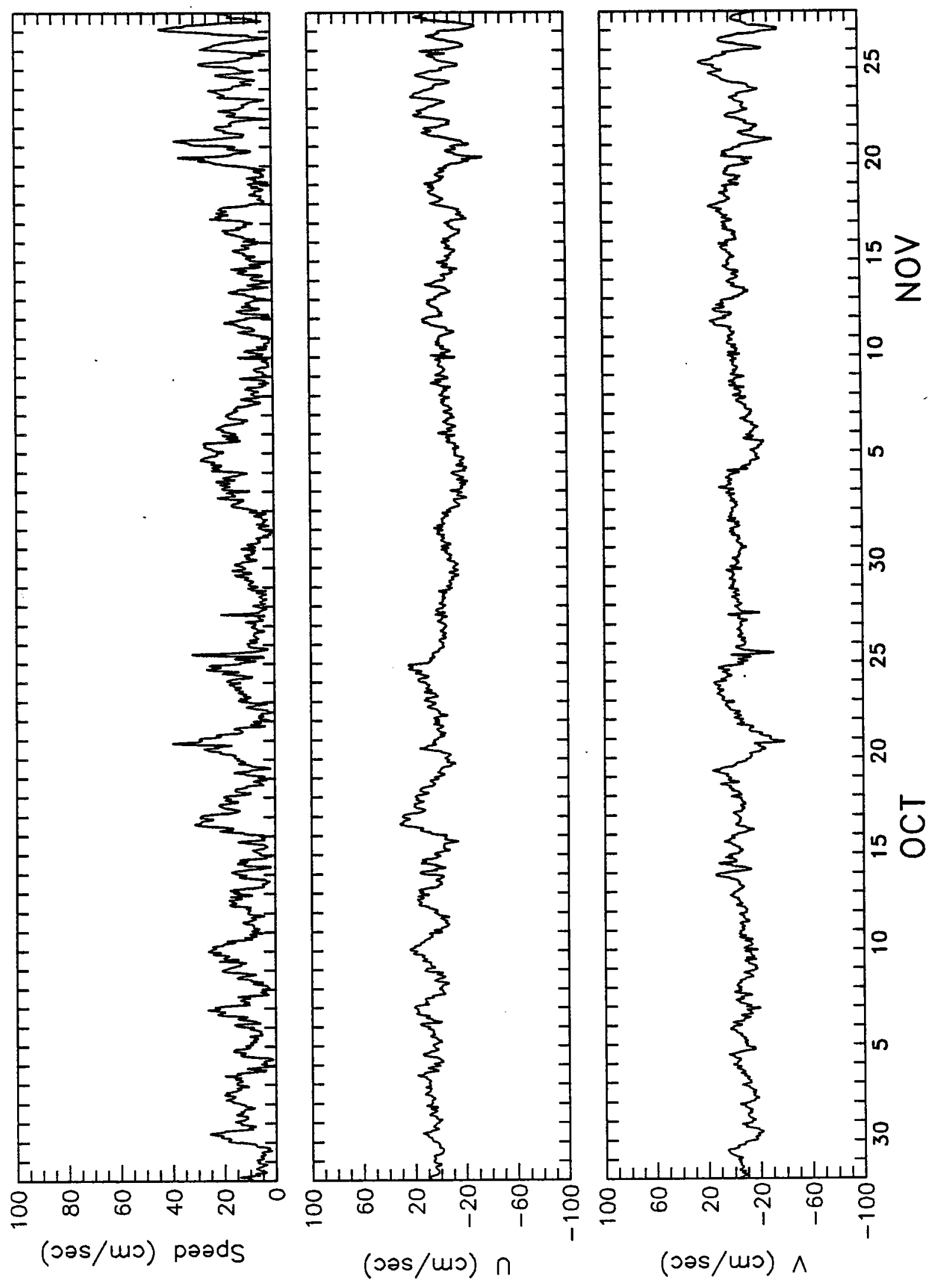


Figure $12 c$

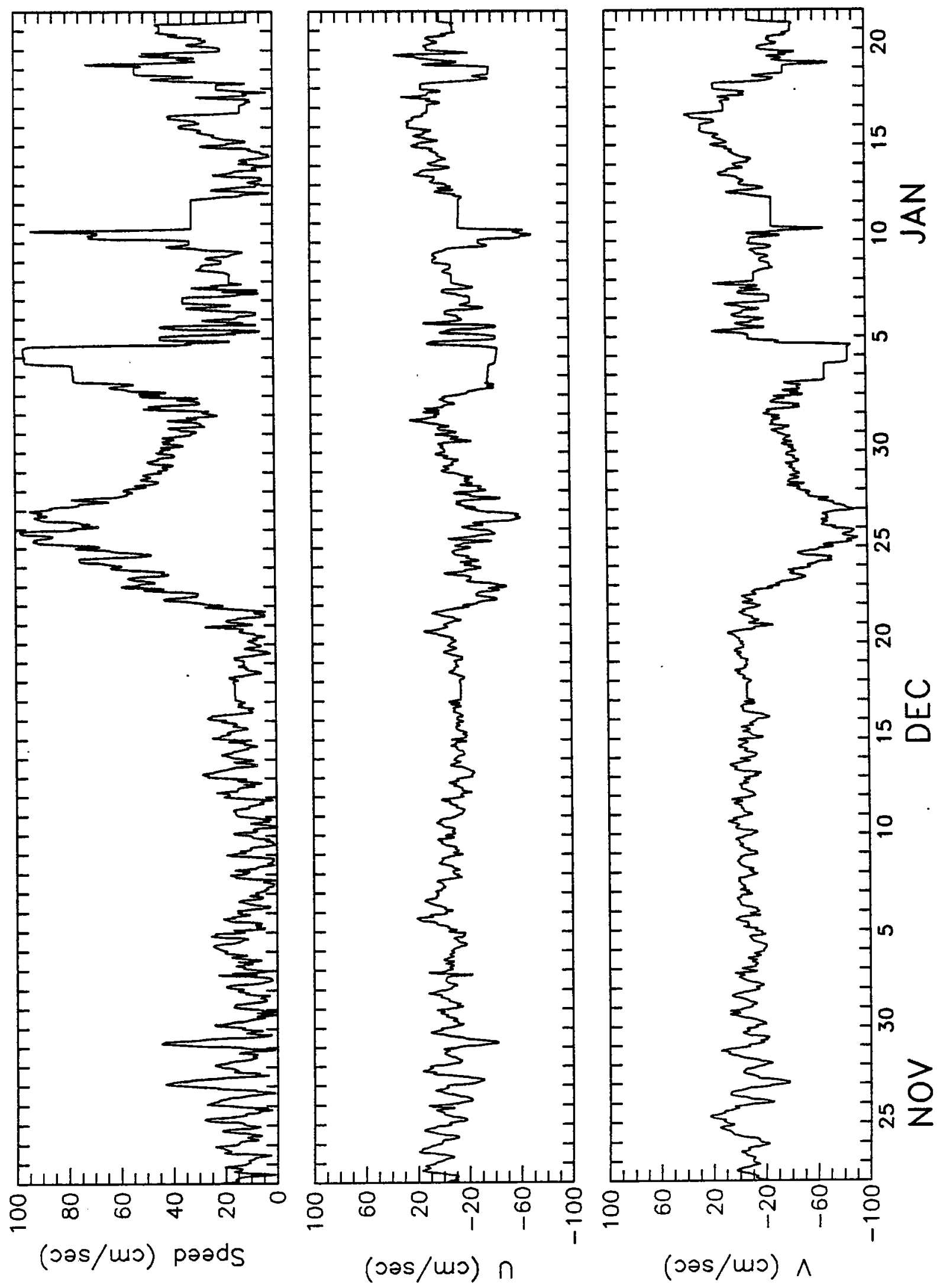


Figure 12d
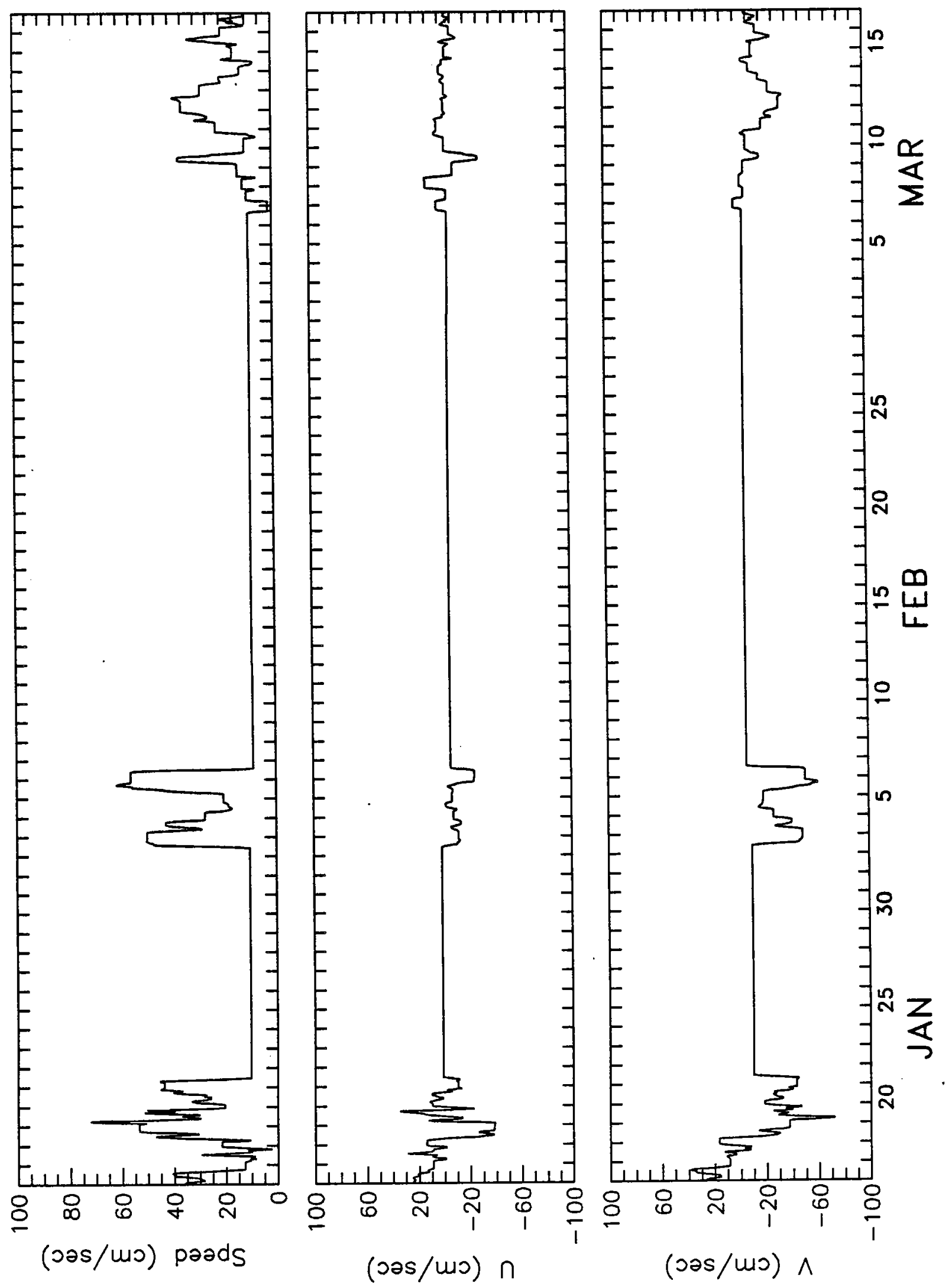
Figure $12 e$
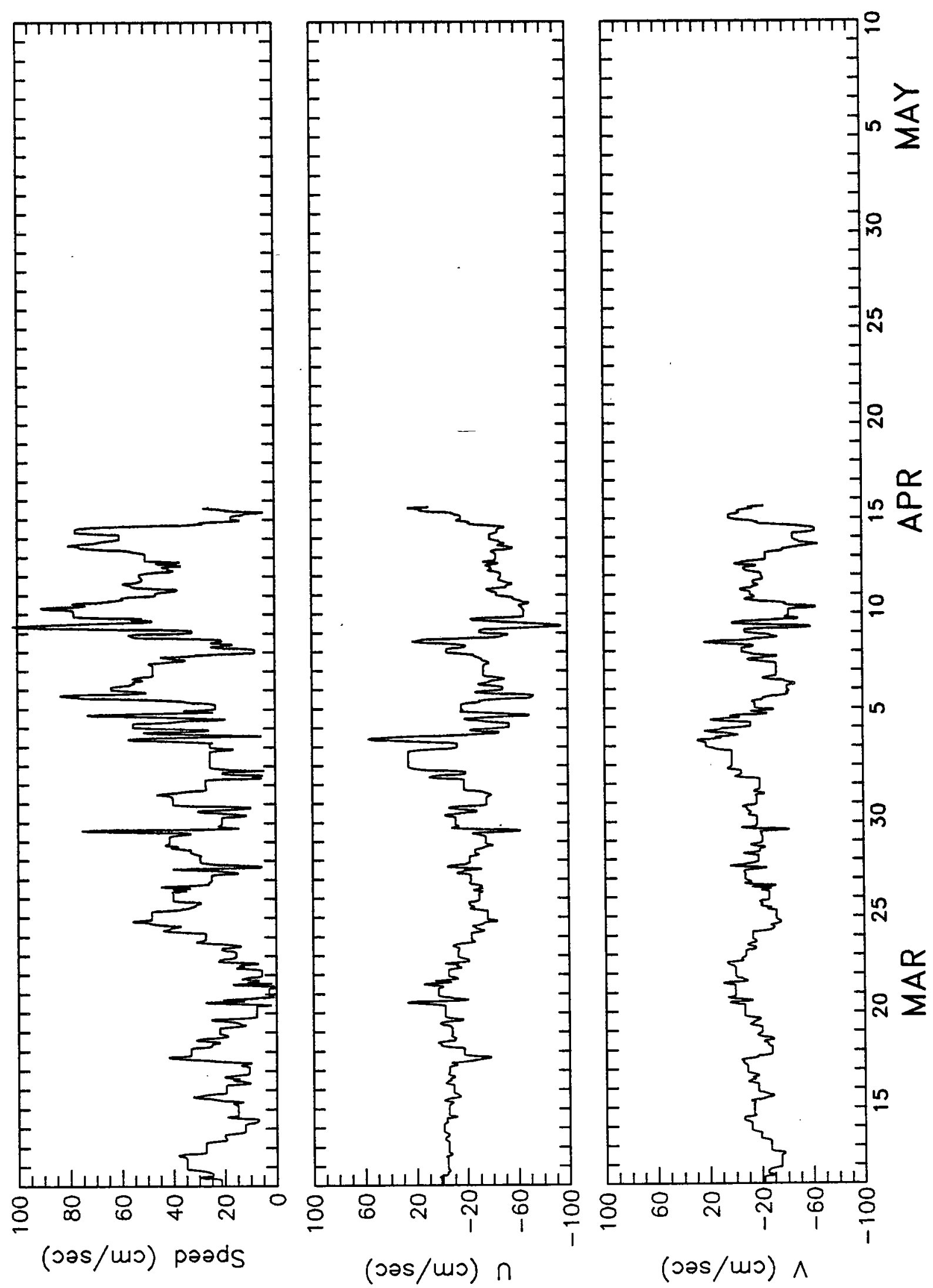
Fig. 13. AEDB sphere temperature time series during sections 1,2 , and 3. Information from only a single temperature sensor of PTT 8441 is shown, since differences between all 6 sensors mounted at separate locations in the sphere were insignificant. The sphere temperature provides a rough indication of the temperature of the surrounding environment, but is not exactly the air temperature. The processed measurements do indicate that the inner surface of the yellow steel shell varied from +10 to $-38^{\circ} \mathrm{C}$, and reveal the moment when the float fell into the seawater on 2 January 1988 by a sudden increase of the temperature stabilizing at $-2^{\circ} \mathrm{C}$. The plot ends on the following day, when the sphere became dented and the sensors no longer provided valid data.

Like the ARGOS location data, the raw temperature data from the PTTs produced a series unevenly spaced in time. A straight-line interpolation method was used to generate an hourly spaced time series. The thermistor electronics were uncalibrated in the lab, and displayed substantial biases from the air temperature after deployment of the float. Using air temperature data provided by Dr. H. Hoebert of the Meterological Institute of the University of Hamburg from another drifter $550 \mathrm{~m}$ away from, but on the same ice floe as the AEDB, the raw values from PTT 8441 were scaled with a correlation factor of 0.994 . 
Figure 13

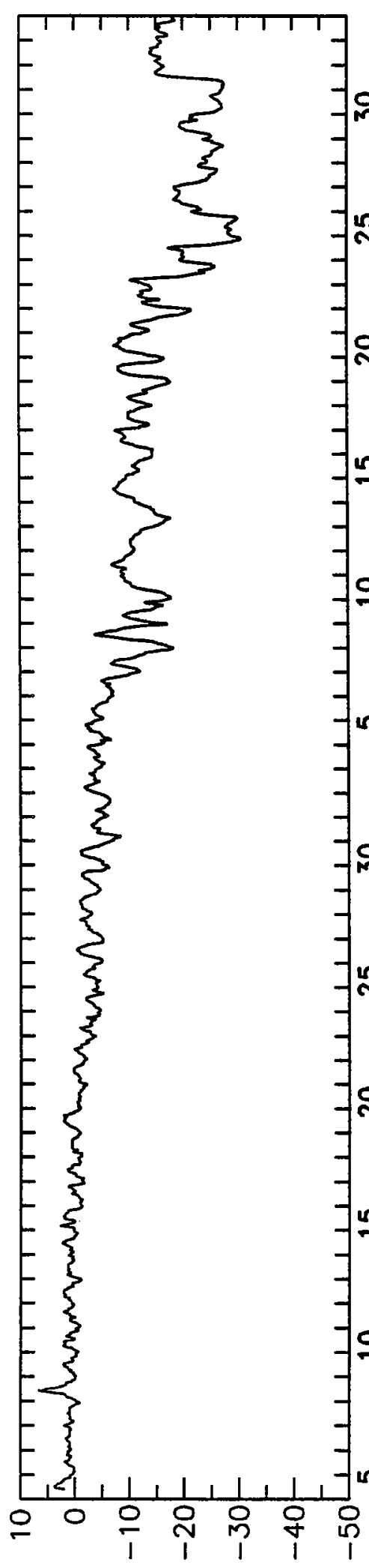

(0) dwal foold

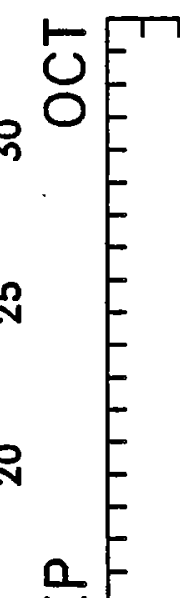

品F

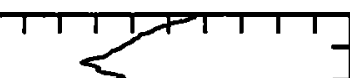

-n
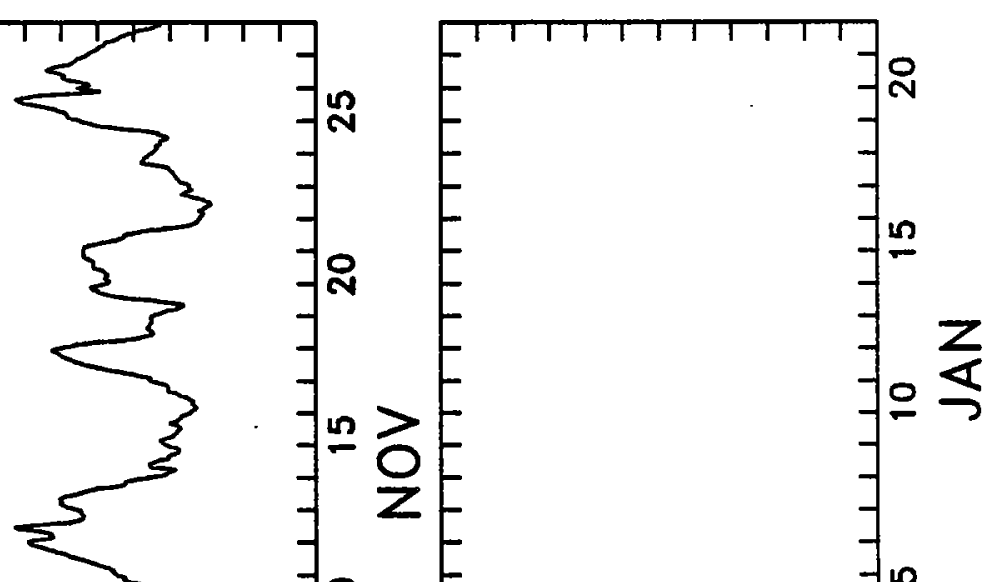

?
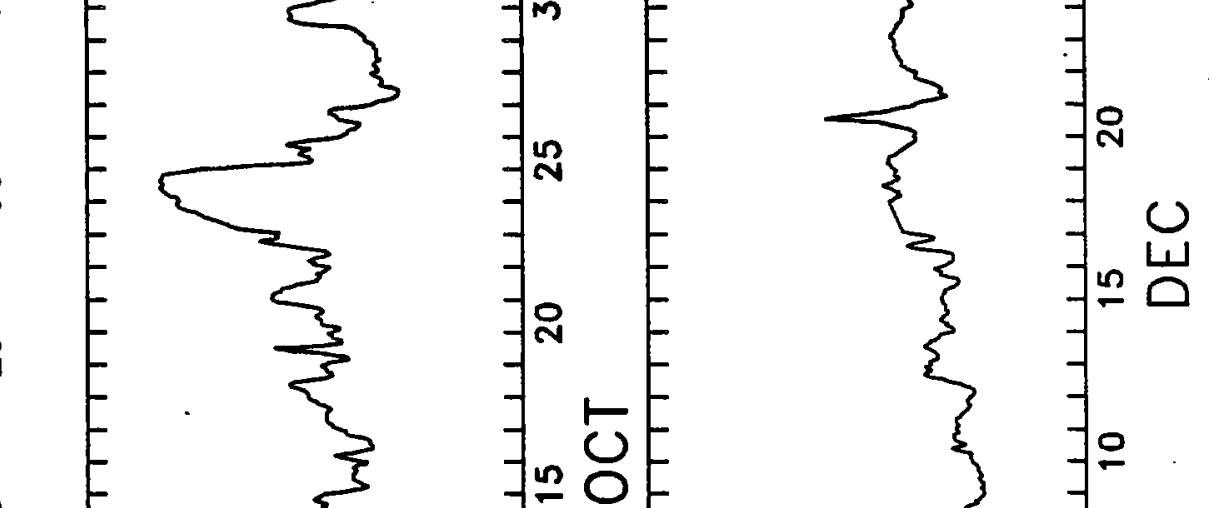

F

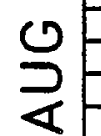

4

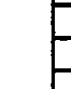

$=$

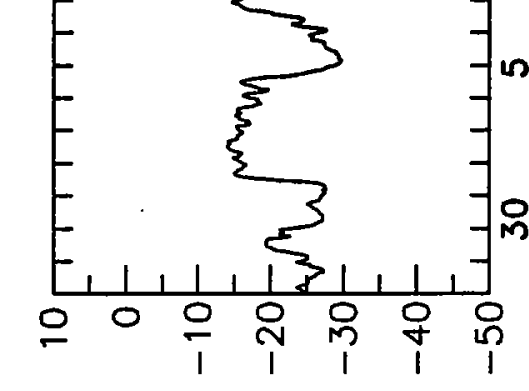

(0) dura fools
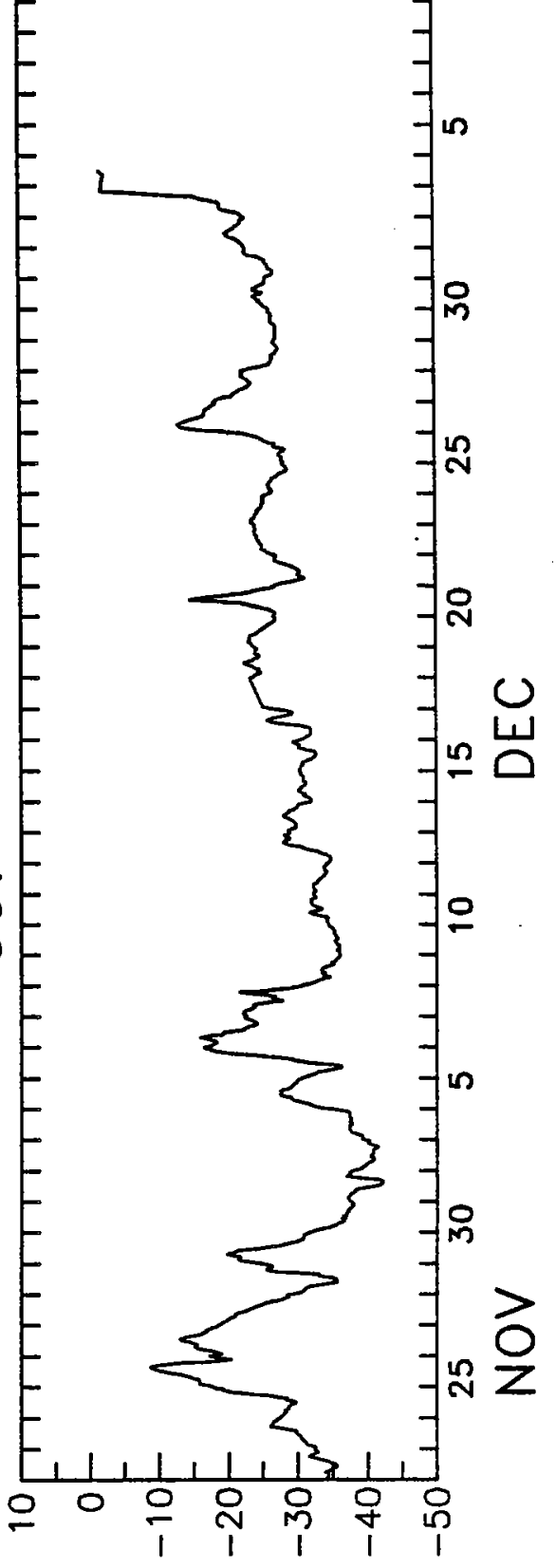

(0) dur| zDOIf 
Fig. 14. The lithium battery voltage providing main power to PTT 8441 : a) sections $1,2,3, b$ ) sections 4,5 . Fluctuations of the voltage are consistent with fluctuations in the temperature series of Figure 13. The raw battery voltage data from the PTT was unevenly spaced in time, and was interpolated with a straight line to produce an hourly spaced time series. Platform 8440 battery voltage is nearly identical. 
Figure 14a

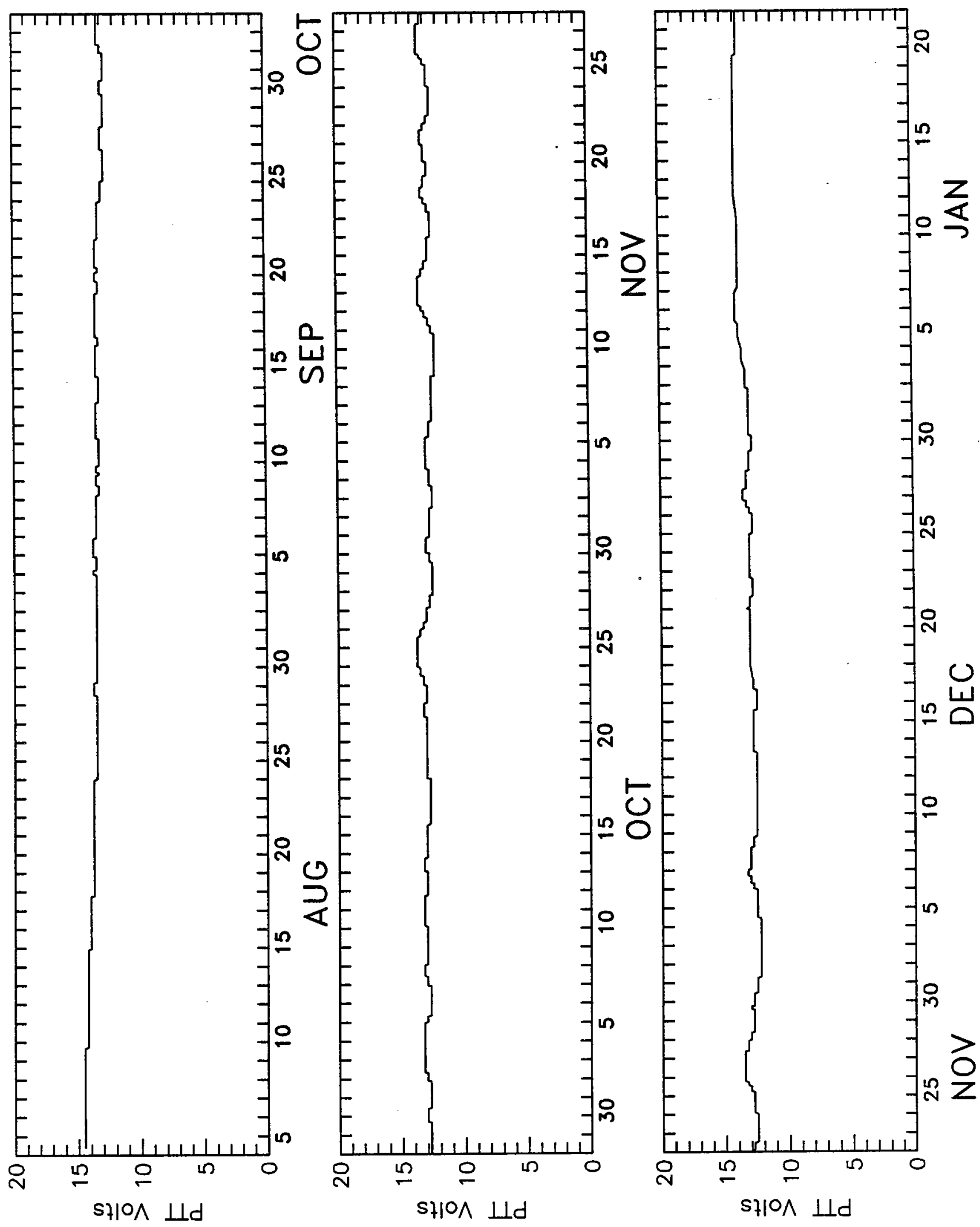


Figure 14b

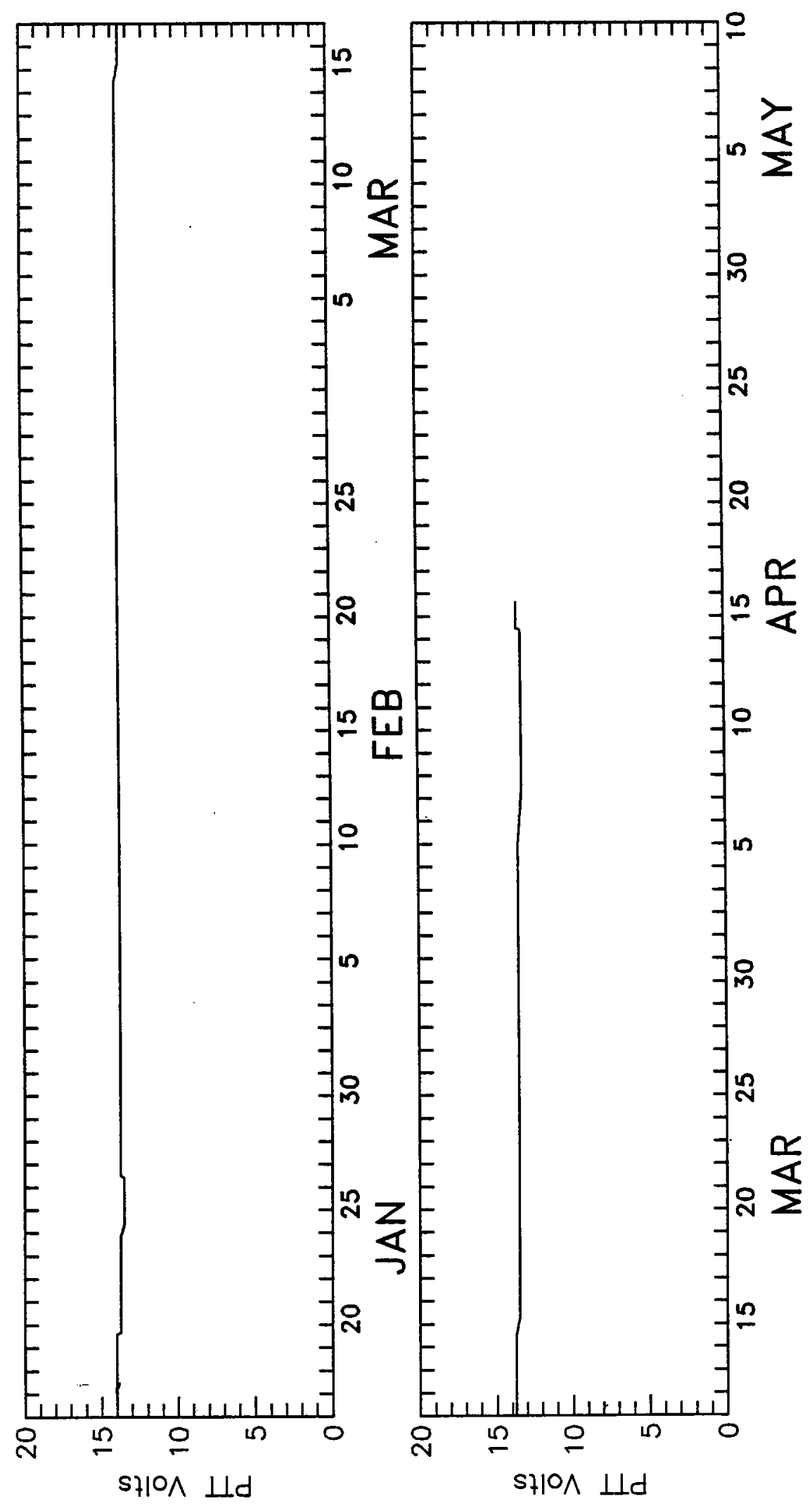


Fig. 15. AEDB sphere strain gauge time series for sections 1, 2, and 3: a) strain gauges $S A 1$ and $S A 2, b)$ strain gauges SB2 and SB1, c) strain gauges $S C 1$ and SC2, d) strain gauges SD2 and SD1; e) strain gauges SD2 and SD1 for section 5. Each plot includes the strain sensors from a vertical section of the sphere; the solid lines are from sensors located on the floor, while the dashed lines are from gauges placed around the equator of the float (Fig. 2).

The raw strain data from the PTTs were unevenly spaced in time, and were straight-line interpolated to produce hourly spaced time series. The displayed strain values are zeroed with respect to the strain present when the buoy was deployed on 4 August 1987. Because strain gauges provide valid data only when the material being stressed is still elastic, any information furnished by these gauges after 4 January 1988 is questionable since the sphere probably was deformed at this time. Most of the gauges went completely off scale immediately afterwards, only PTT 8440 sensors SD1 and SD2 continued to provide data within limits. But because no transmissions were received from PTT 8440 during time section 4 , only section 5 data is plotted. 
Figure 15a

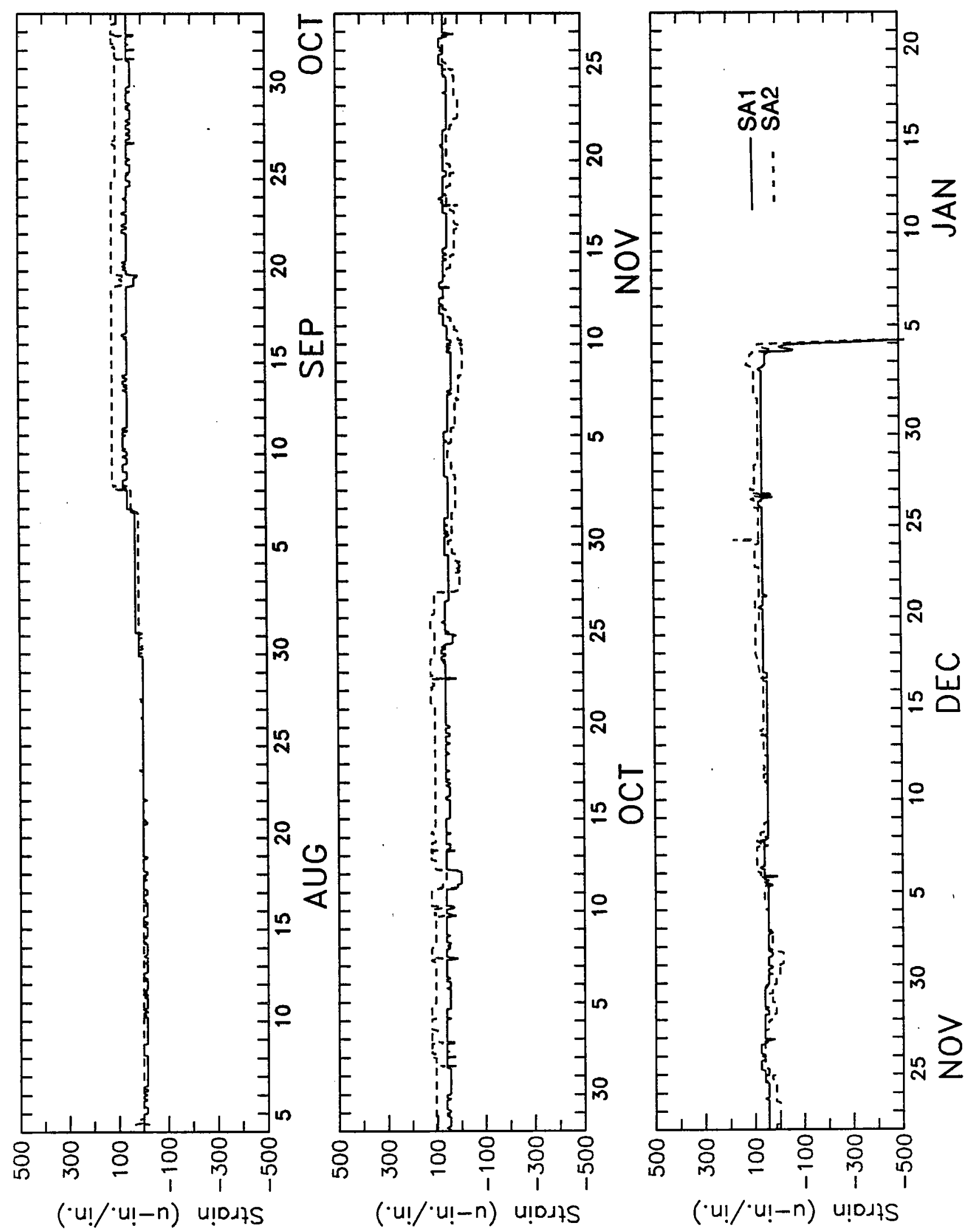


Figure 15b

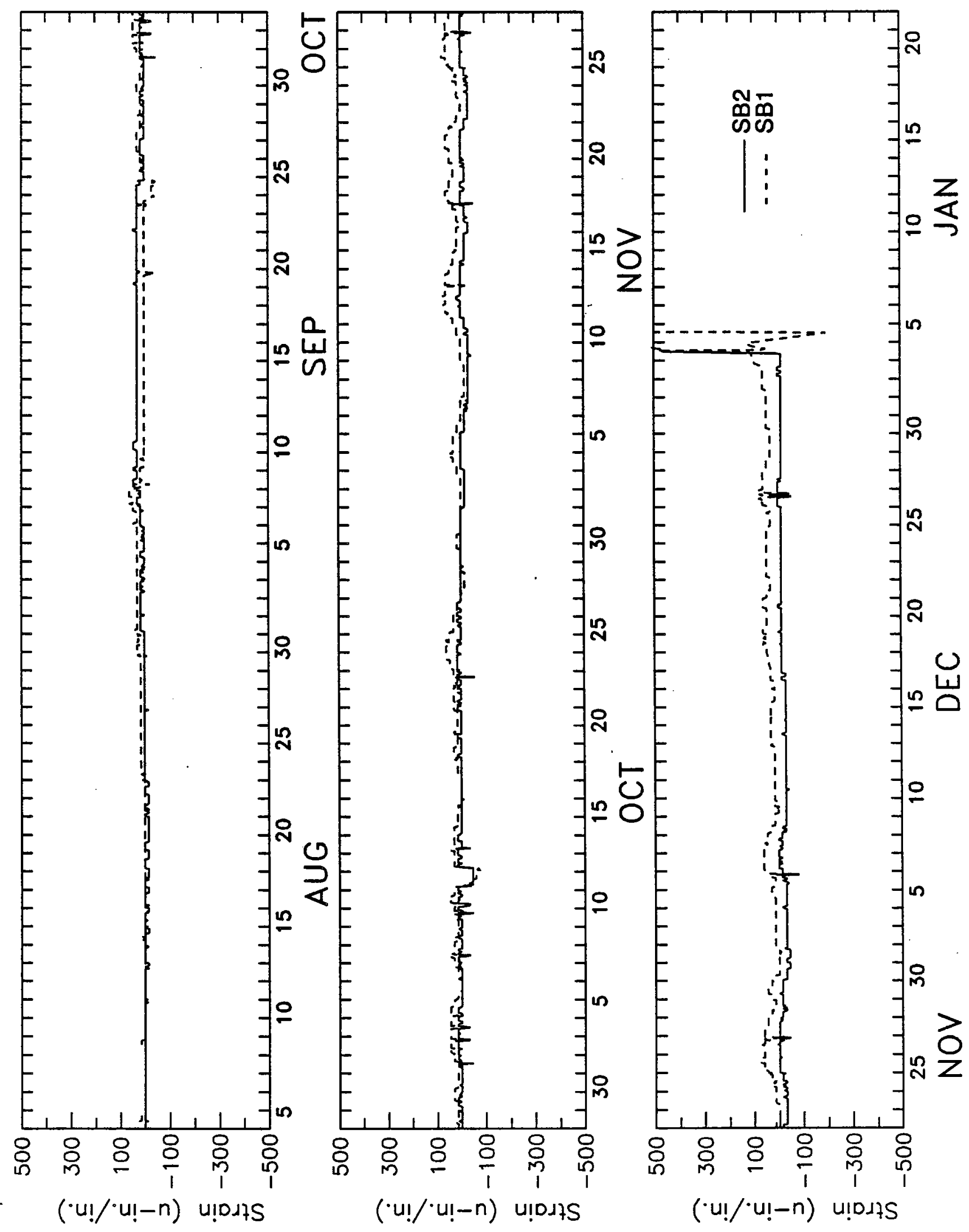


Figure 15c

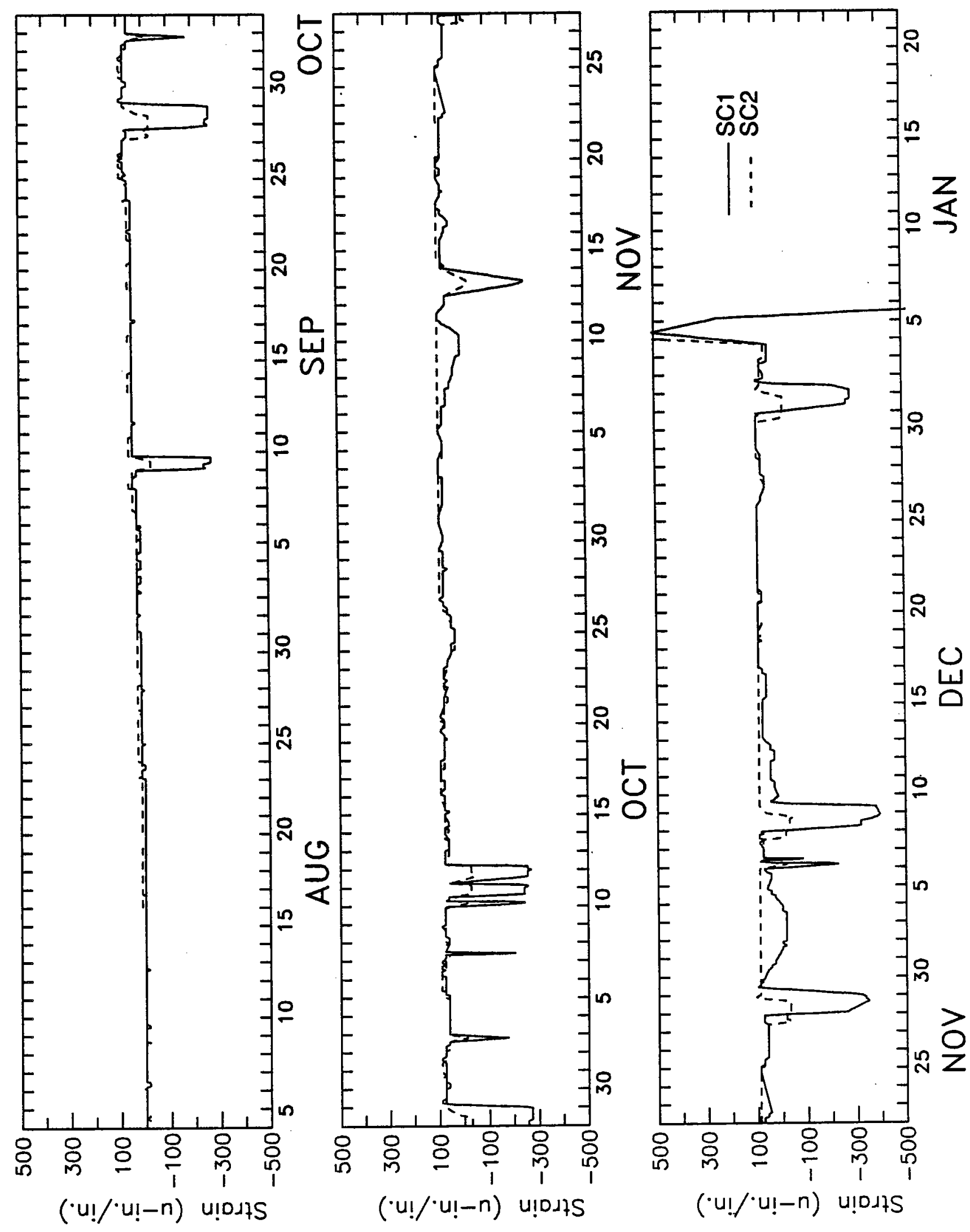


Figure 15d

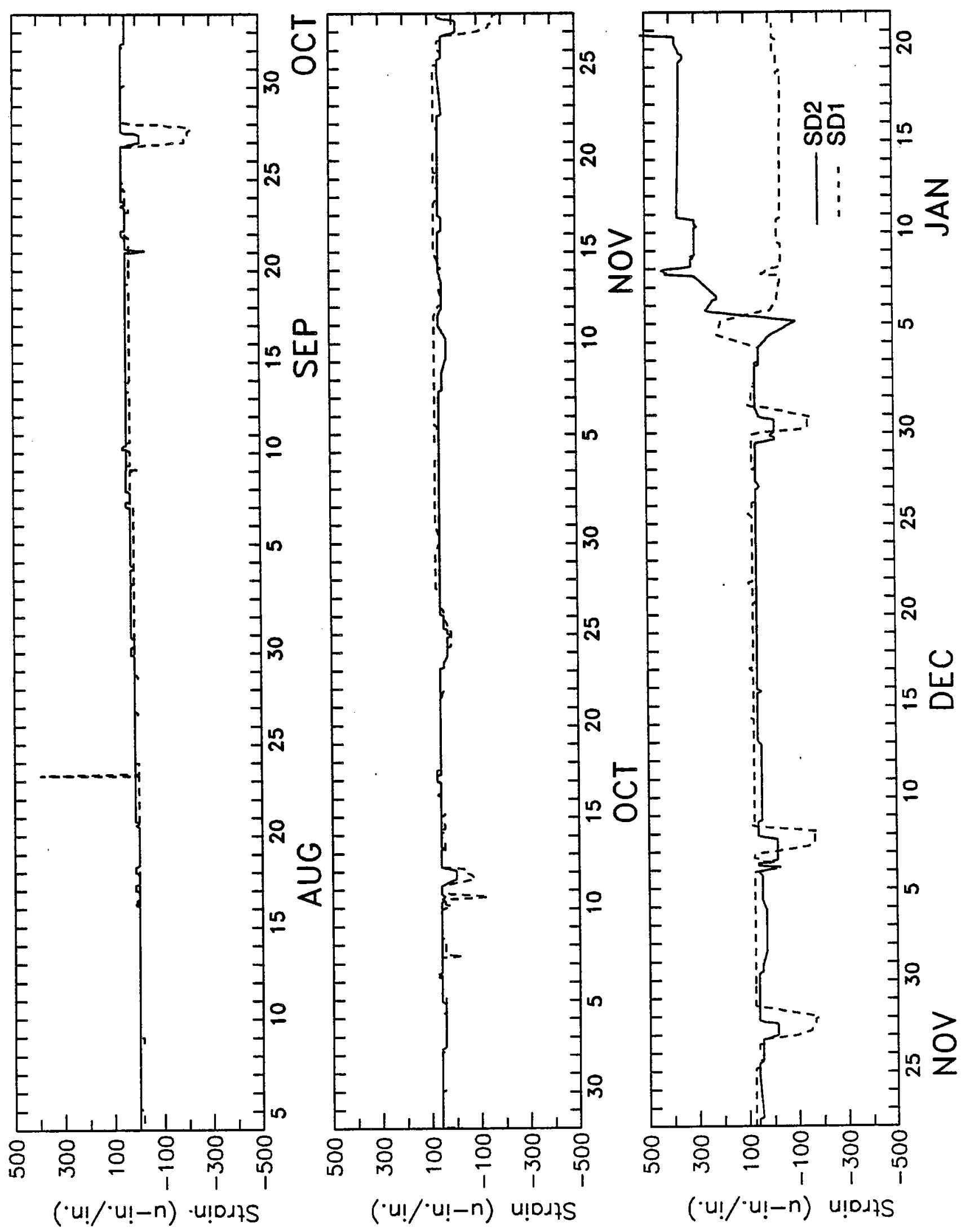


Figure $15 e$

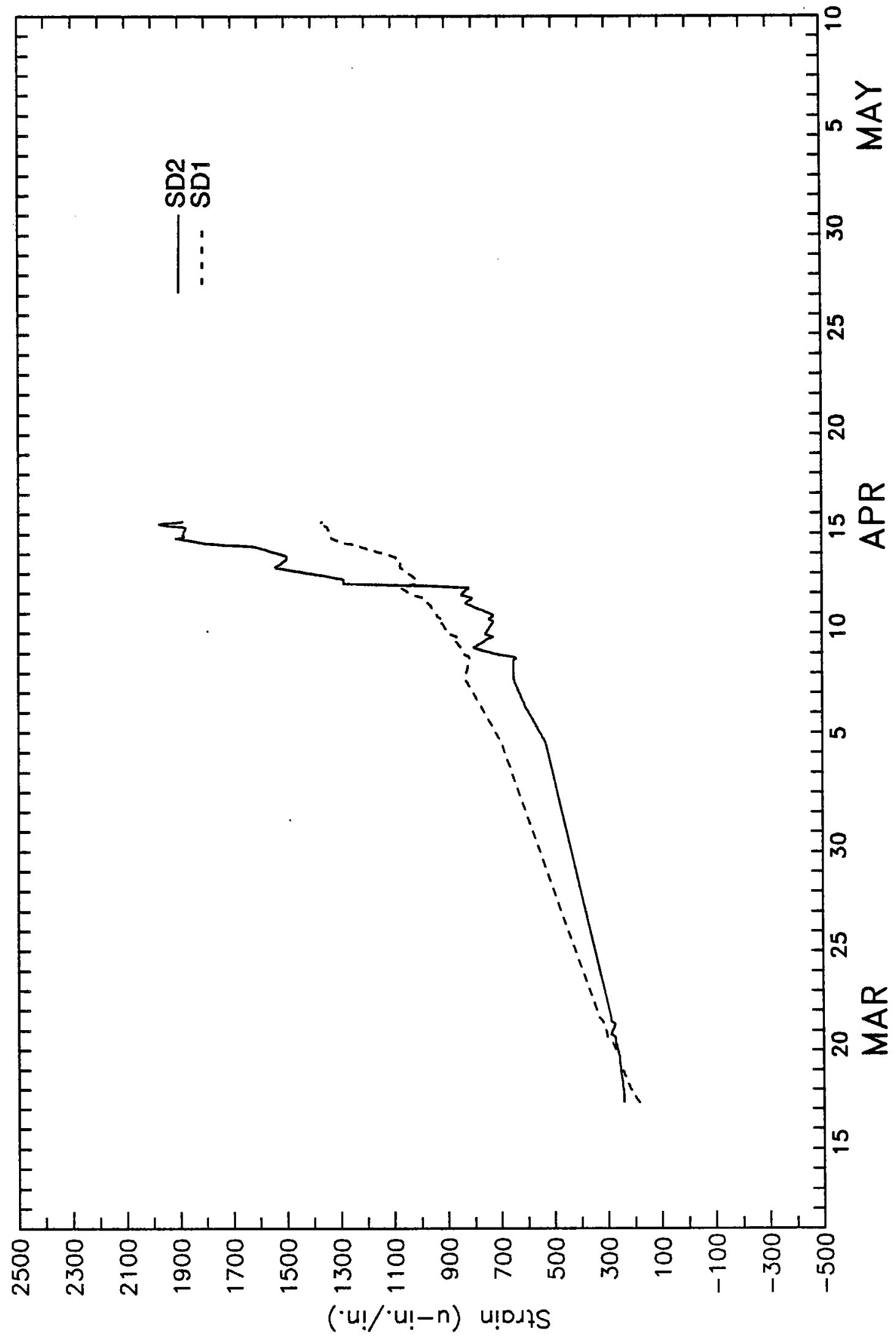

61 
Fig. 16. Comparison of the speed of the AEDB (top) with the ice and water temperature data (bottom) over the time period 14 December 1987 (day 348) to 2 January 1988 (day 367). The $16 \mathrm{~m}$ water temperature series is from the ADCP. The complete sectionalized $16 \mathrm{~m}$ series is presented in Figures $15 \mathrm{a}$ through $15 \mathrm{~d}$. The ice thermistor chains provided the 5.6 and $3.0 \mathrm{~m}$ water temperatures, and the $2.75,2.50$, and $2.25 \mathrm{~m}$ ice temperatures. Depths are measured from the surface of the ice.

The ice thermistor data was analyzed by Perovich et al. (1989). Due to a malfunction in the data logger's storage module, information from August 4 to December 14 was lost. However, there was a total of $0.72 \mathrm{~m}$ of bottom melting during this period, indicating a time-averaged oceanic heat flux of $14 \mathrm{~W} / \mathrm{m}^{2}$.

During the time that data was collected, the buoy experienced a rapid acceleration through the warmer waters of the Fram Strait, attaining speeds as great as $80 \mathrm{~km} /$ day. Before the speed up (day 355), the heat flux averaged 7 $\mathrm{W} / \mathrm{m}^{2}$, and no appreciable bottom ablation occurred. During the following 7 days, $0.23 \mathrm{~m}$ of the ice bottom melted and the oceanic heat flux increased by a factor of 18 to $128 \mathrm{~W} / \mathrm{m}^{2}$. The time series terminates on 2 January, when the ice thermistor chains were torn from the float as the ice floe fragmented. . 
Figure 16

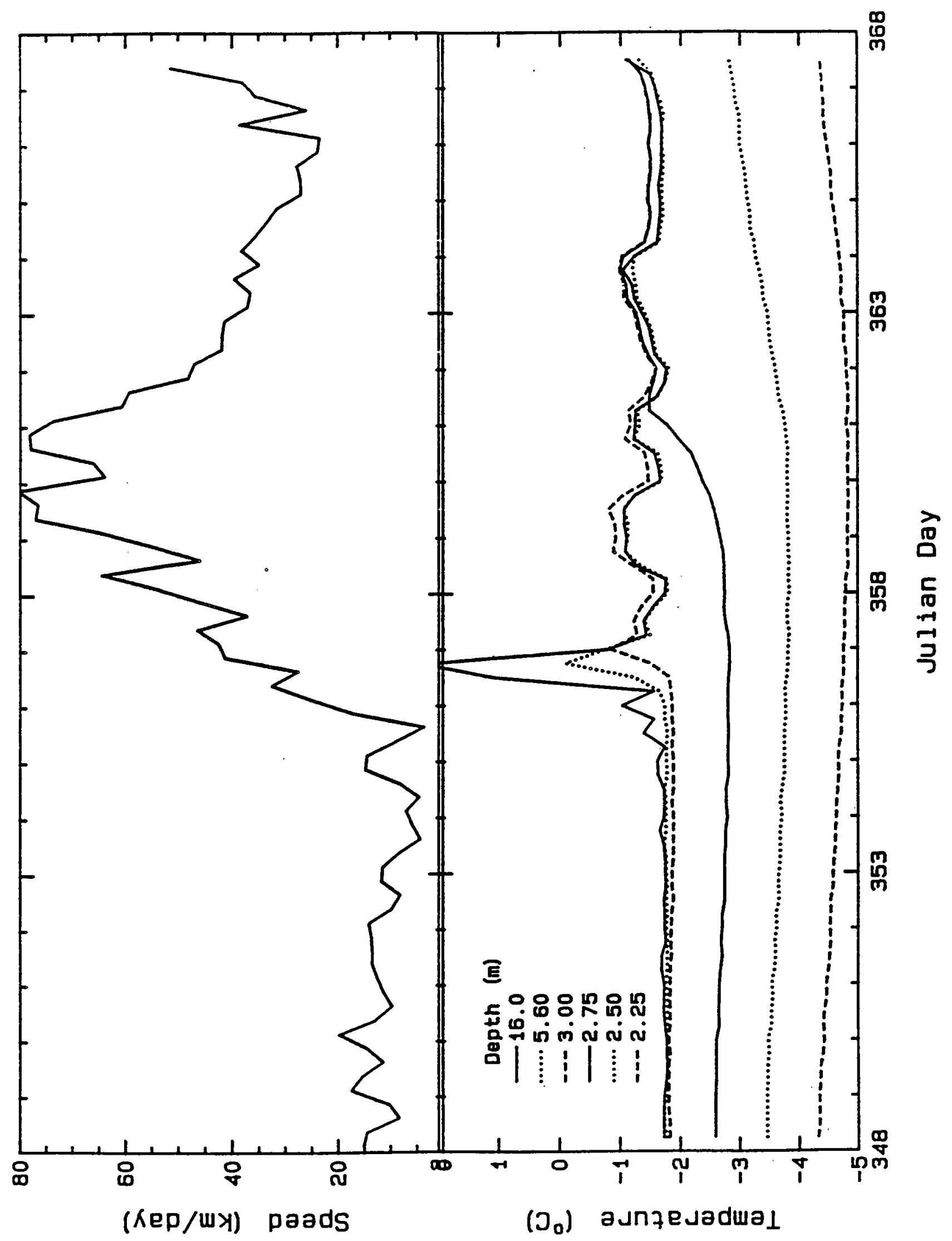


Fig. 17. AEDB fluorometry time series at 10 and $20 \mathrm{~m}$ below the surface: a) sections 1 and 2, b) sections 3,4 , and 5 . The solid line displays information from the instrument located at $10 \mathrm{~m}$ below the AEDB and the dashed line from the instrument at $20 \mathrm{~m}$. The unfiltered data is plotted as a percentage of the full scale value, which is approximately $5 \mathrm{ug} / \mathrm{l}$ of chlorophyll $a$ at the high sensitivity setting (Appendix B), but depends upon the particular type of plankton in the water. Up until 2 January 1988, the $10 \mathrm{~m}$ fluorometer was actually in 6 to $7 \mathrm{~m}$ of seawater below 3 to $4 \mathrm{~m}$ of ice. Likewise, the $20 \mathrm{~m}$ fluorometer was 16 to $17 \mathrm{~m}$ below the icefloe. The record of the deeper fluorometer ends on 18 January due to a hardware malfunction. Biofouling may have gradually reduced the sensitivity of both fluorometers over the course of the deployment. 
Figure 17a

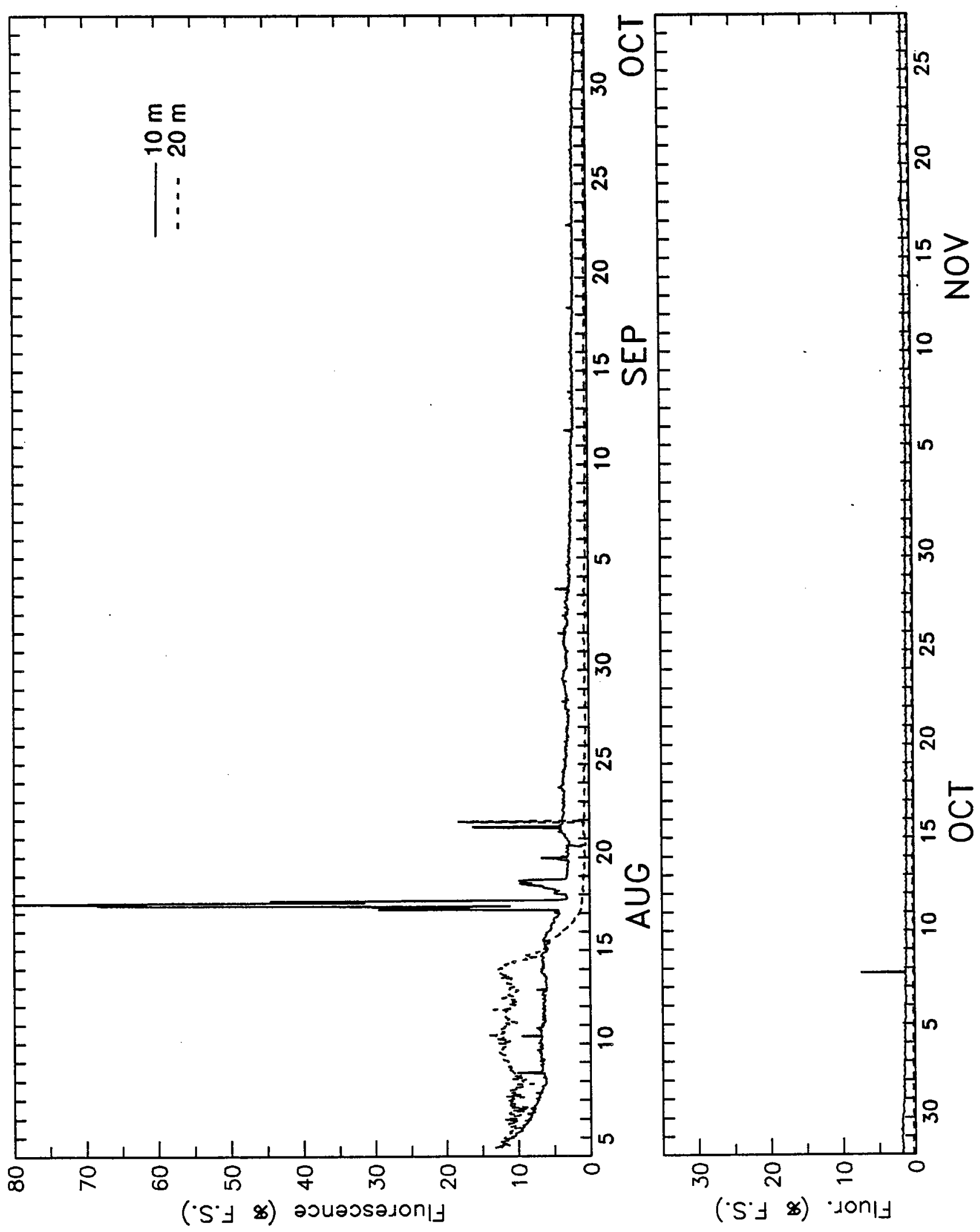


Figure $17 b$

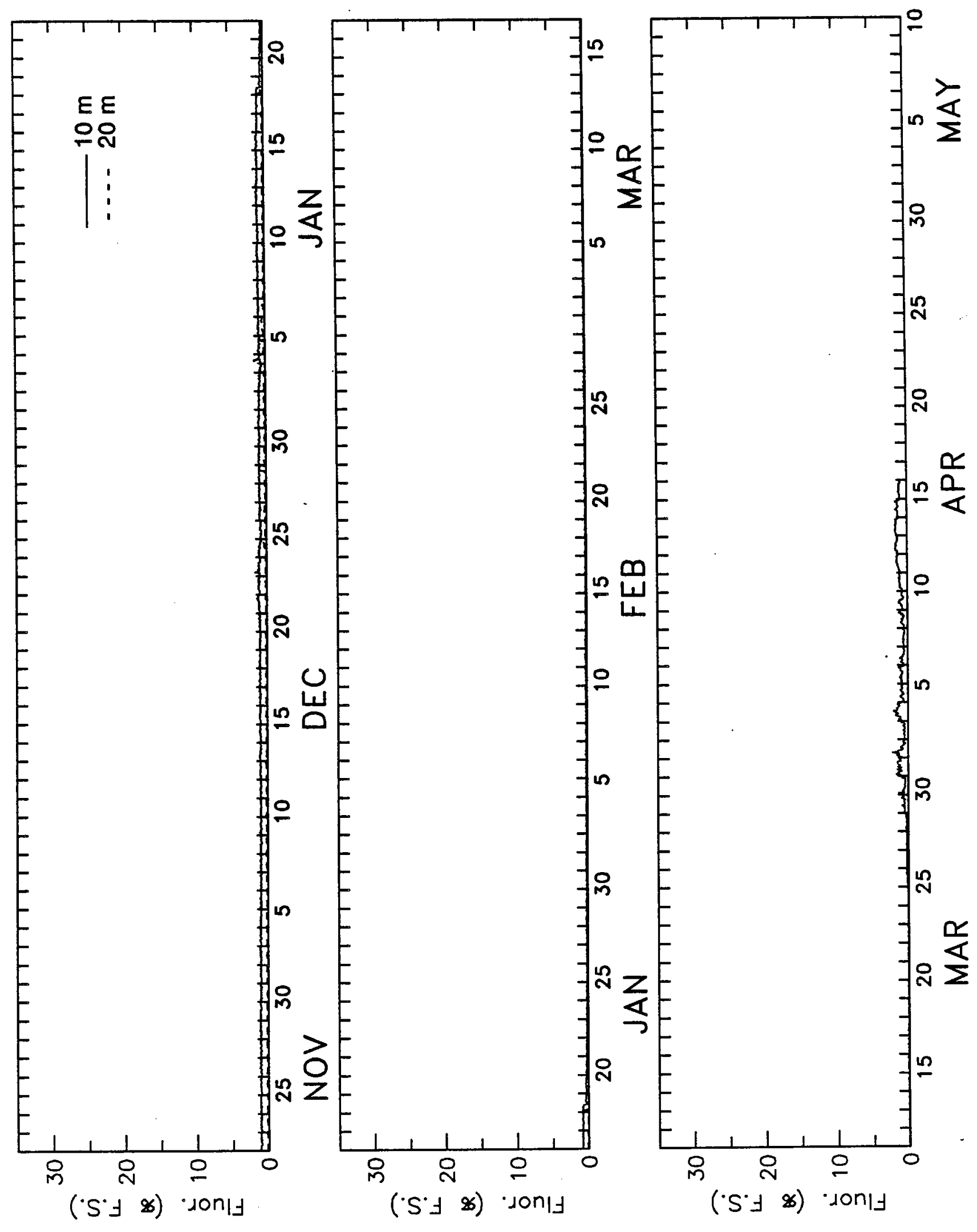


Fig. 18. ADCP heading, tilt, and temperature time series: a) section 1, b) section $2, c)$ section $3, d$ ) section 4 . Heading is the output from an EG\&G flux gate compass with a stated accuracy of $2^{\circ}$. Heading data were corrected for variation in magnetic declination over the drift track of the AEDB prior to transformation of velocity to geographic coordinates. The plotted heading is uncorrected. Tilt is from a pair of Humphrey pendulum tilt sensors with a stated accuracy of $1 \%$ and installed with a tolerance of $+/-1^{\circ}$ over a $10^{\circ}$ range. Temperature is measured by a thermistor mounted in the center of the four transducers. The thermistor has a stated accuracy of $0.1^{\circ} \mathrm{C}$ over a range from -5 to $45^{\circ} \mathrm{C}$.

The raw $A D C P$ records represent an average of 40 samples separated by one second in time. A record is recorded every half hour. Bad points in the raw records were identified by computing the statistics of the first difference of the data with time. Records were de-spiked by eliminating points where the first difference was greater than three times the standard deviation of the first difference. Values were averaged over one hour prior to plotting. 
Figure $18 a$

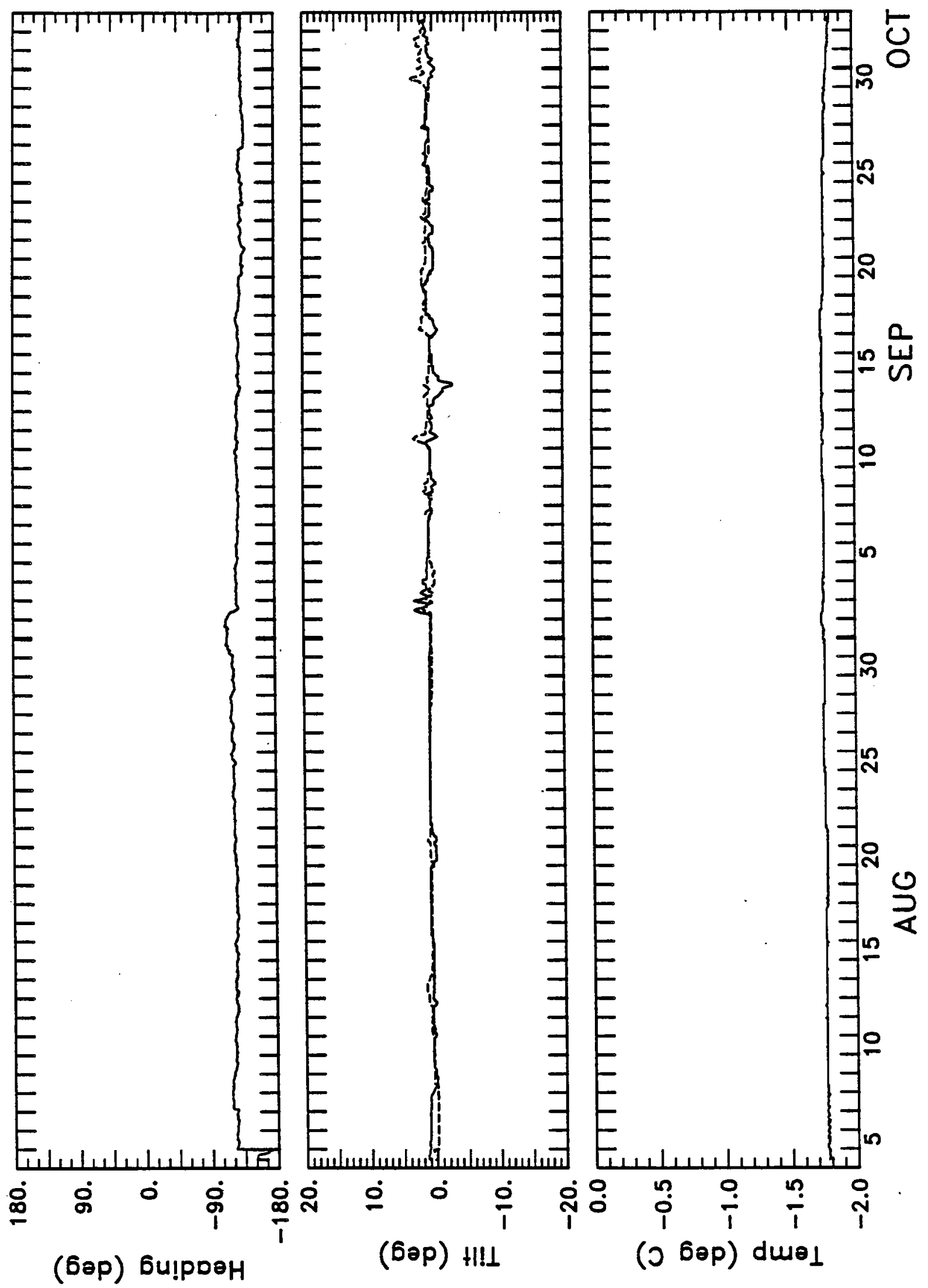


Figure $18 b$

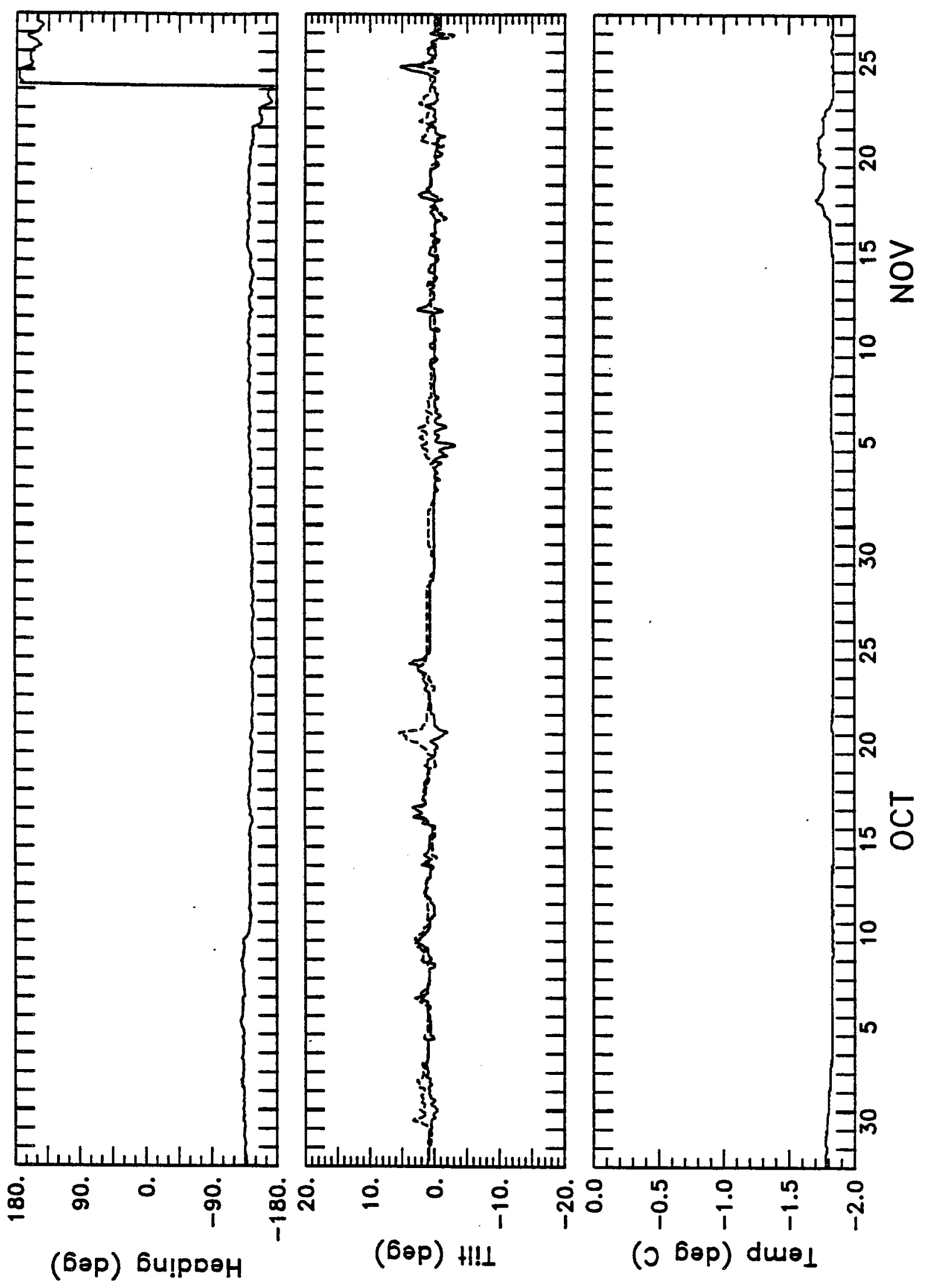


Figure 18c
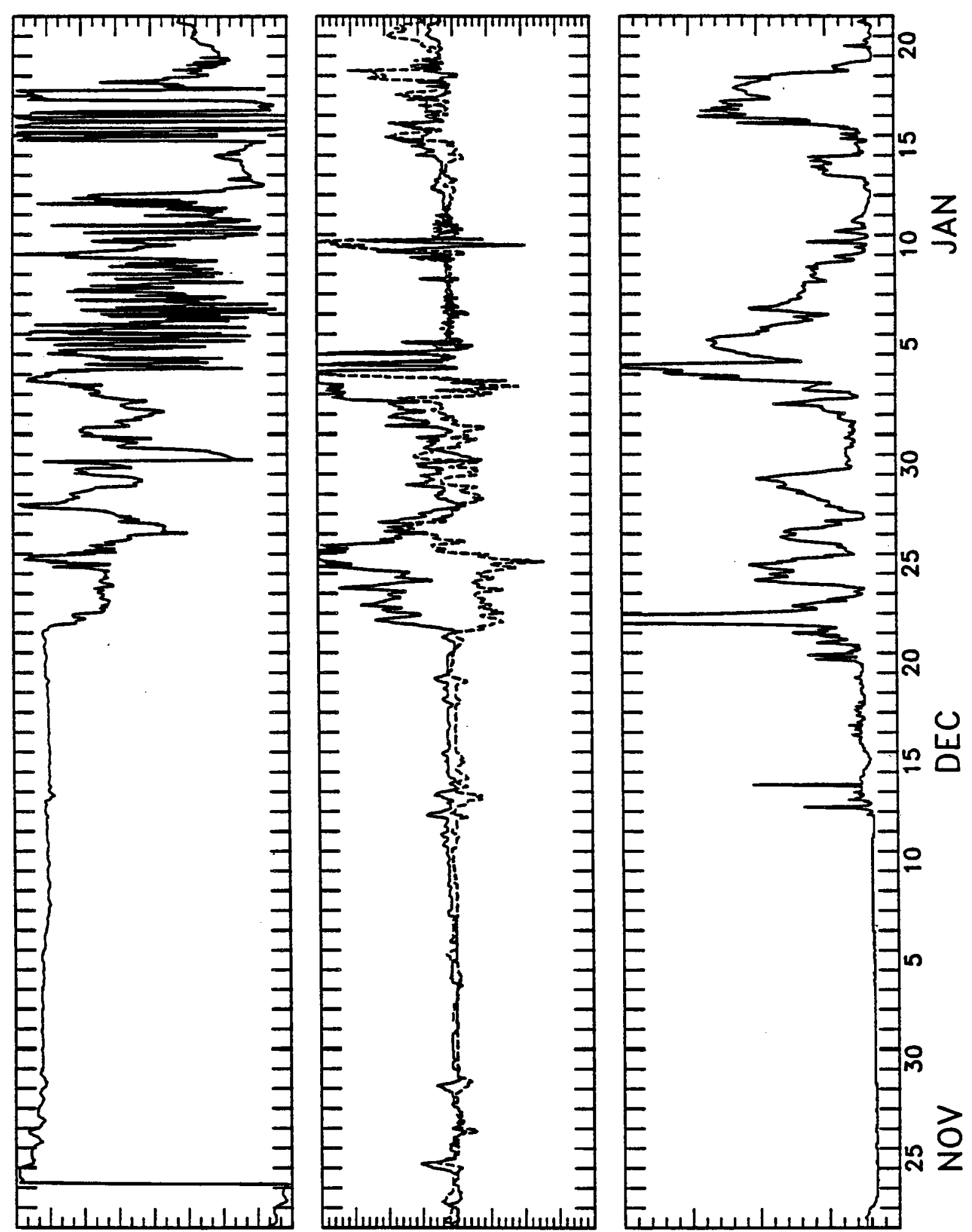

ஓ $\dot{0} 0 \dot{\circ}$

(Gәp) Gu!pDәH

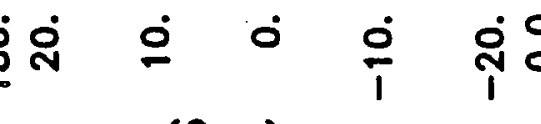
(Gop) HIII
(o Gep) dwa 1 
Figure 18d

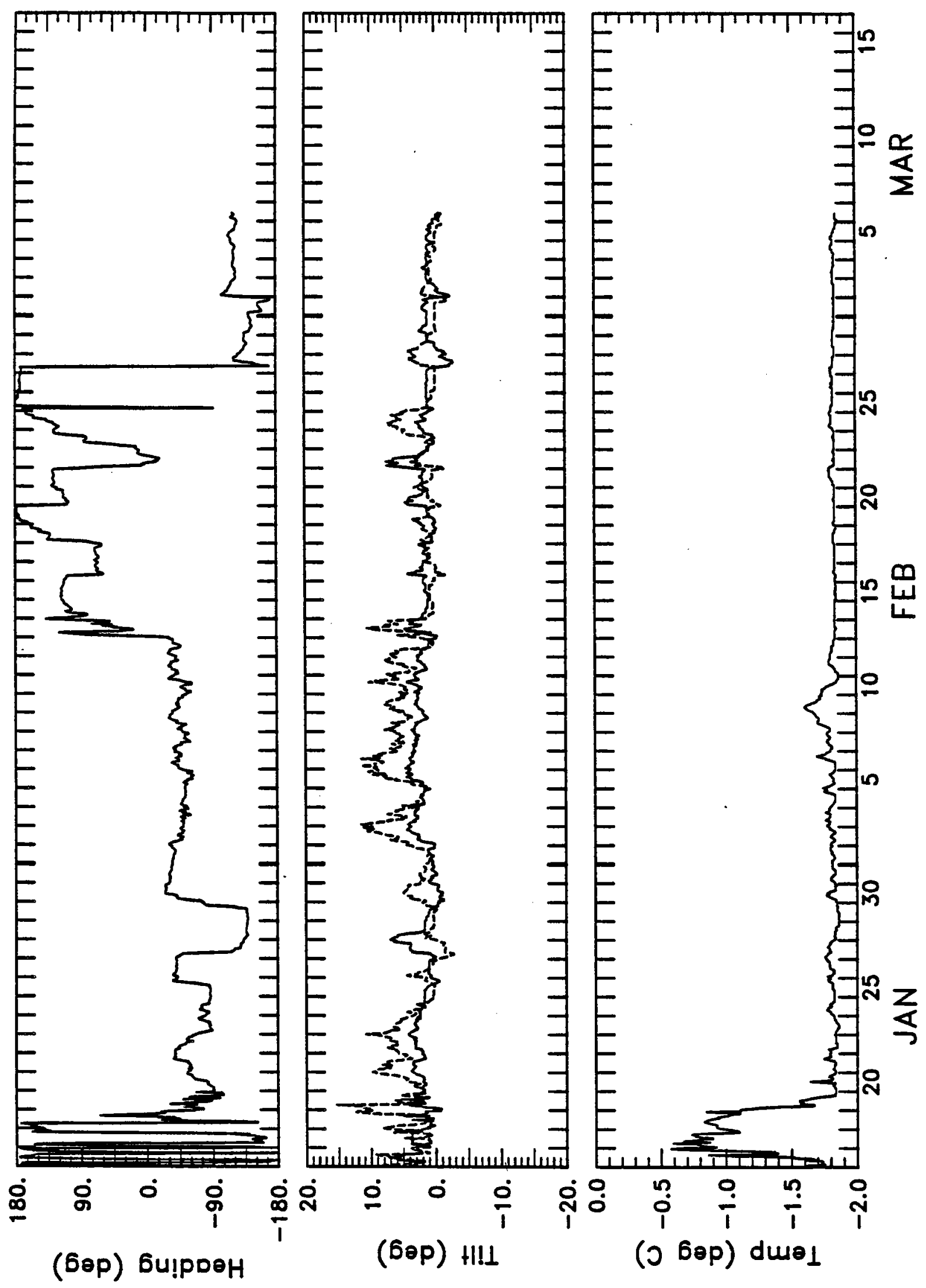


Fig. 19. ADCP battery voltage and transmit current time series: a) section $1, b)$ section 2, c) section 3, d) section 4 . The high voltage input value represents the voltage from the $\mathrm{V} 2$ battery pack available for acoustic pulse transmission and for powering the $60 \mathrm{Mb}$ tape recorder. This voltage is expected to be between 14 and 40 volts. The low voltage input value represents the voltage from the $\mathrm{V} 1$ battery pack available for powering ADCP logic, memory, and control circuits. This value is expected to be between 5.5 and 12 volts. The transmit current is a relative measure of the current available at the output of the power amplifier board and is representative of the current used to drive each of the four transducers. This value is adjusted so that a current of 1.7 to 1.8 amps is observed with $V 2$ at 40 volts.

The raw ADCP records represent an average of 40 samples separated by one second in time. A record is recorded every half hour. Bad points in the raw records were identified by computing the statistics of the first difference of the data with time. Records were de-spiked by eliminating points where the first difference was greater than three times the standard deviation of the first difference. Values were averaged over one hour prior to plotting. 
Figure 19a

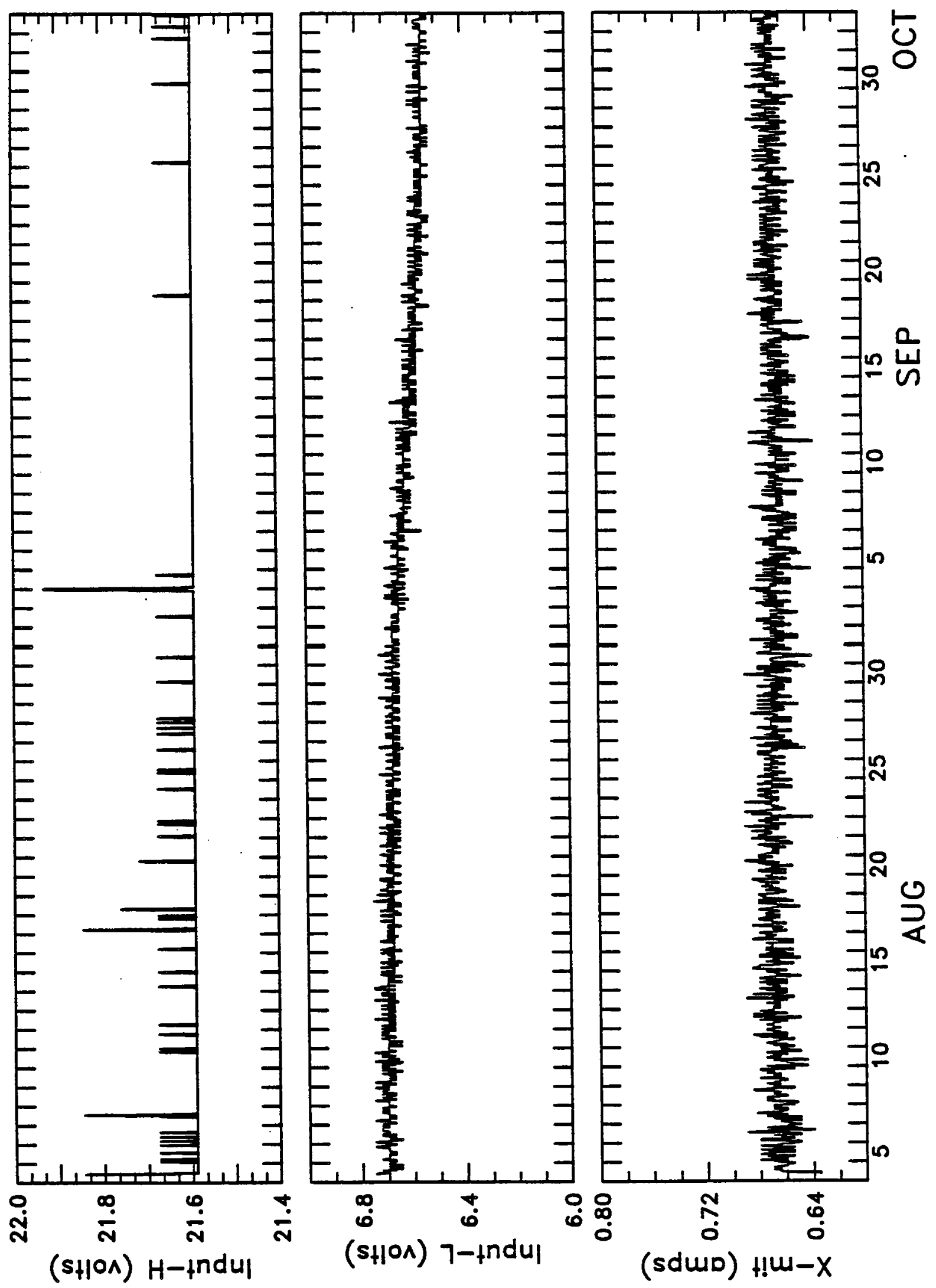


Figure $19 b$

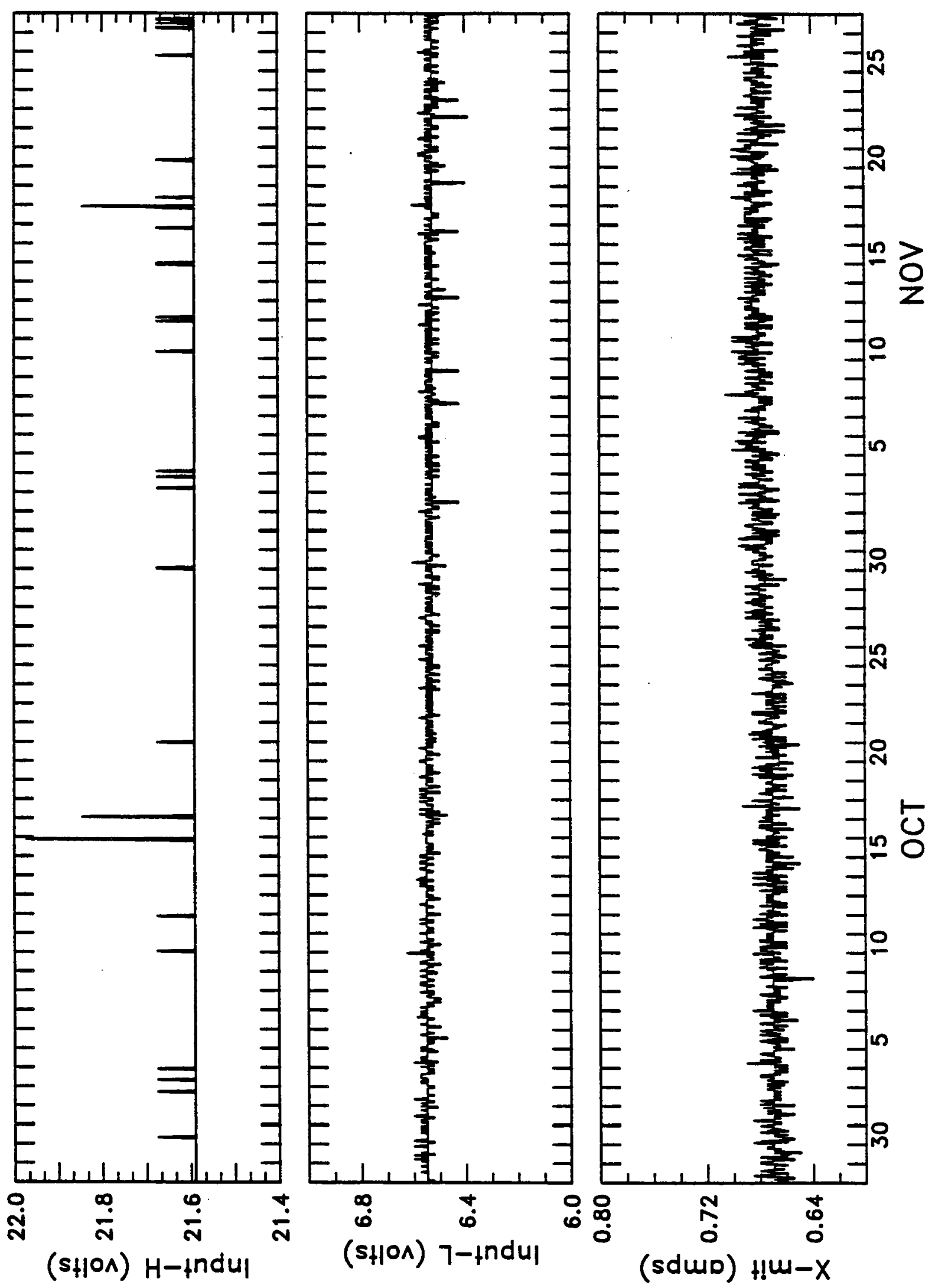


Figure 19c

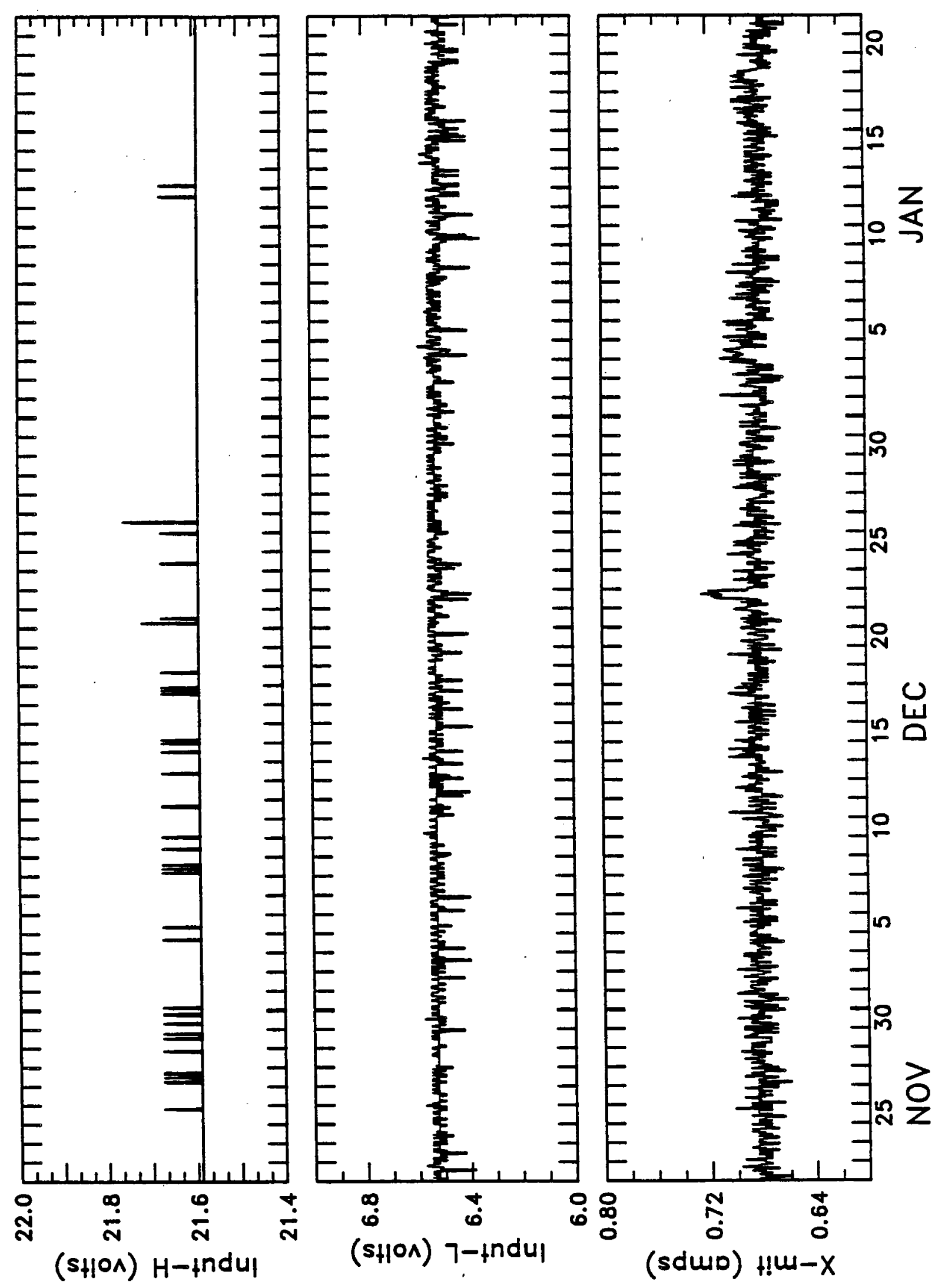


Figure 19d

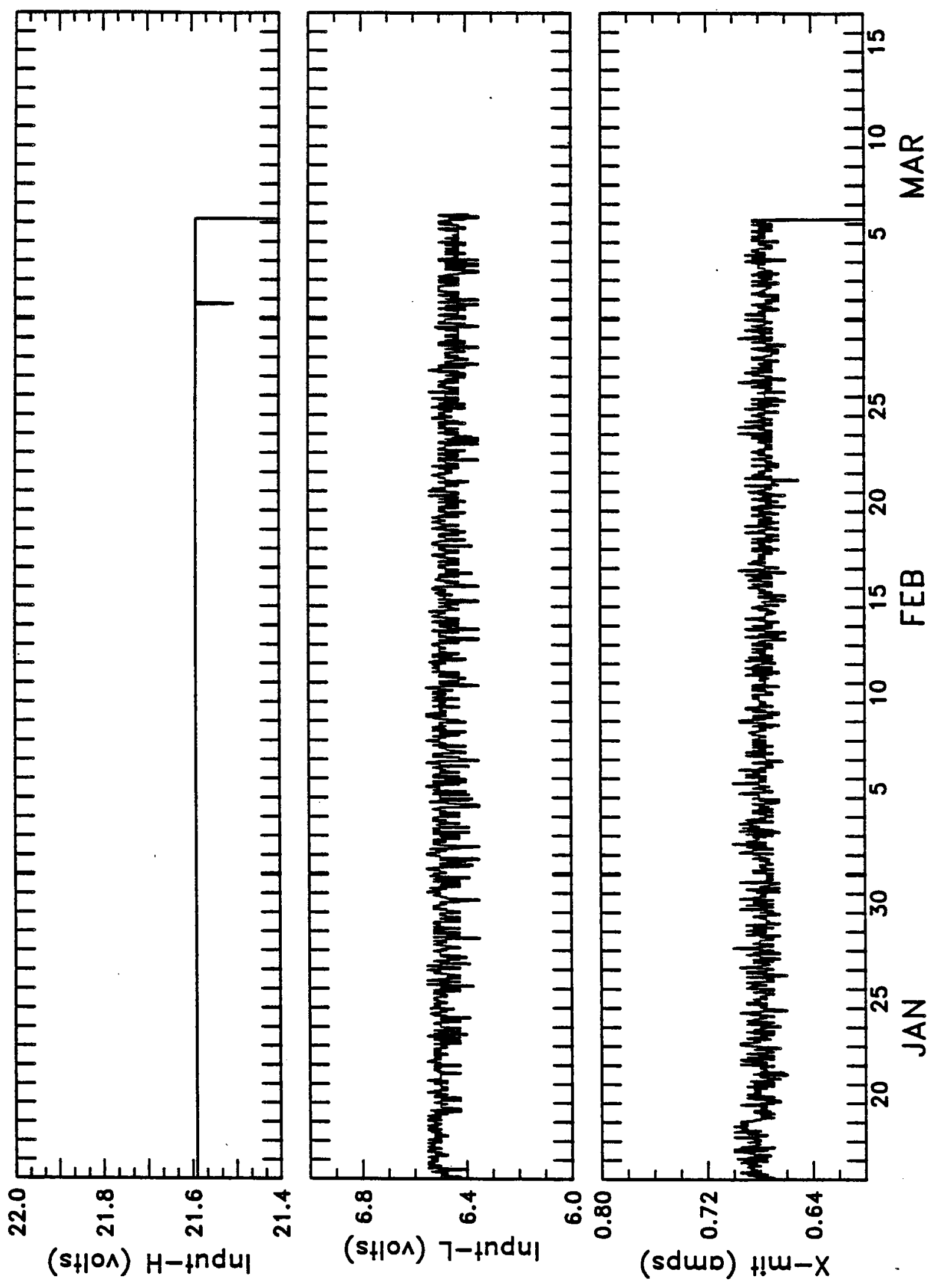


Fig. 20. ADCP echo amplitude data for beam 1: a) section 1, b) section 2, c) section $3, d$ ) section 4 . A record containing a relative measure of echo amplitude for the 20 range bins of each of the four ADCP beams is recorded every half hour. For the downward facing ADCP deployed on the AEDB the data from the 20 range bins of each beam form a vertical profile of echo amplitude. The raw $A D C P$ records represent an average of 40 profiles separated by one second in time. The echo amplitude is monotonically decreasing with increasing range from the transducers. Hence, the uppermost line on the plots represents the most shallow range bin at $32 \mathrm{~m}$ depth and lines with successively smaller echo amplitude represent increasing depth in $16 \mathrm{~m}$ intervals to a maximum depth of $336 \mathrm{~m}$. The large spacing between the upper lines represents an initial rapid decrease of echo amplitude with range due to attenuation and spreading of the acoustic pulse. The closely spaced lower lines indicate little change in amplitude at the furthest ranges where the echo amplitude has decayed almost completely and the amplitude approaches a limiting value representing the instrument noise floor.

Bad points in the raw records were identified by computing the statistics of the first difference of the data with time and with depth. Records were de-spiked by eliminating points where the first difference in time or depth was greater than three times the standard deviation of the first difference. Echo amplitude time series at each depth were averaged over 24 hours and decimated by 6 hours prior to plotting. 
Figure 20a

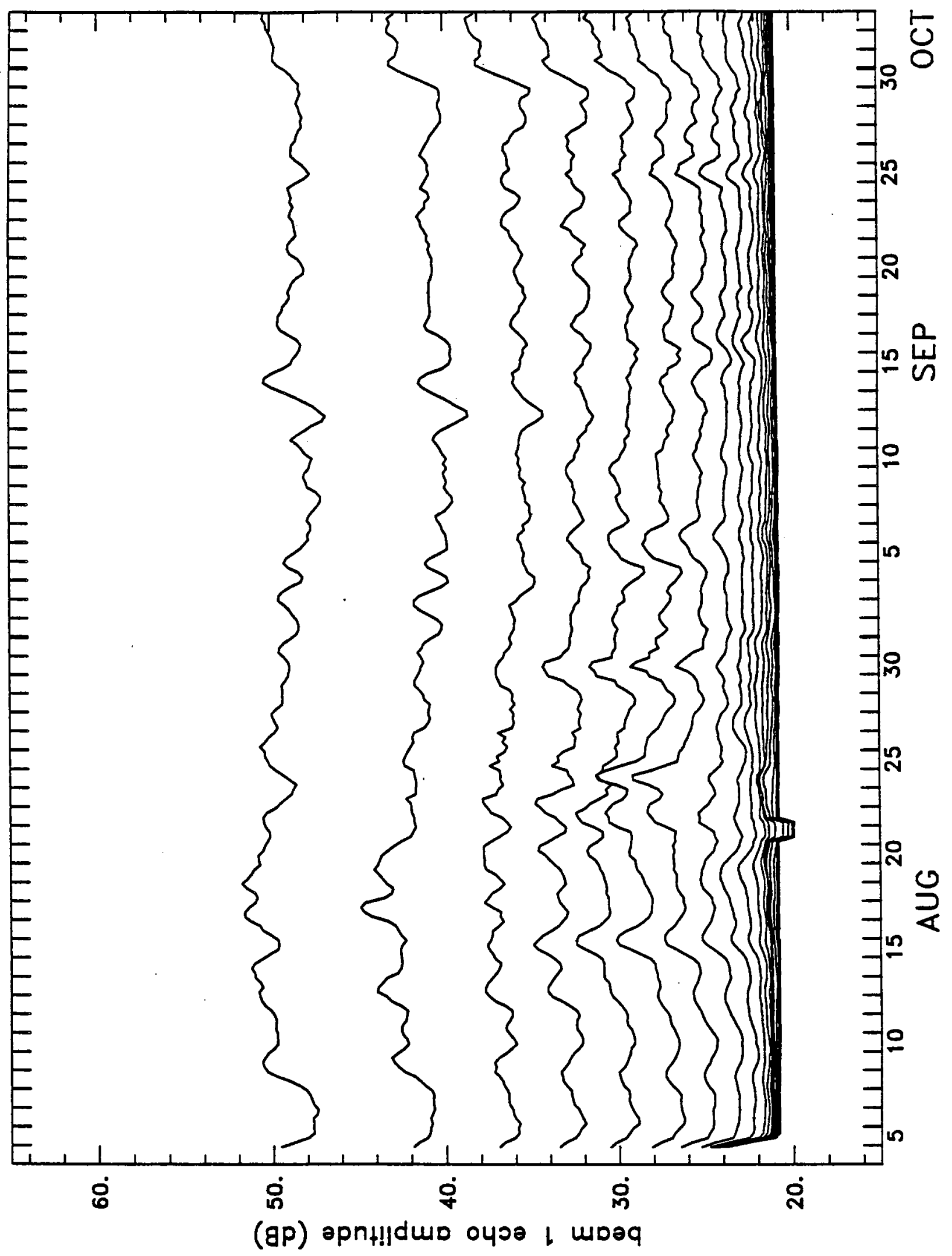


Figure 20b

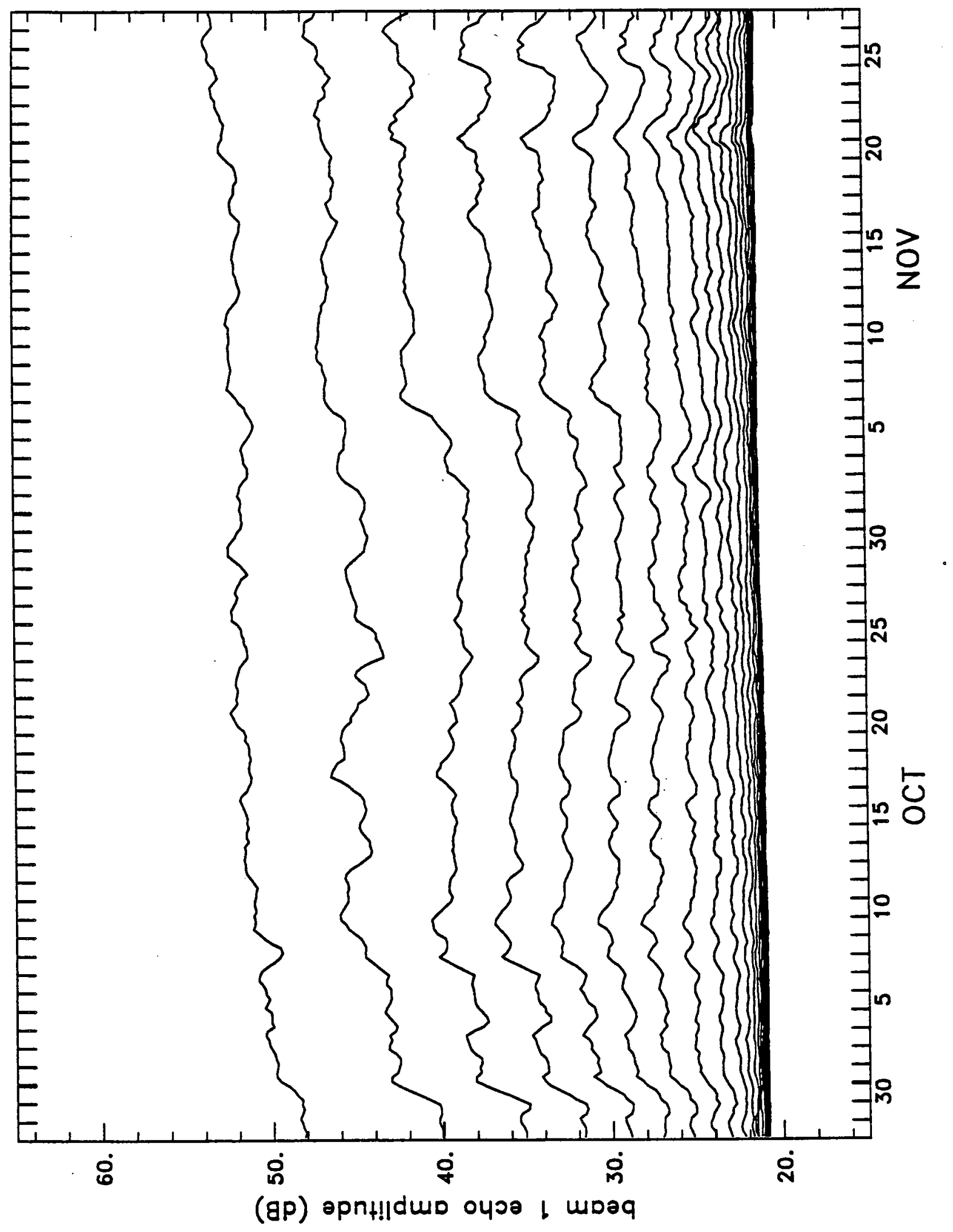


Figure 20c

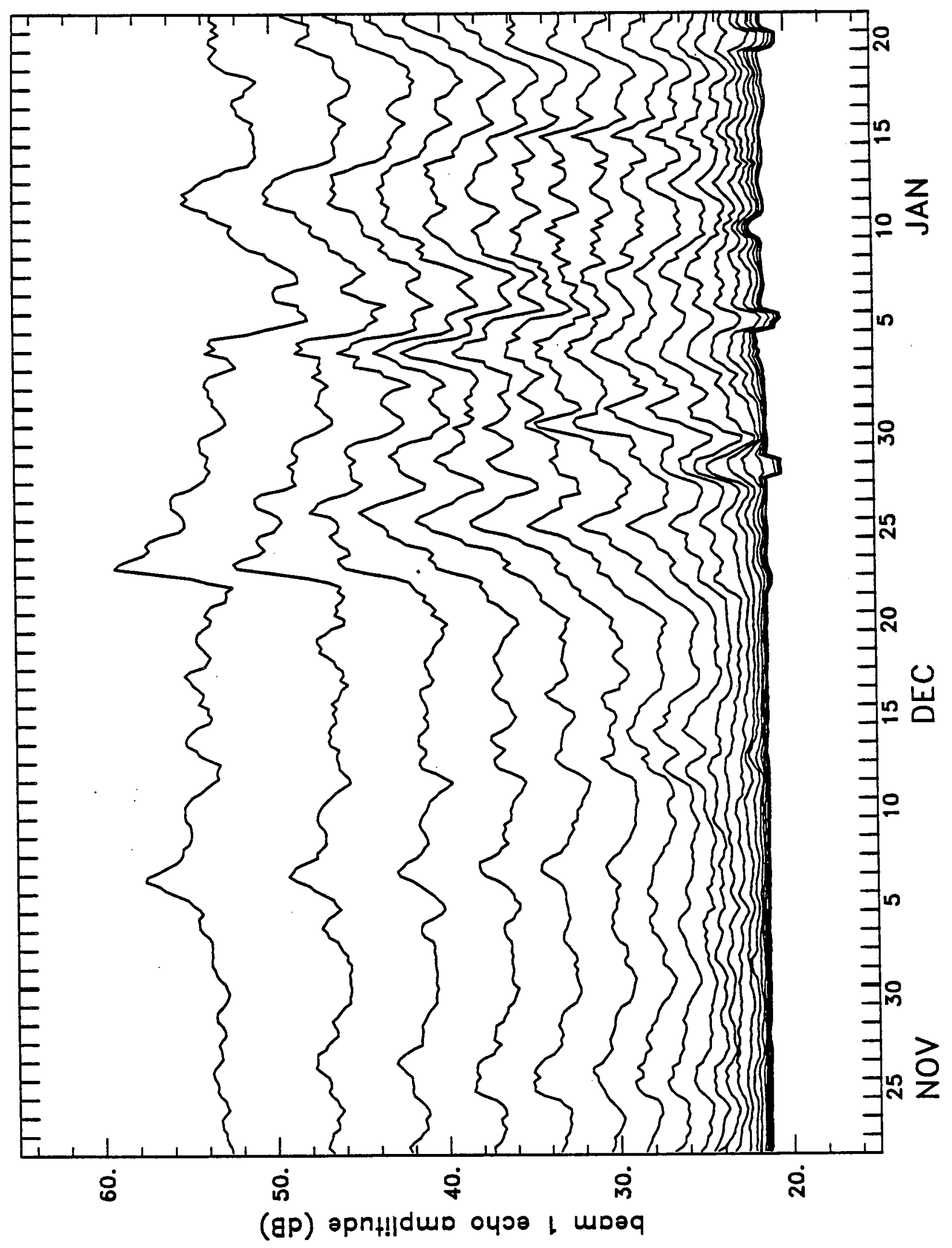


Figure 20d

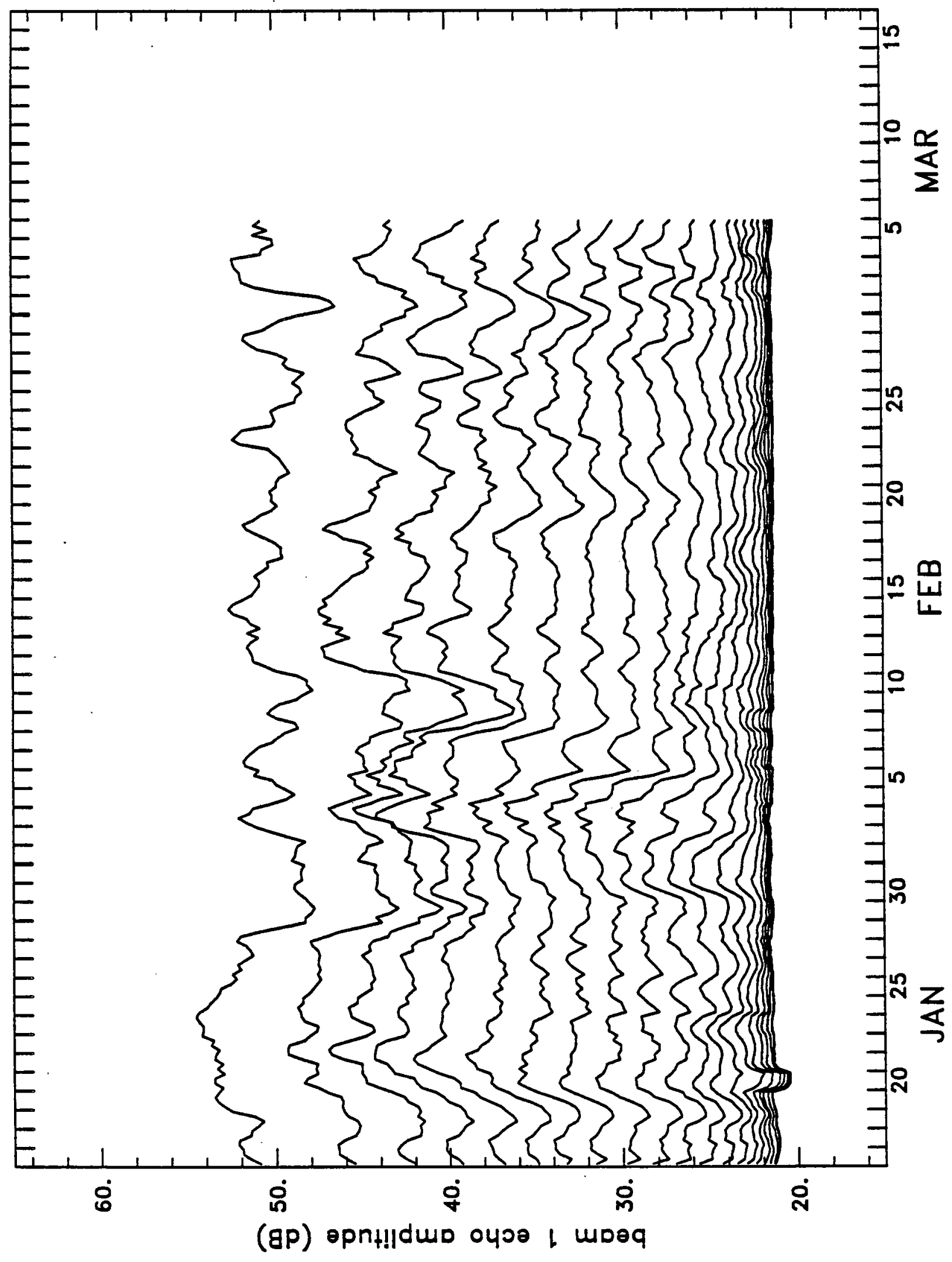


Fig. 21. ADCP echo amplitude data for beam 2: a) section 1, b) section 2, c) section 3, d) section 4. Description same as for Fig. 20. 
Figure 21a

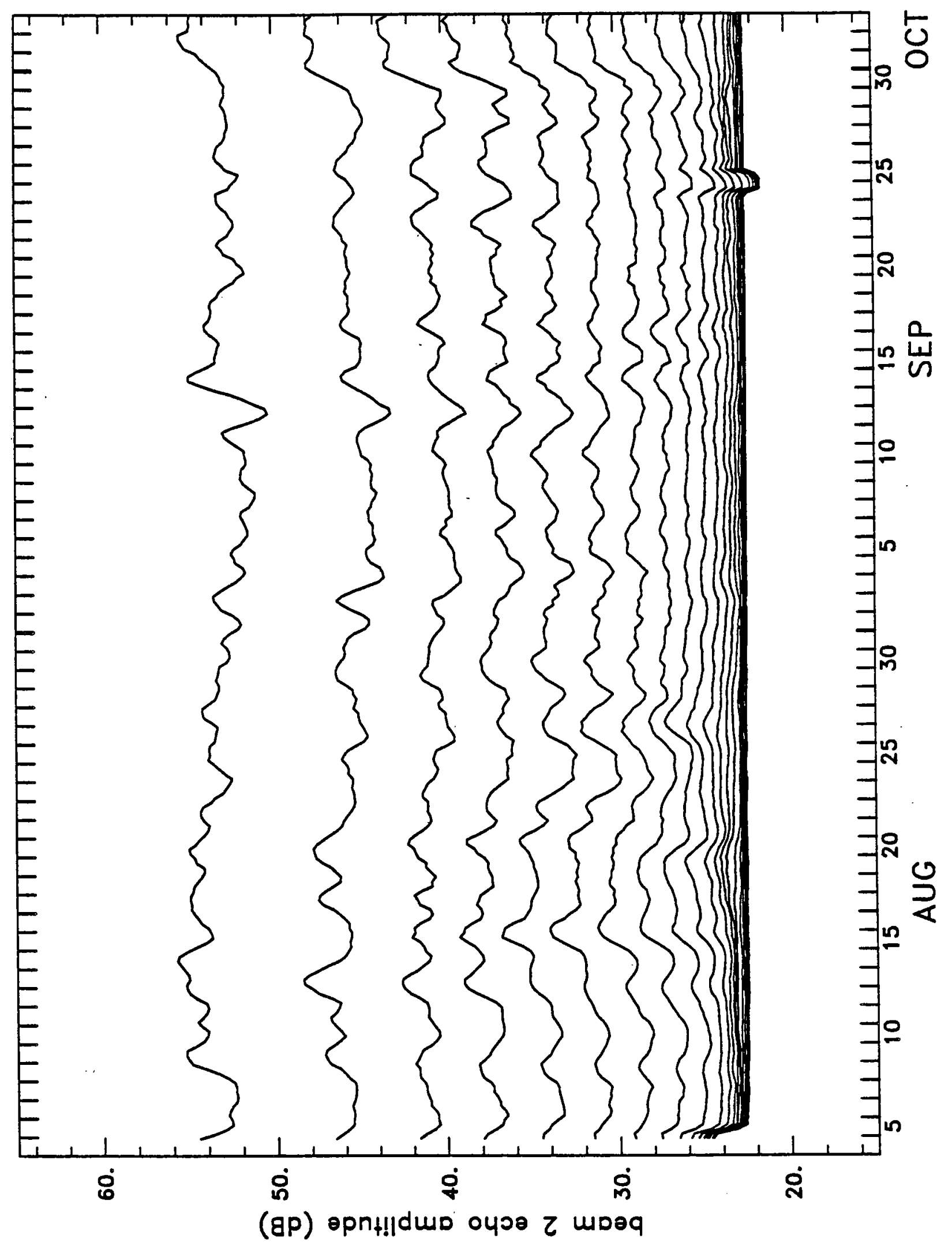


Figure 21b

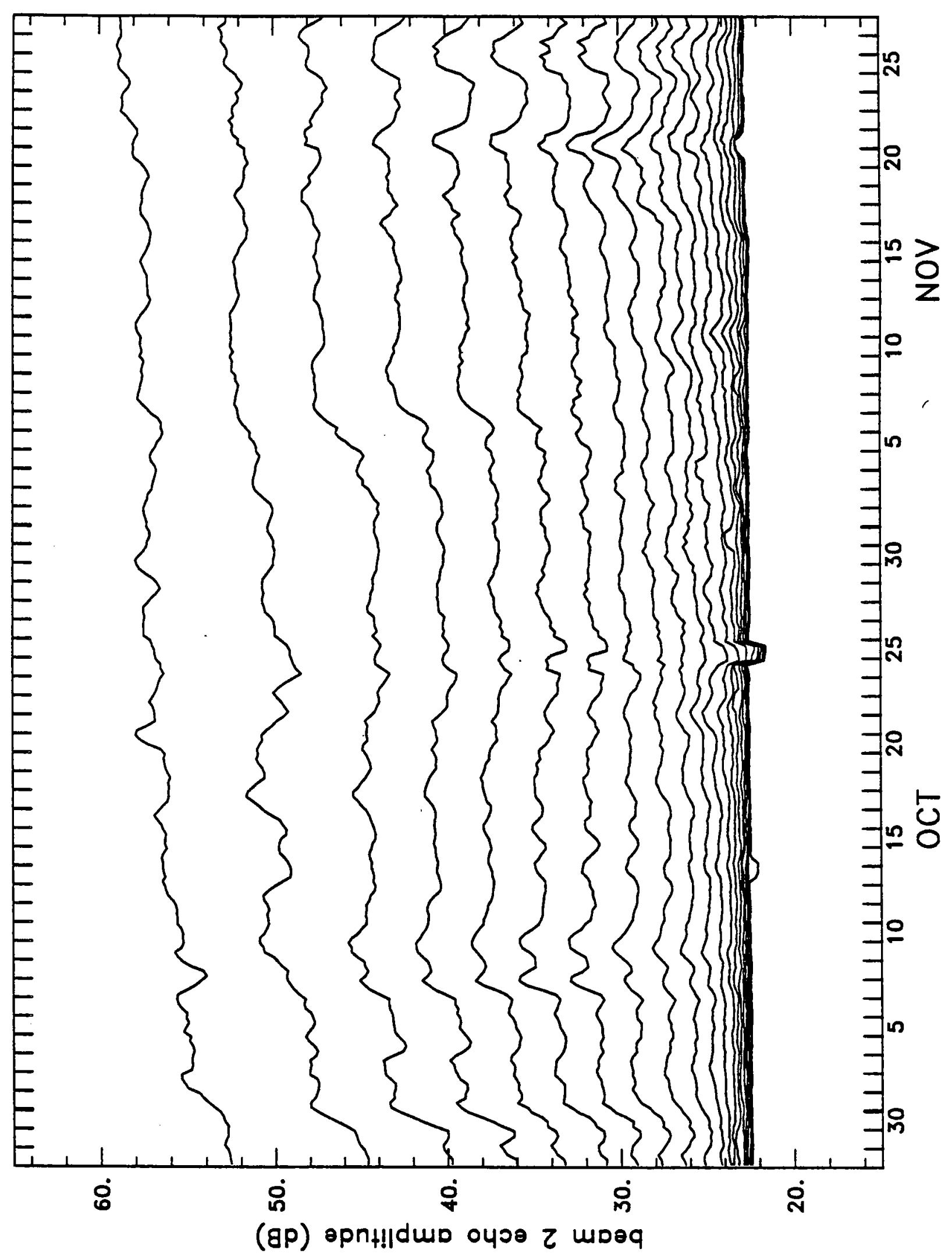

84 
Figure 21c

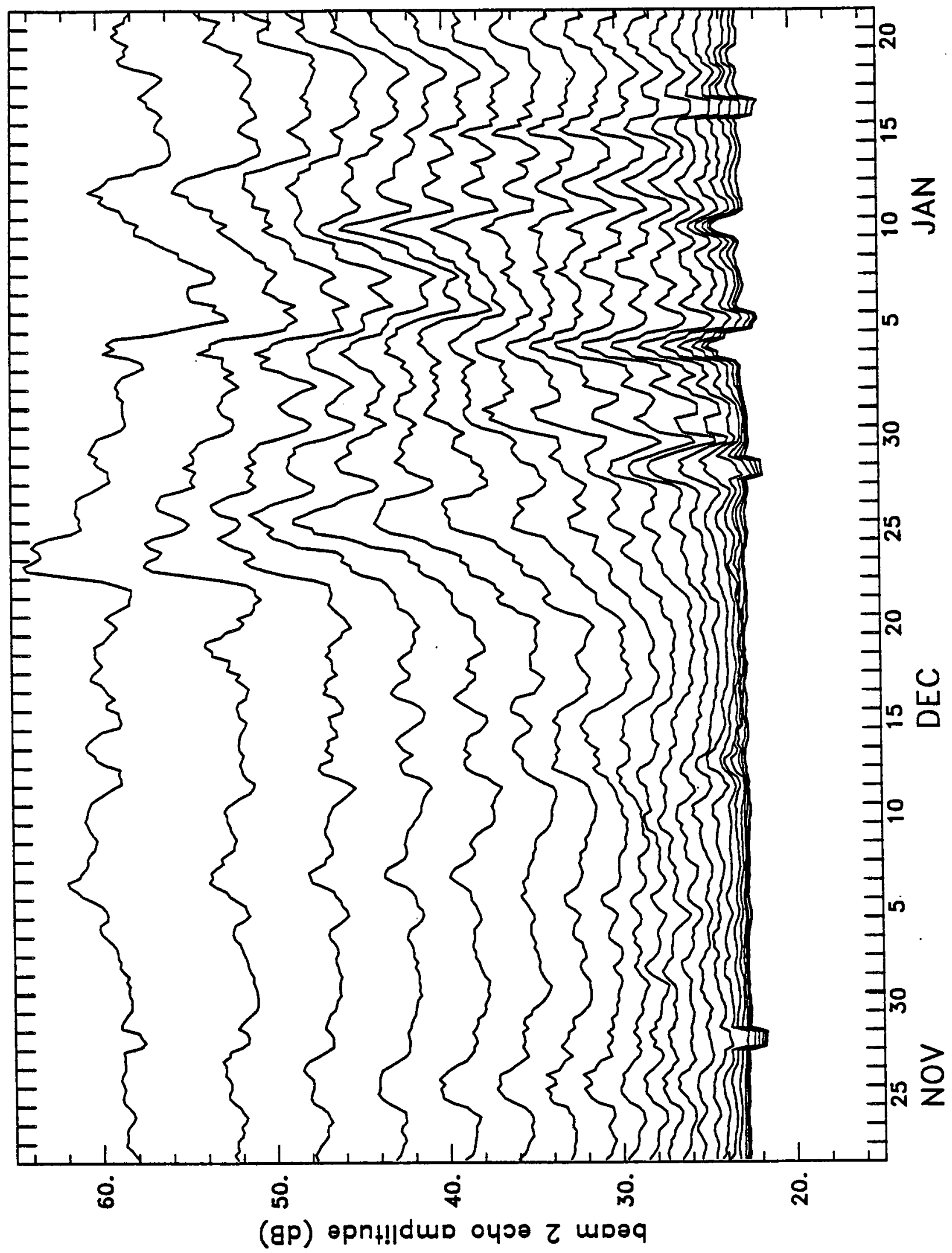

85 
Figure 21d

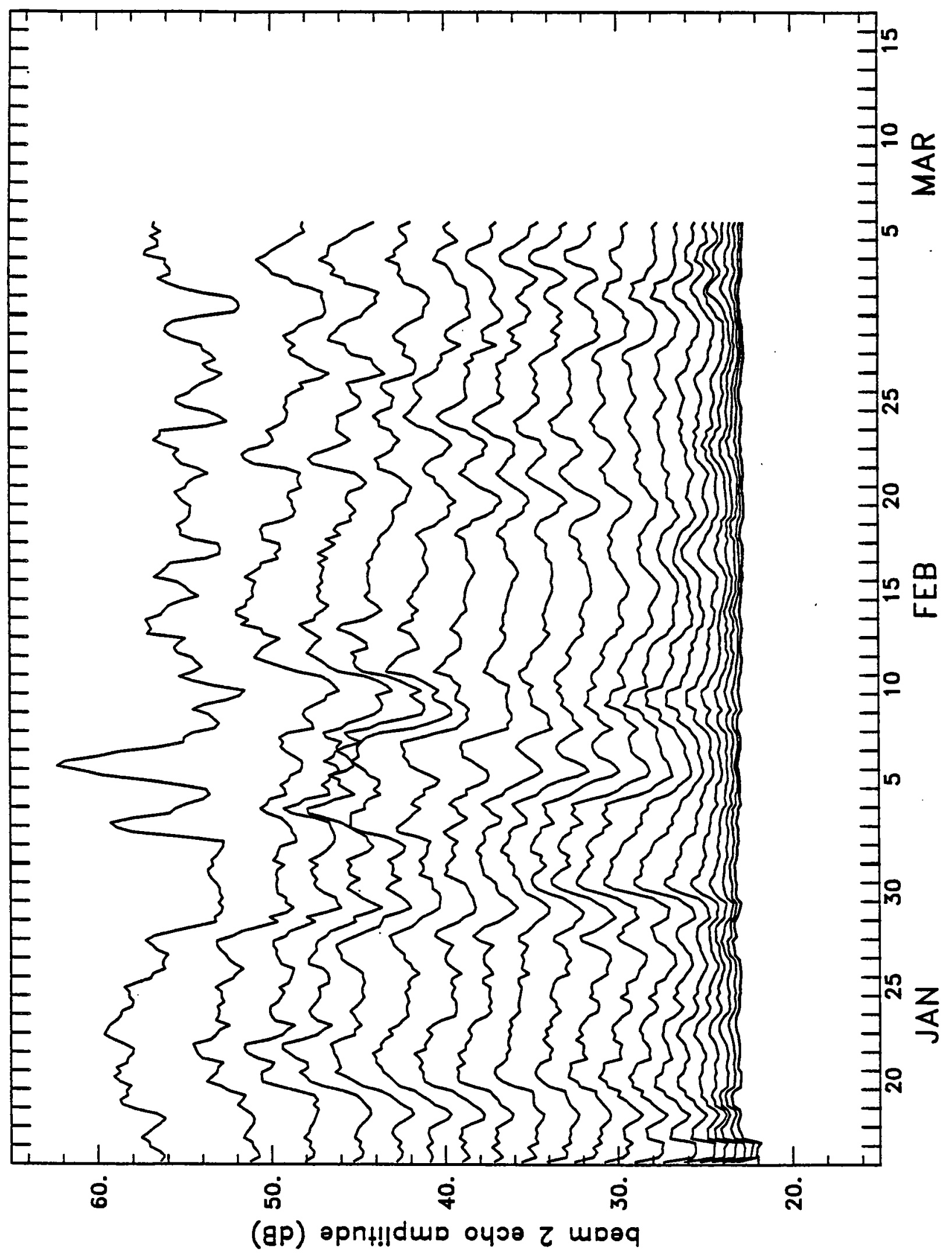


Fig. 22. ADCP echo amplitude data for beam 3: a) section 1, b) section 2, c) section 3, d) section 4. Description same as for Fig. 20. 
Figure 22a

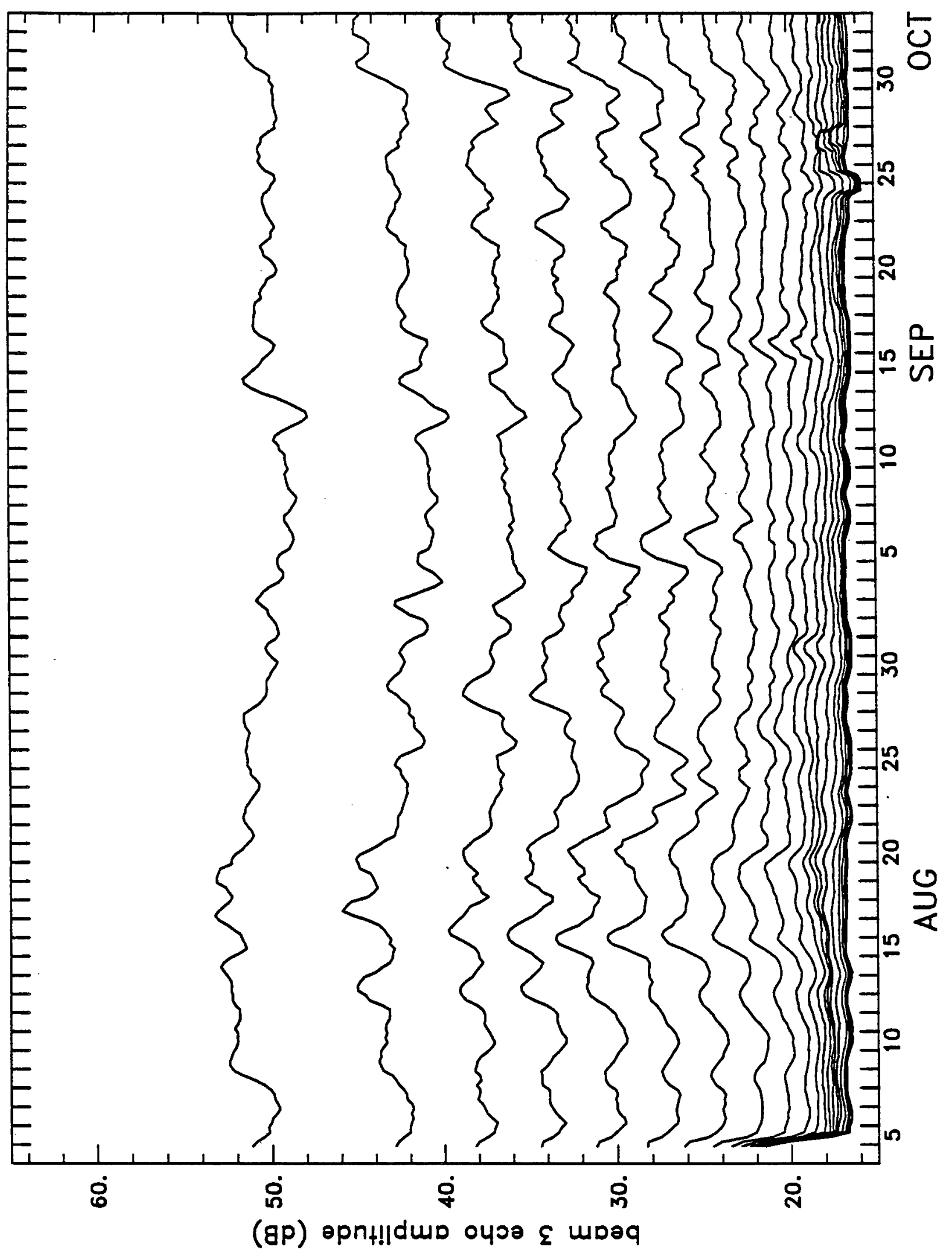


Figure 22b

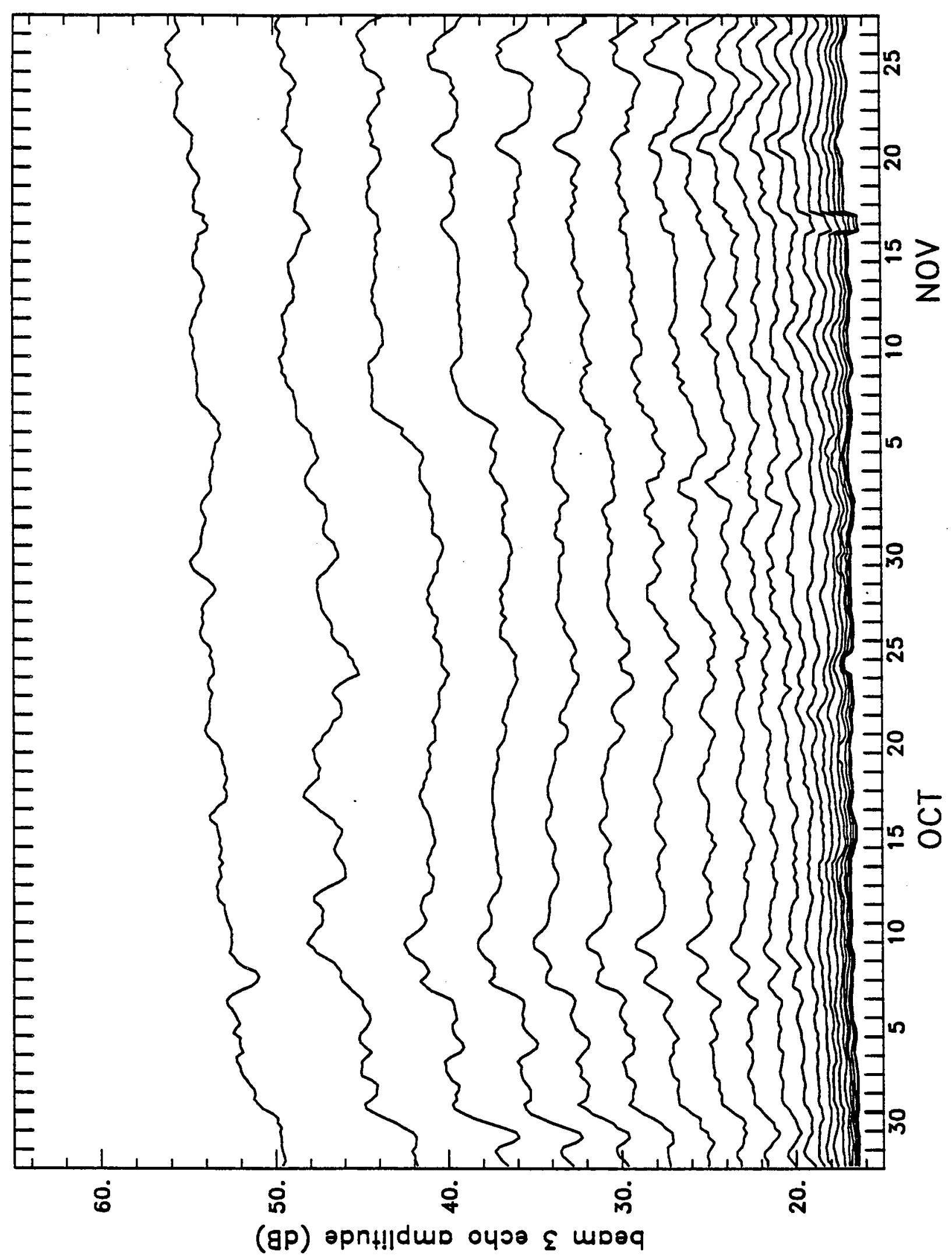


Figure 22c

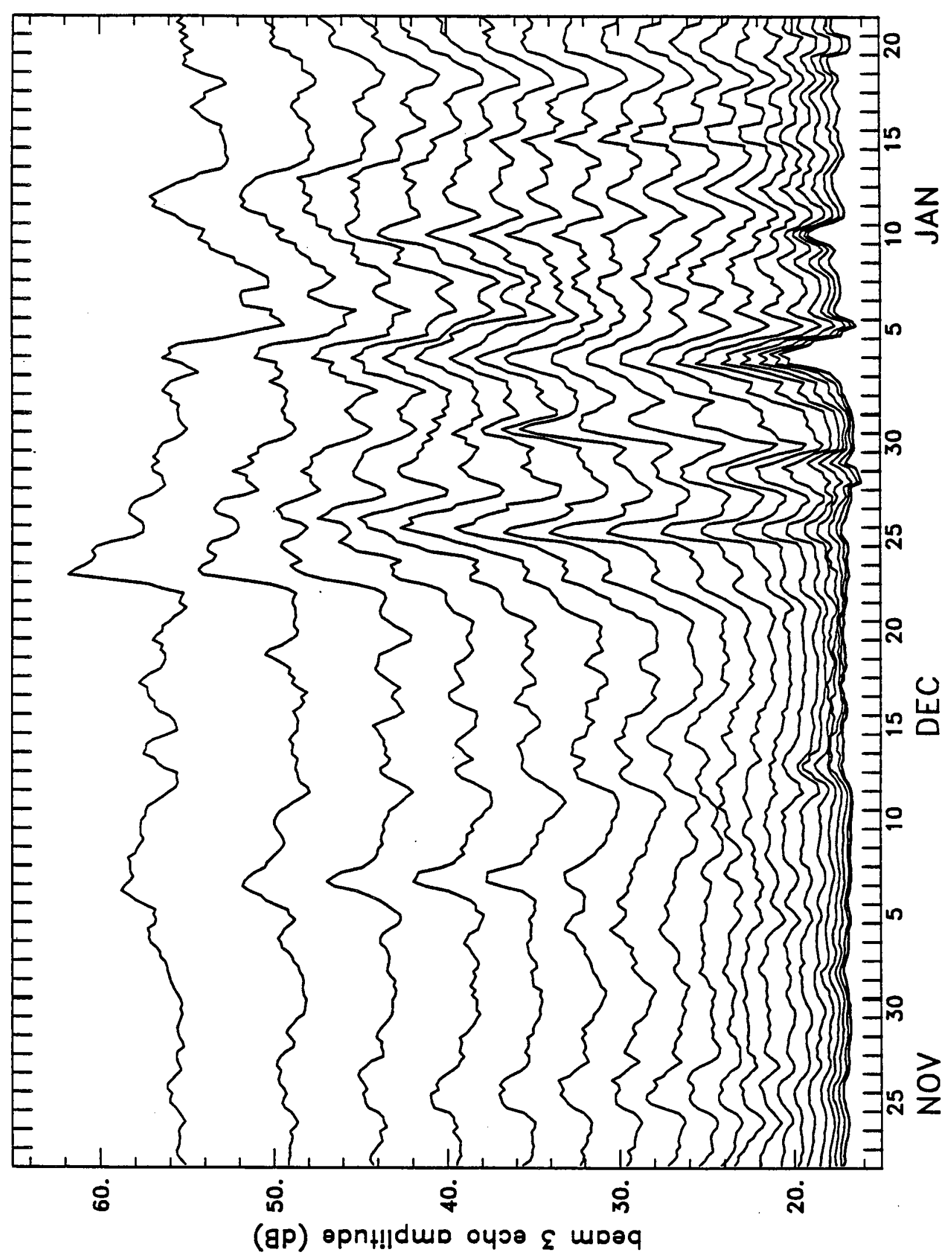

90 
Figure 22d

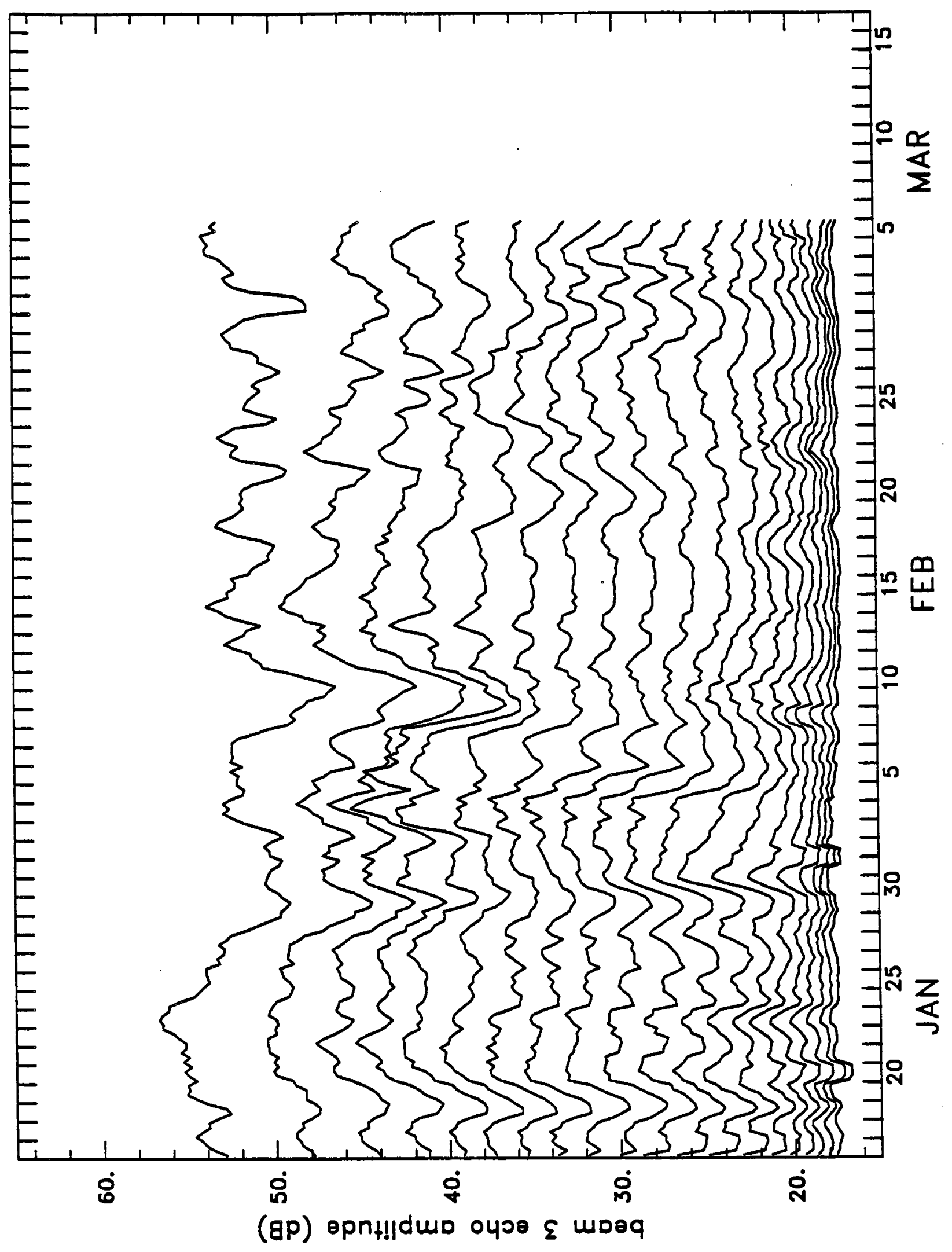


Fig. 23. ADCP echo amplitude data for beam 4: a) section 1, b) section 2, c) section 3, d) section 4. Description same as for Fig. 20. 
Figure 23a

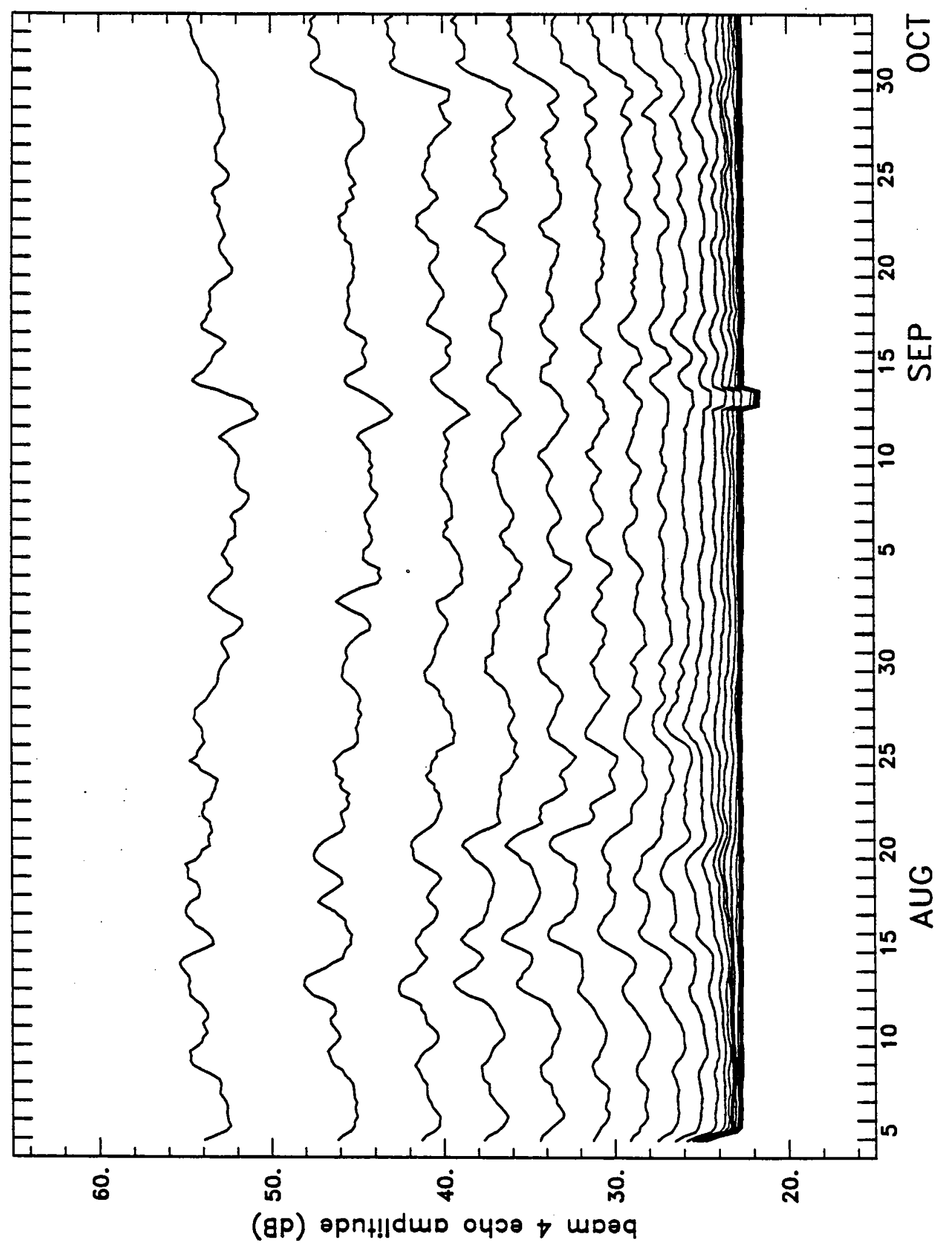


Figure 23b

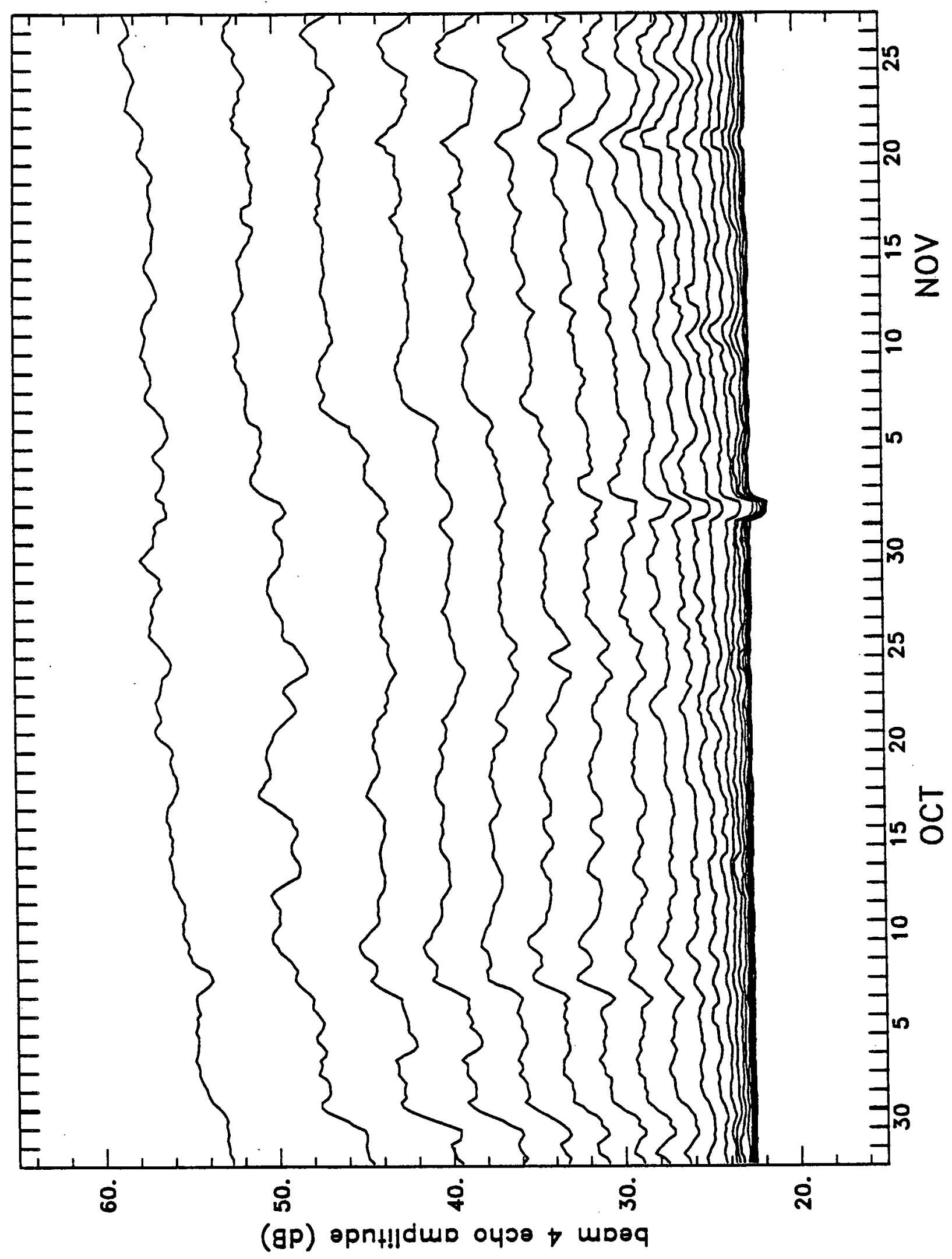


Figure 23c

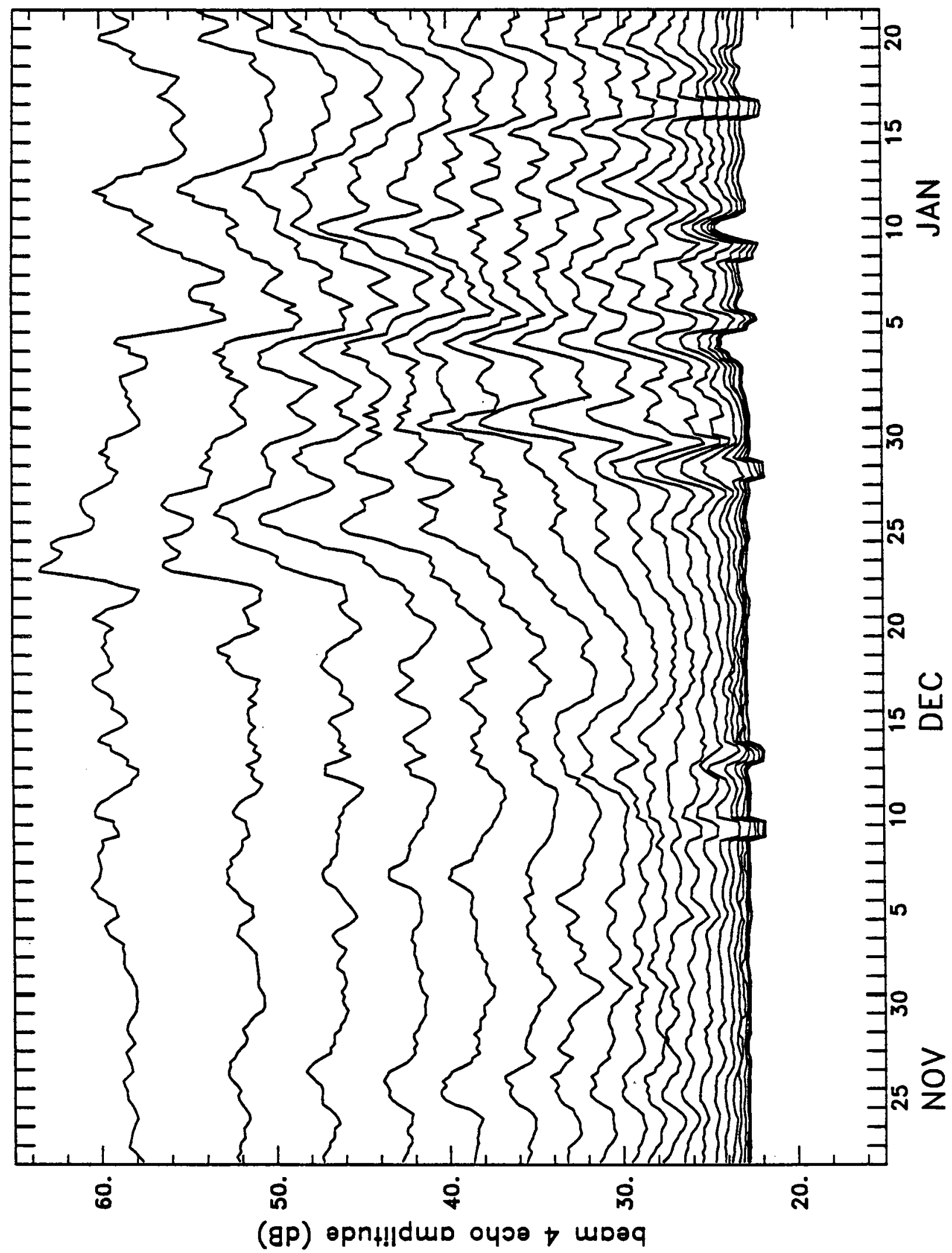

95 
Figure 23d

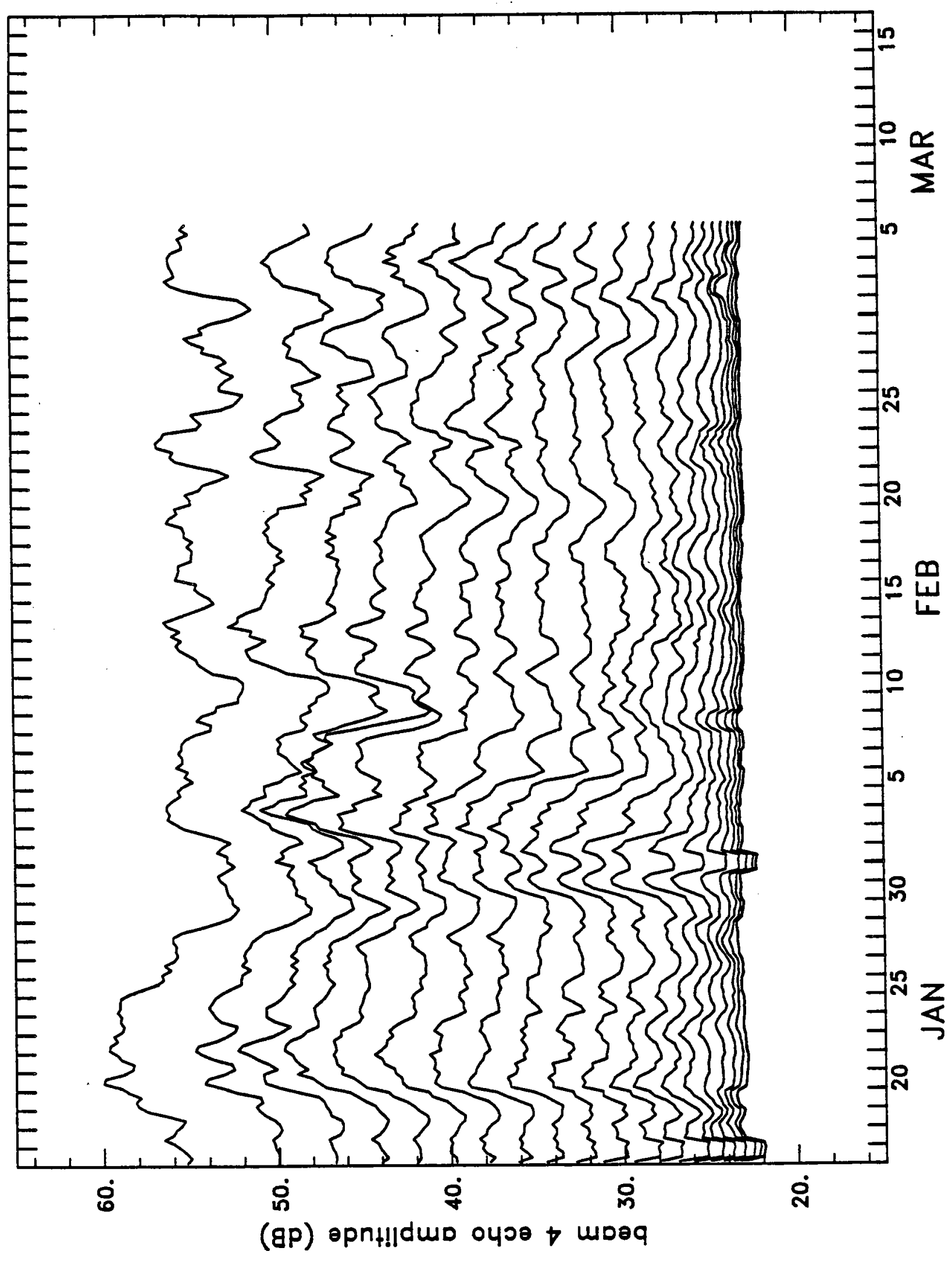


Fig. 24. ADCP absolute velocity time series for the east direction: a) section 1, b) section $2, c$ ) section 3, d) section 4 . The vertical scale is correct for the uppermost time series which is centered at a depth of $40 \mathrm{~m}$. Each successive time series is offset by $-30.0 \mathrm{~cm} / \mathrm{s}$ on the vertical scale and, since these data are averaged over 2 depth bins, each successive line is $32 \mathrm{~m}$ deeper. Velocity time series at each depth were averaged over 4 hours and decimated by 2 hours prior to plotting.

A record containing radial velocities for the 20 range bins of each of the four ADCP beams is recorded every half hour. For the downward facing ADCP deployed on the AEDB the data from the 20 range bins of each beam form a vertical profile of velocity. The raw ADCP records represent an average of 40 profiles separated by one second in time. Bad points in the raw records were identified by computing the statistics of the first difference of the data with time and with depth. Records were de-spiked by eliminating points where the first difference in time or depth was greater than three times the standard deviation of the first difference.

The four radial beam velocities are combined to form estimates of horizontal and vertical velocities in the instrument coordinate system. These velocities are then transformed to geographic coordinates using output from the tilt and heading sensors in the instrument. At this stage, the horizontal velocities represent the relative velocity between the water and the drifting AEDB. The absolute velocity is estimated by adding the AEDB drift velocity to the observed $A D C P$ velocity at each time step. 
Figure 24a

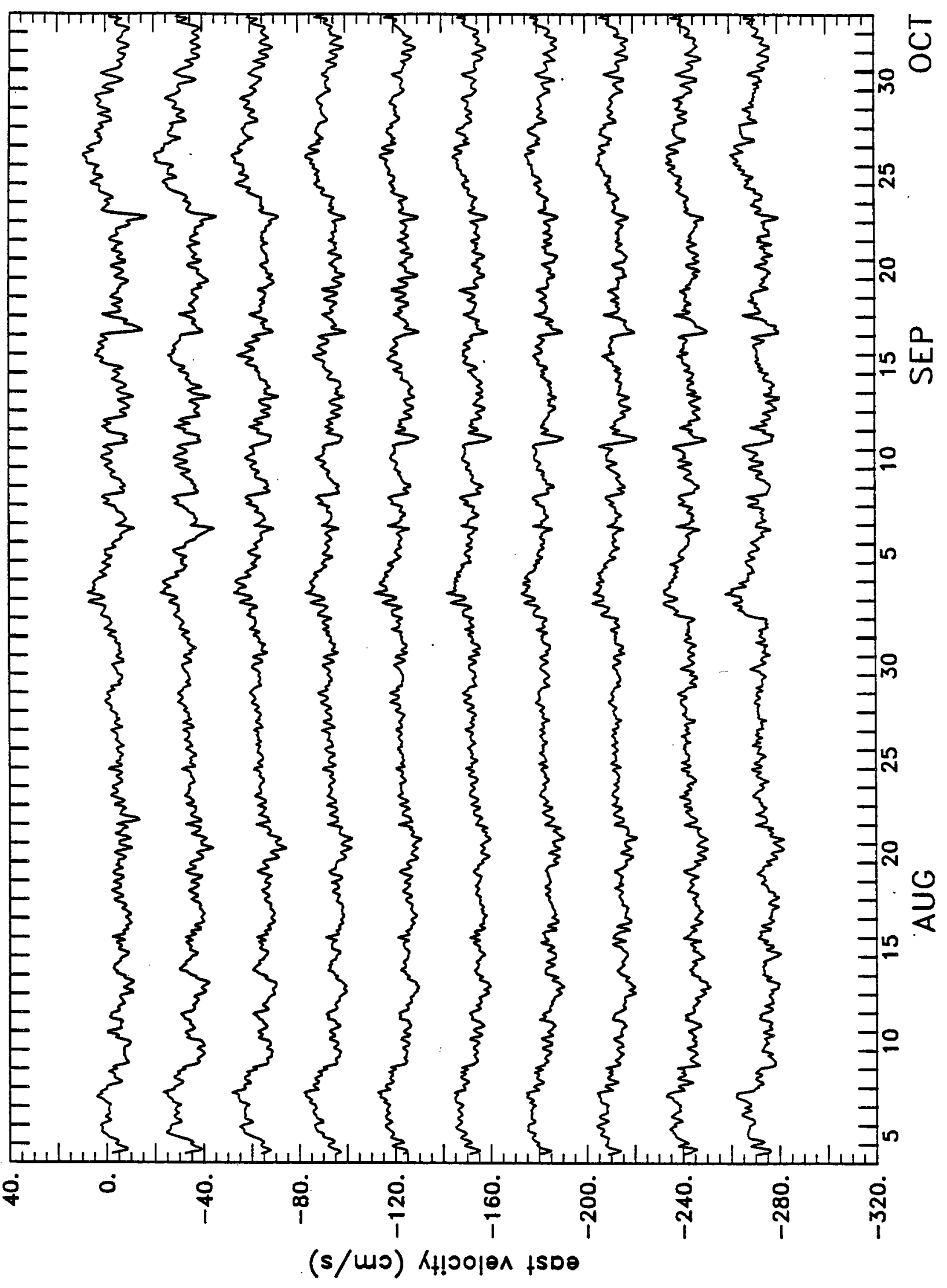


Figure 24b

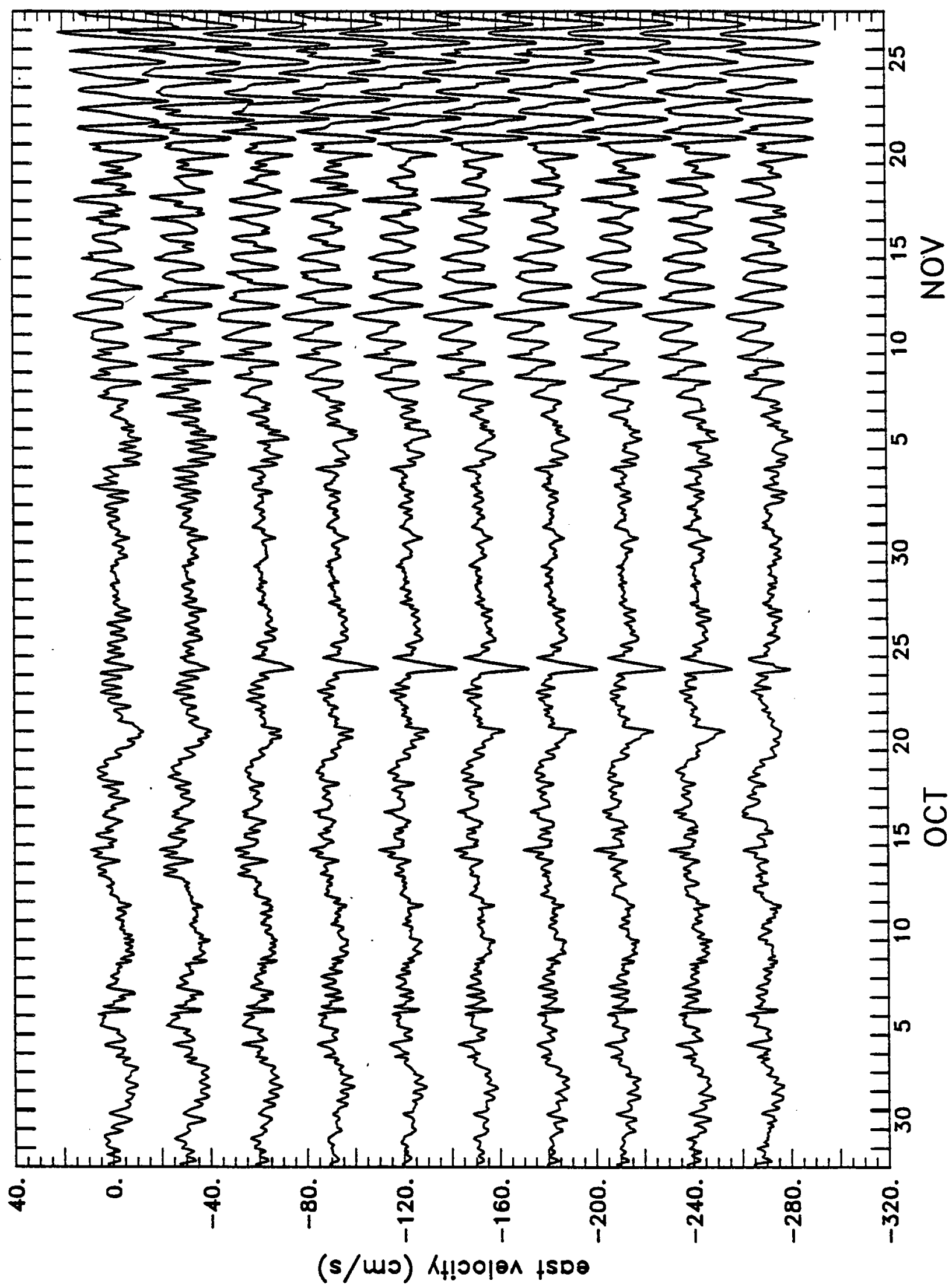


Figure 24c

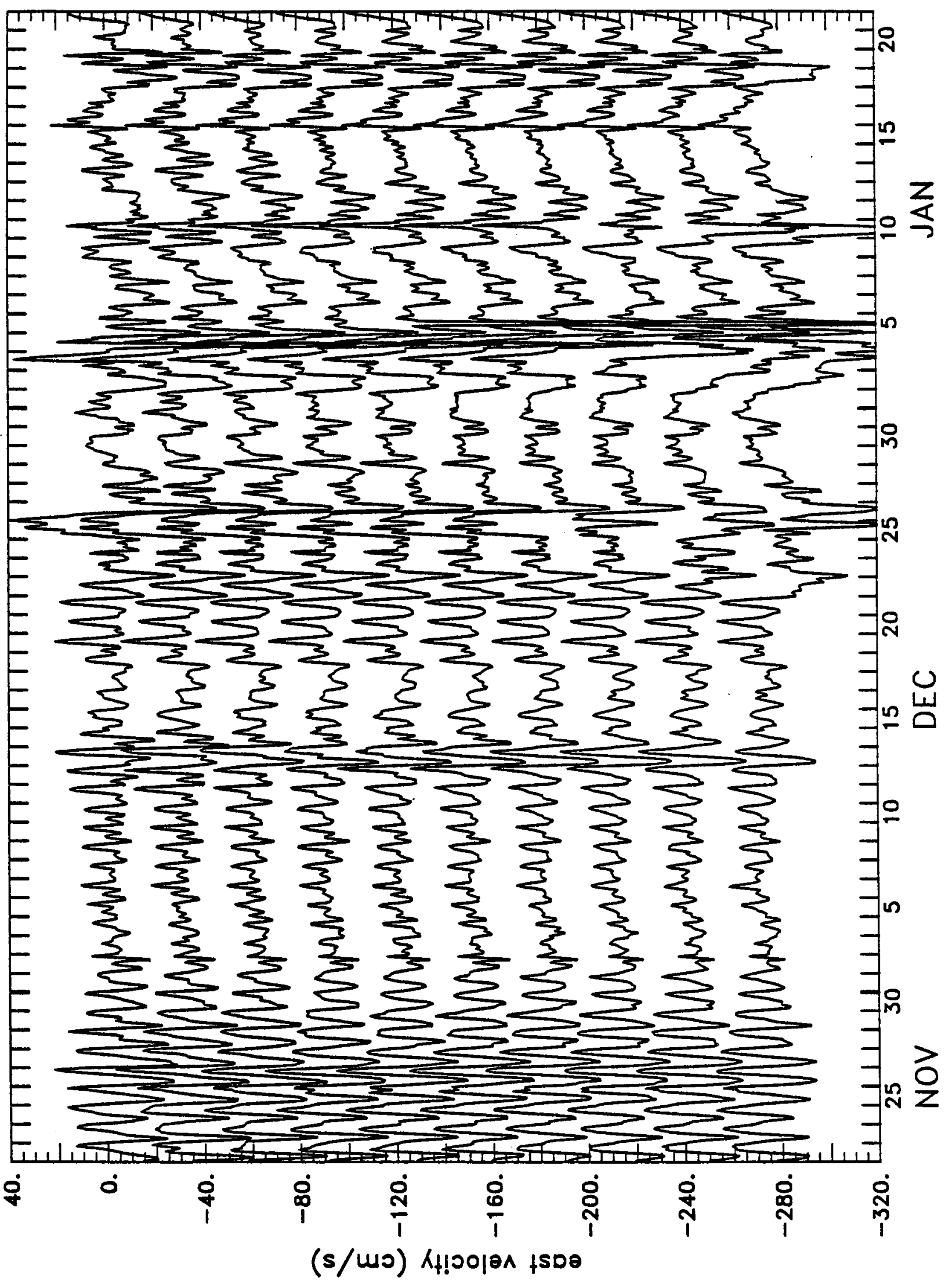


Figure 24d

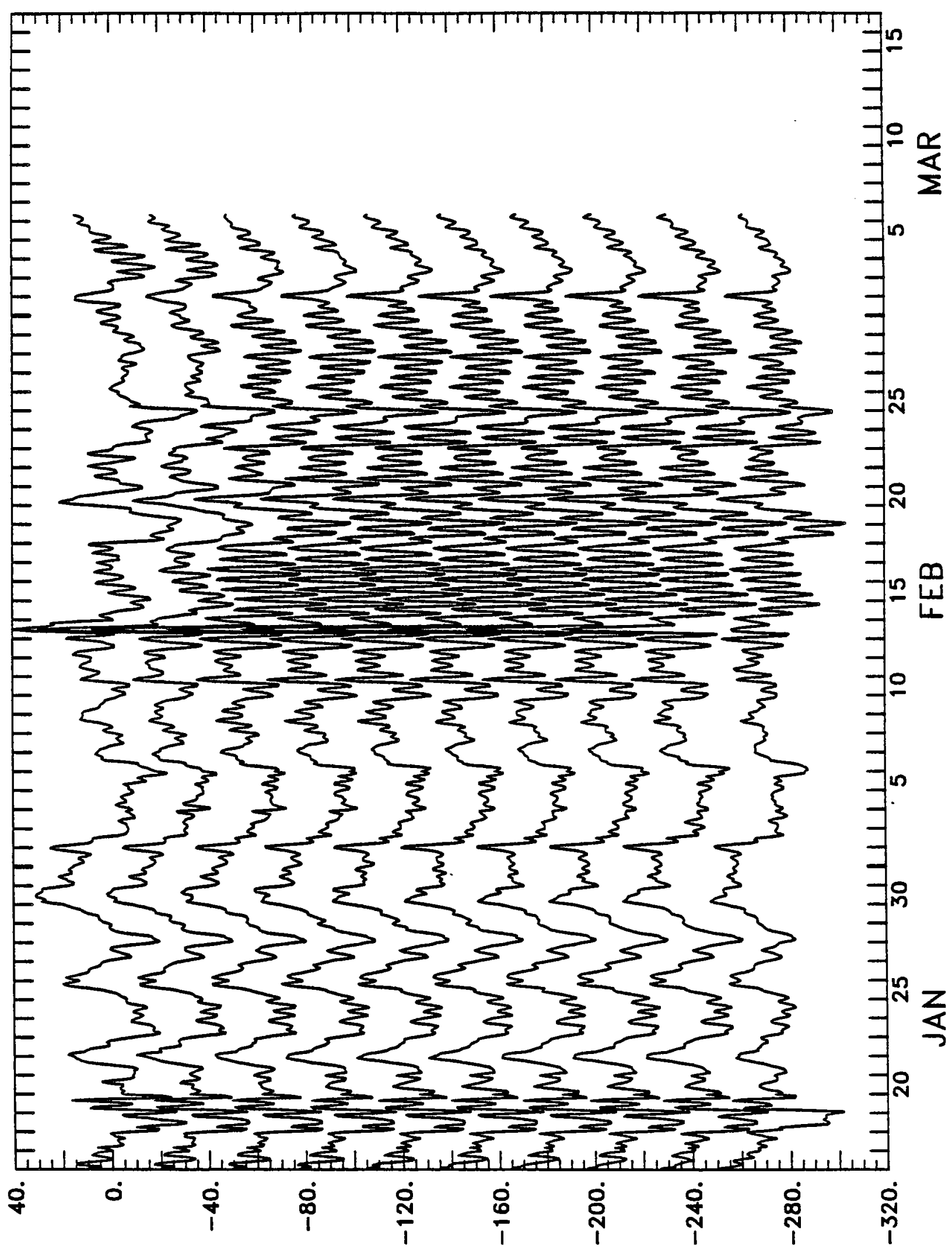

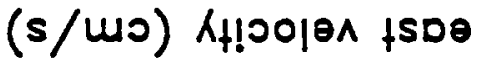


Fig. 25. ADCP absolute velocity time series for the north direction: a) section 1, b) section 2, c) section 3, d) section 4. Description same as for Fig. 24. 
Figure 25a

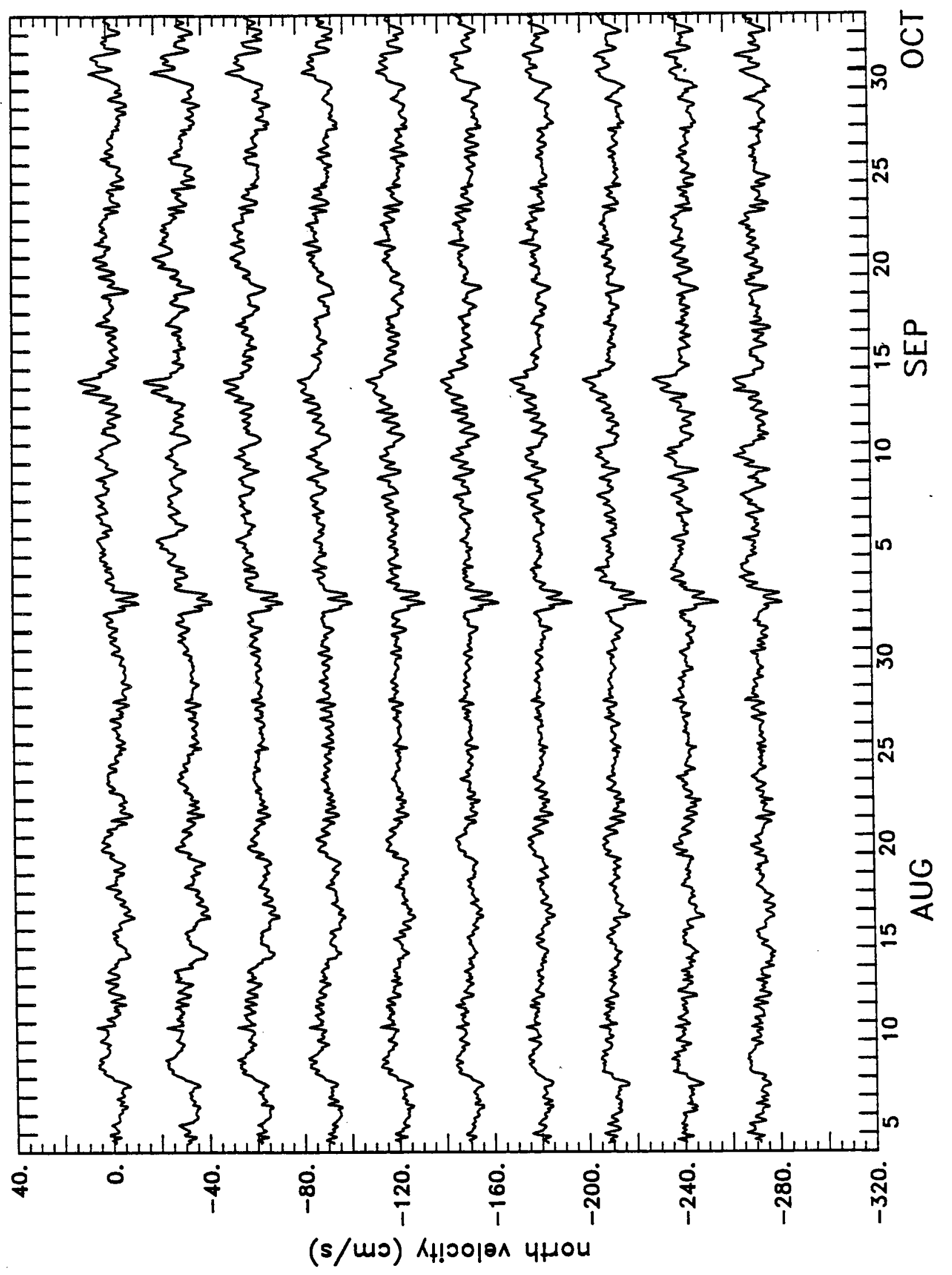


Figure 25b

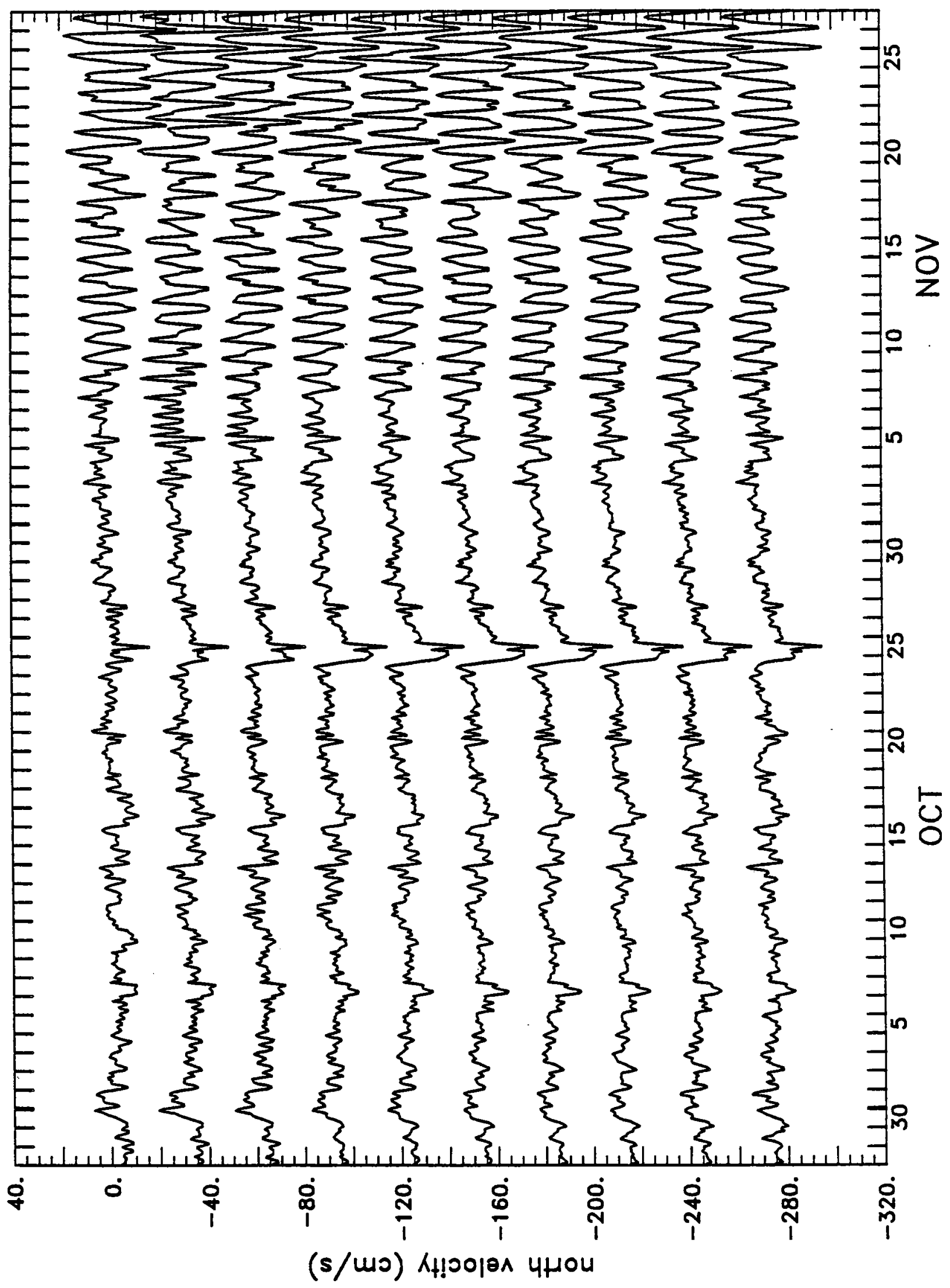


Figure 25c

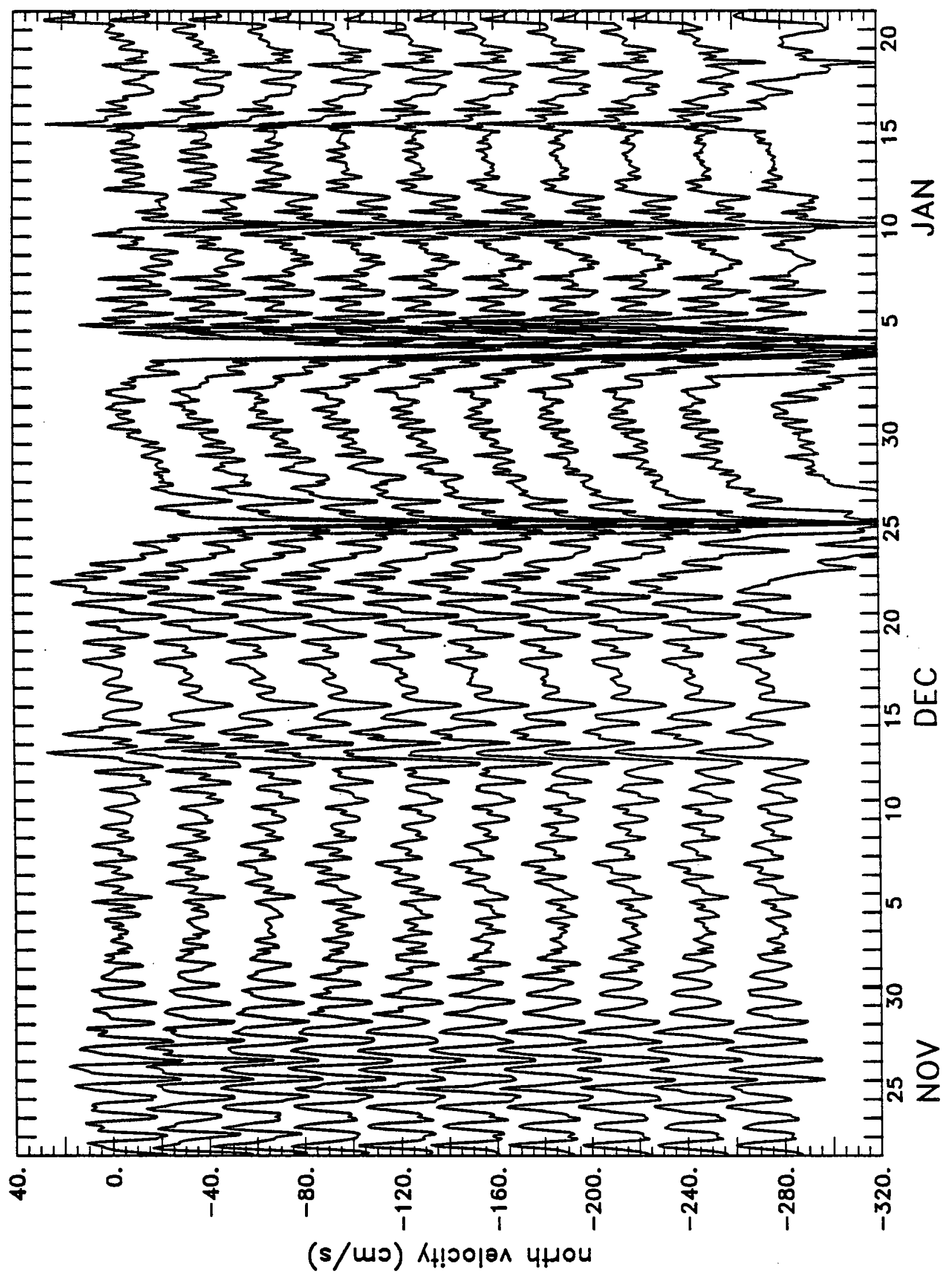


Figure 25d

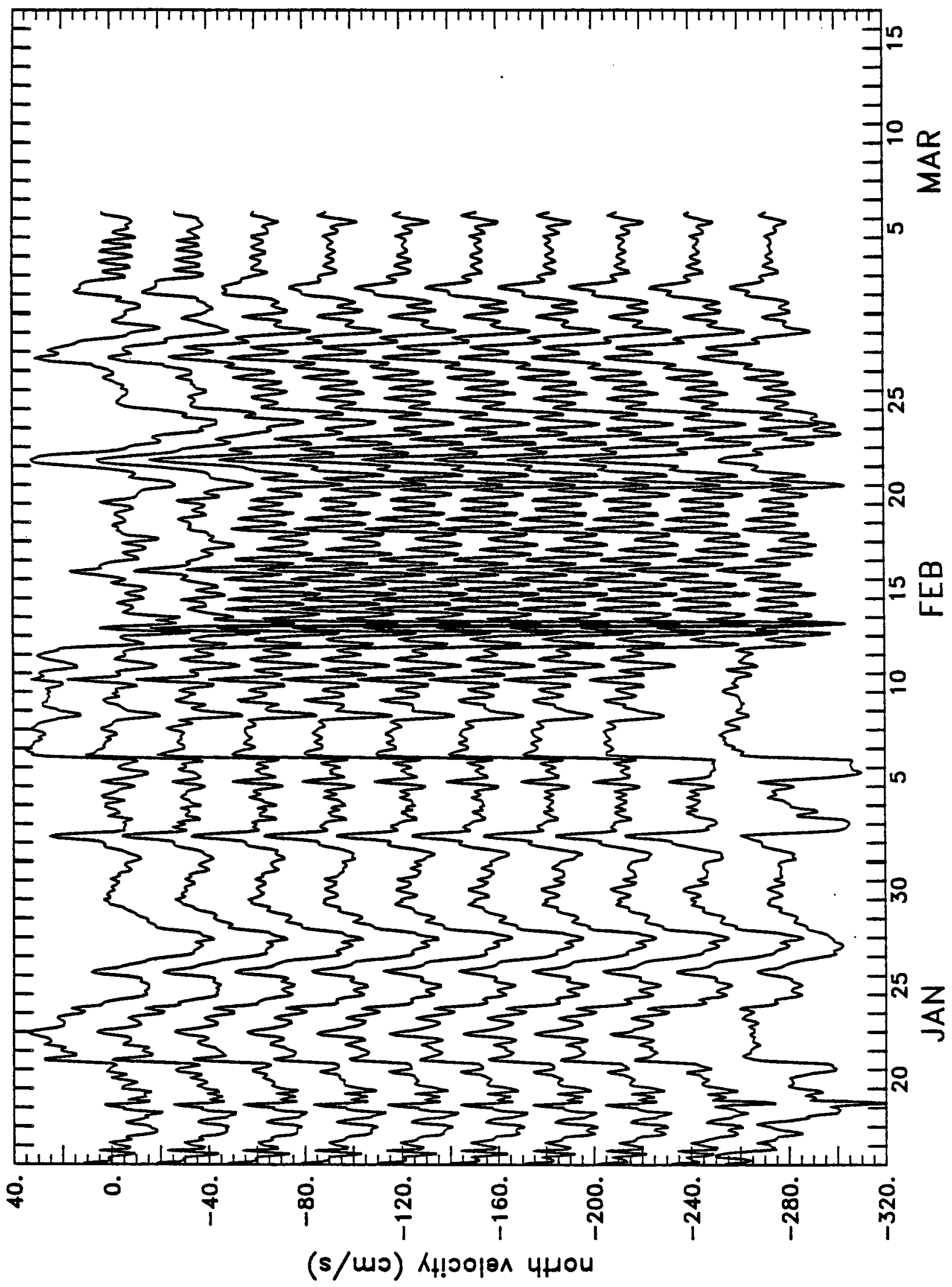


Fig. 26. ADCP velocity time series with depth average removed, east direction: a) section $1, b$ ) section $2, c$ ) section $3, d$ ) section 4 . The vertical scale is correct for the uppermost time series which is centered at a depth of $40 \mathrm{~m}$. Each successive time series is offset by $-10.0 \mathrm{~cm} / \mathrm{s}$ on the vertical scale and, since these data are averaged over 2 depth bins, each successive line is $32 \mathrm{~m}$ deeper. Velocity time series at each depth were averaged over 4 hours and decimated by 2 hours prior to plotting.

A record containing radial velocities for the 20 range bins of each of the four ADCP beams is recorded every half hour. For the downward facing ADCP deployed on the AEDB, the data from the 20 range bins of each beam form a vertical profile of velocity. The raw ADCP records represent an average of 40 profiles separated by one second in time. Bad points in the raw records were identified by computing the statistics of the first difference of the data with time. Records were de-spiked by eliminating points where the first difference was greater than three times the standard deviation of the first difference.

The four radial beam velocities are combined to form estimates of horizontal and vertical velocities in the instrument coordinate system. These velocities are then transformed to geographic coordinates using output from the tilt and heading sensors in the instrument. At this stage the horizontal velocities represent the relative velocity between the water and the drifting AEDB. The velocities plotted in this figure are formed by computing the average velocity for depths between $36 \mathrm{~m}$ and $268 \mathrm{~m}$ for each time step and subtracting the depth average from the original velocity at each depth. This technique effectively corrects for the relative motion of the buoy through the water, but also removes any component of the absolute velocity that is uniform over the $232 \mathrm{~m}$ where the depth average is computed. 
Figure 26a

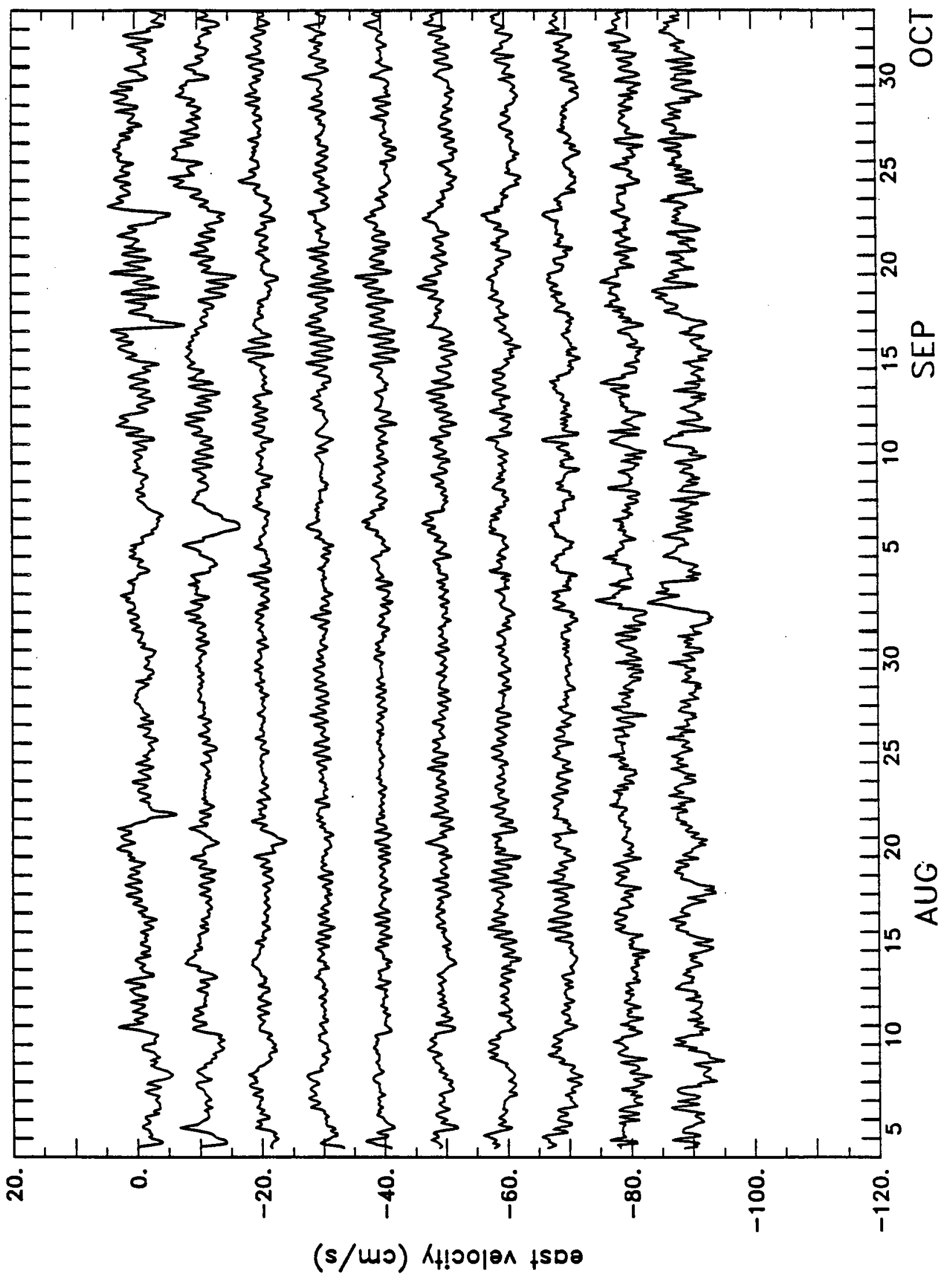


Figure 26b

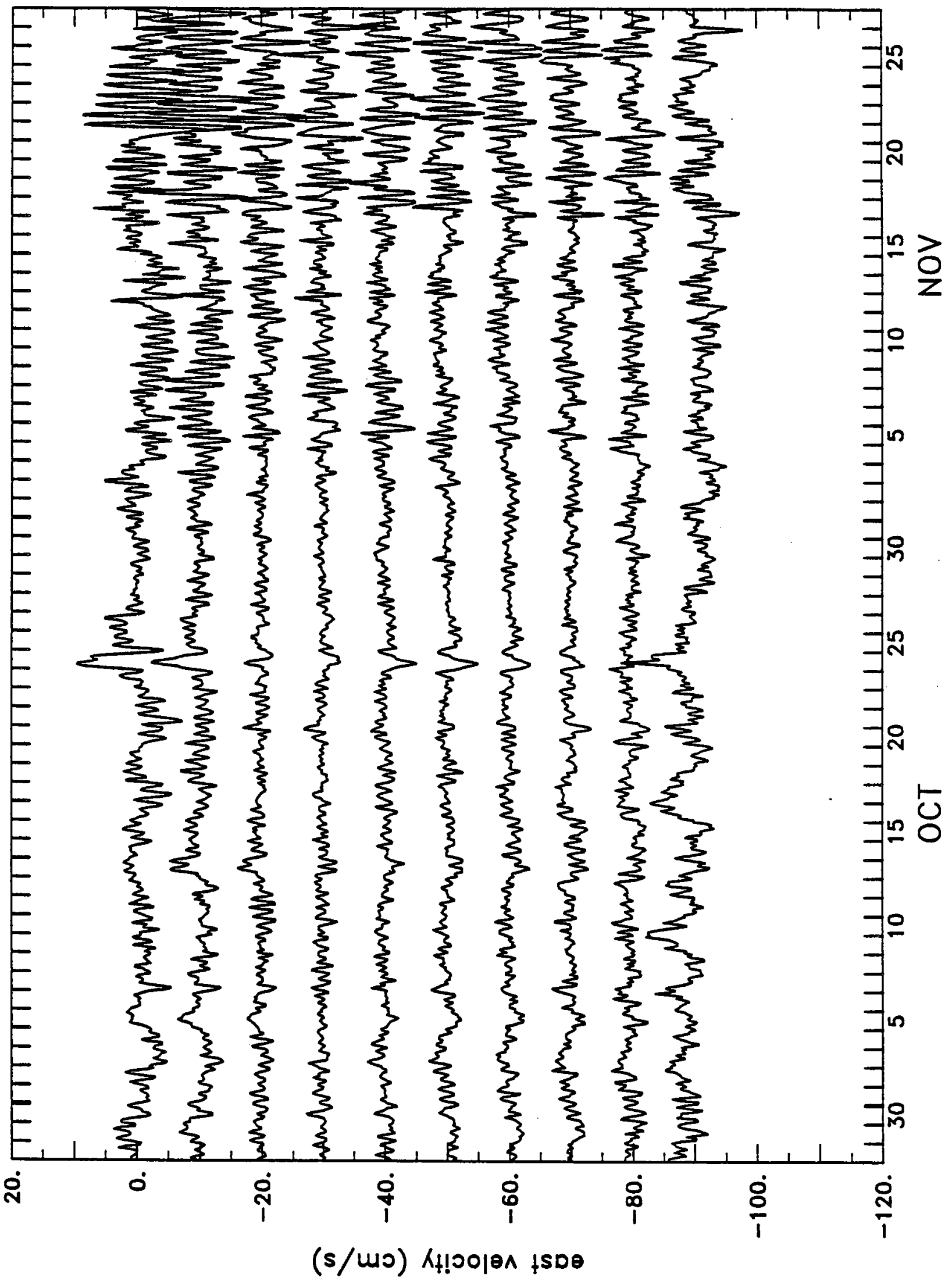


Figure 26c

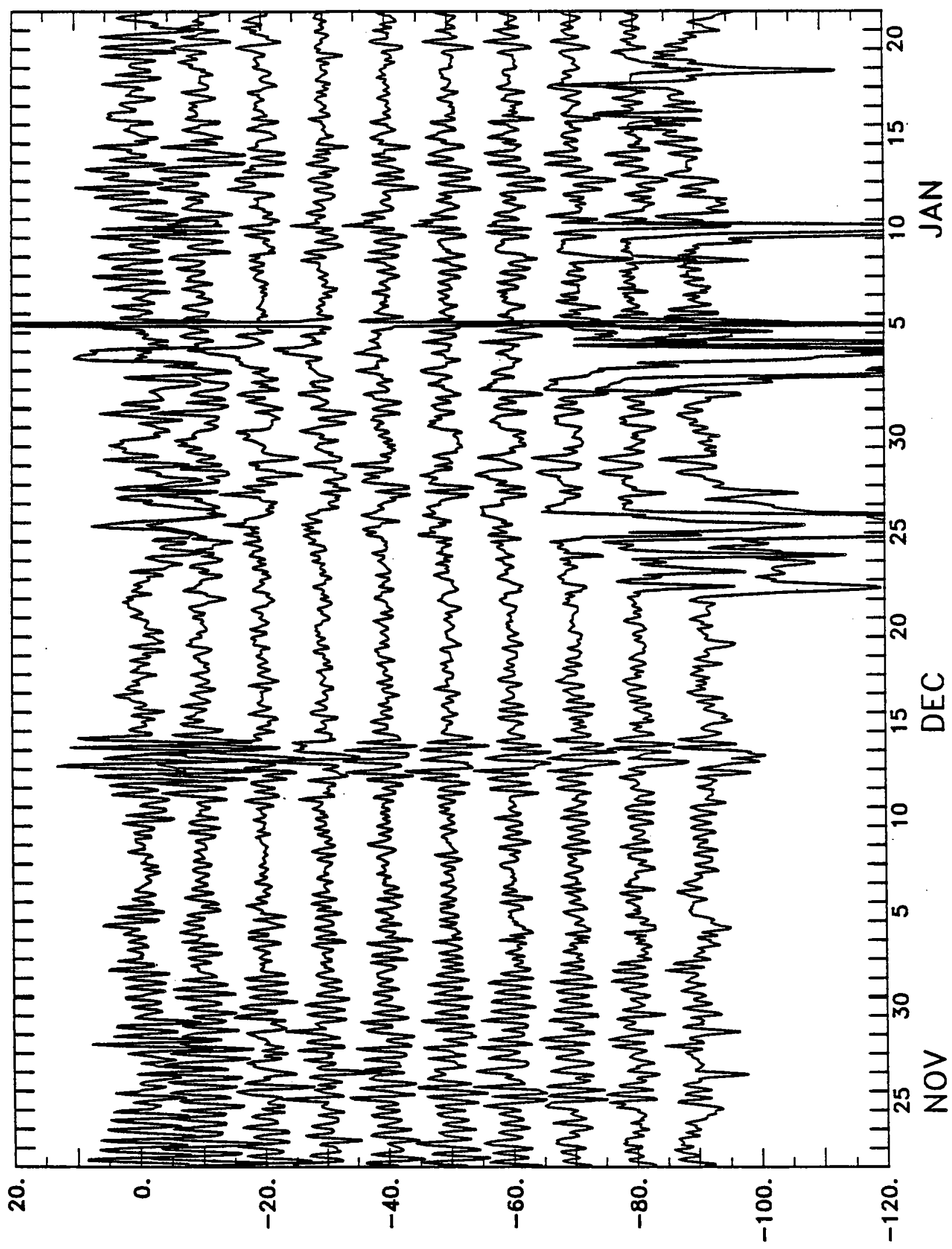

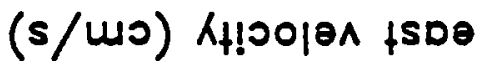


Figure 26d

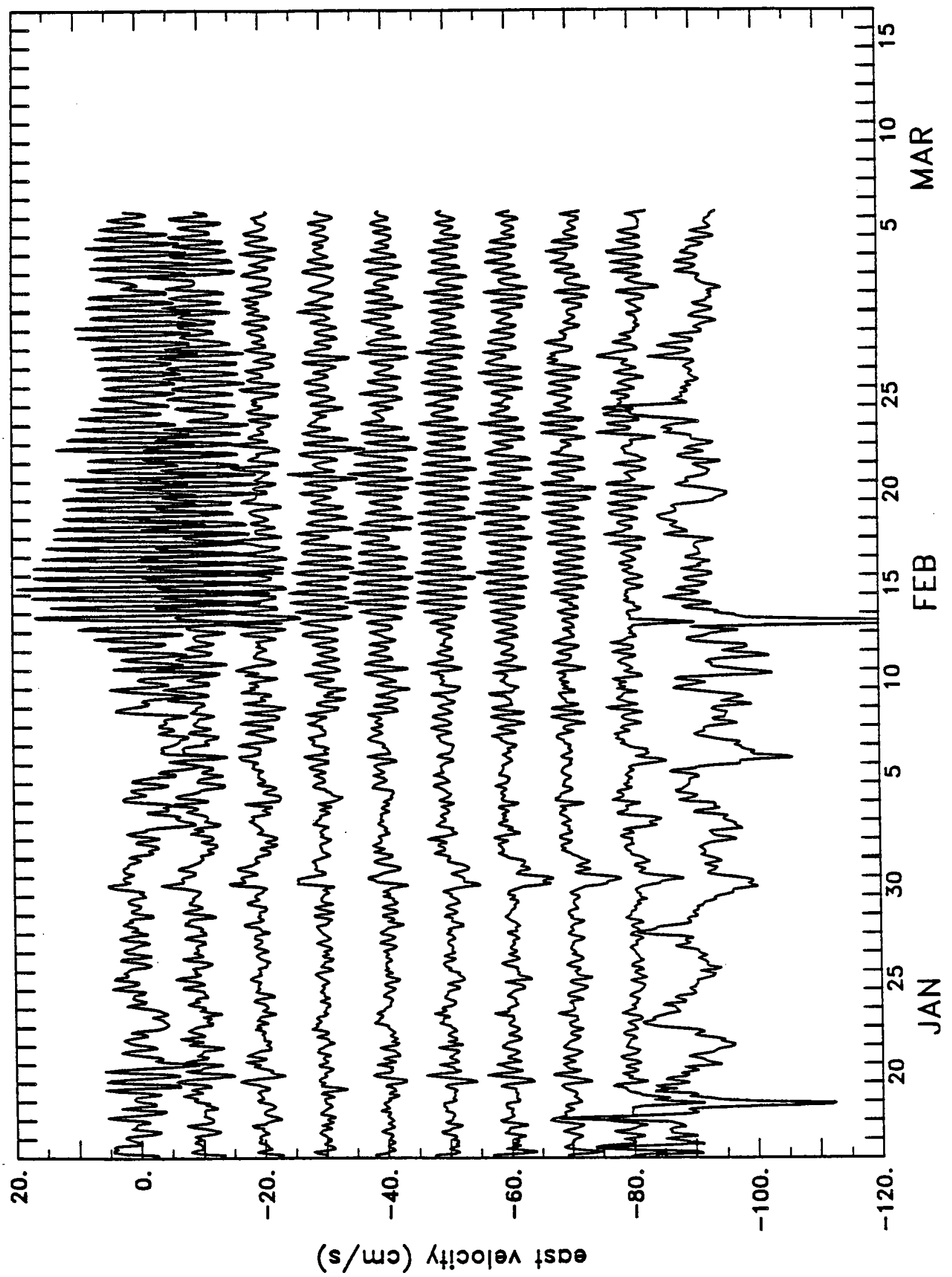


Fig. 27. ADCP velocity time series with depth average removed, north direction: a) section 1, b) section 2, c) section 3, d) section 4 . Description same as for Fig. 26. 
Figure 27a

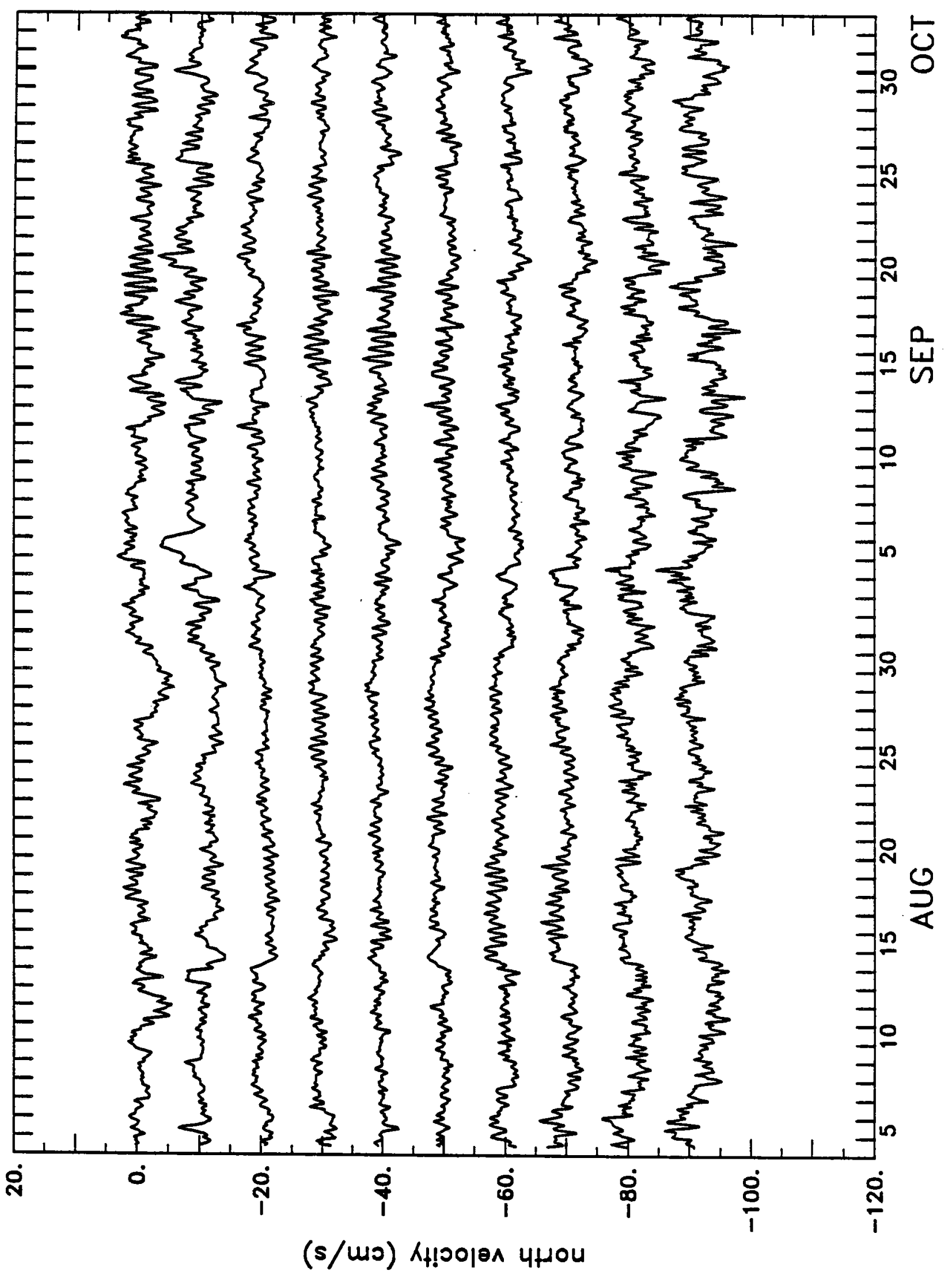


Figure 27b

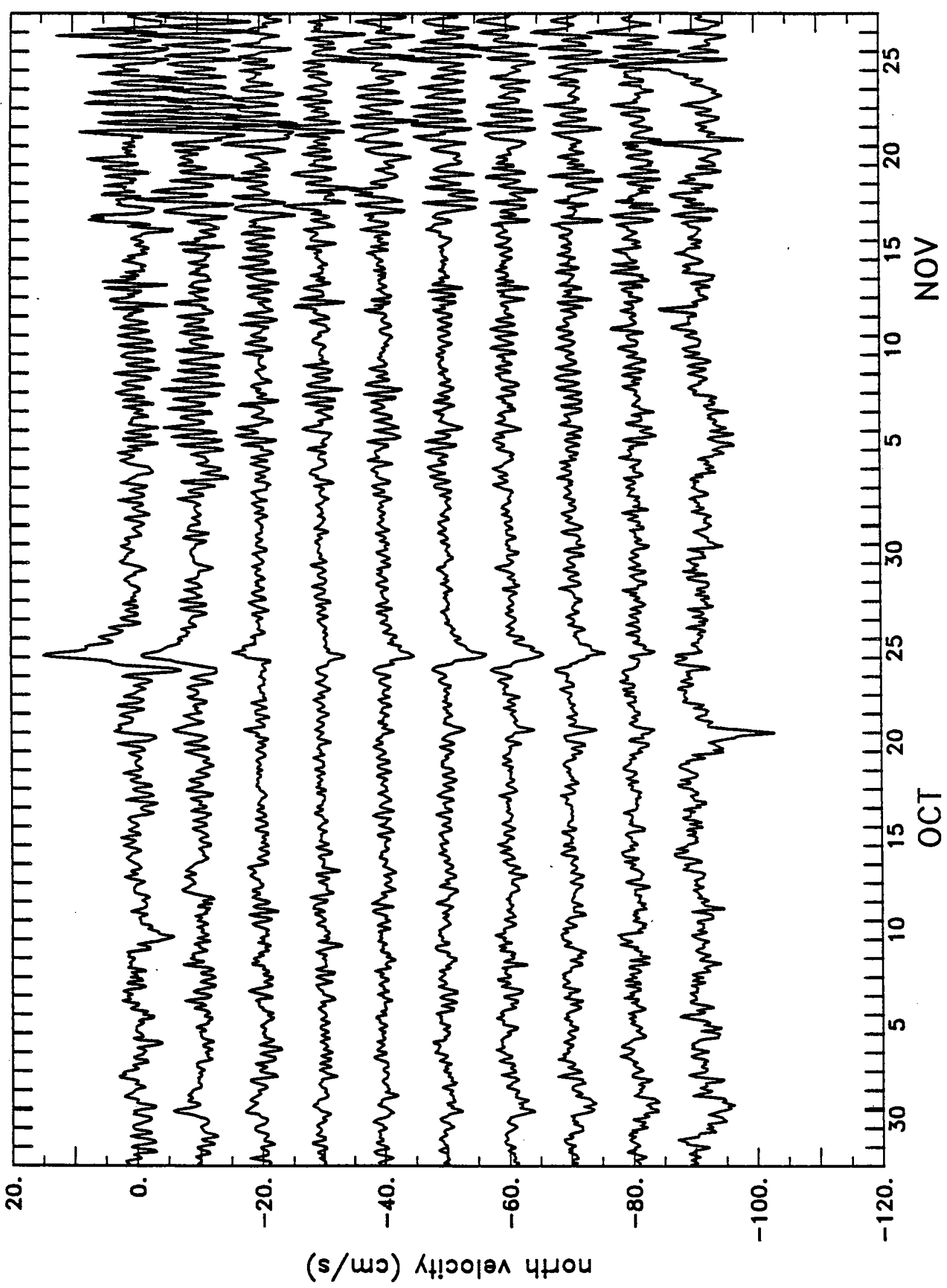


Figure 27c

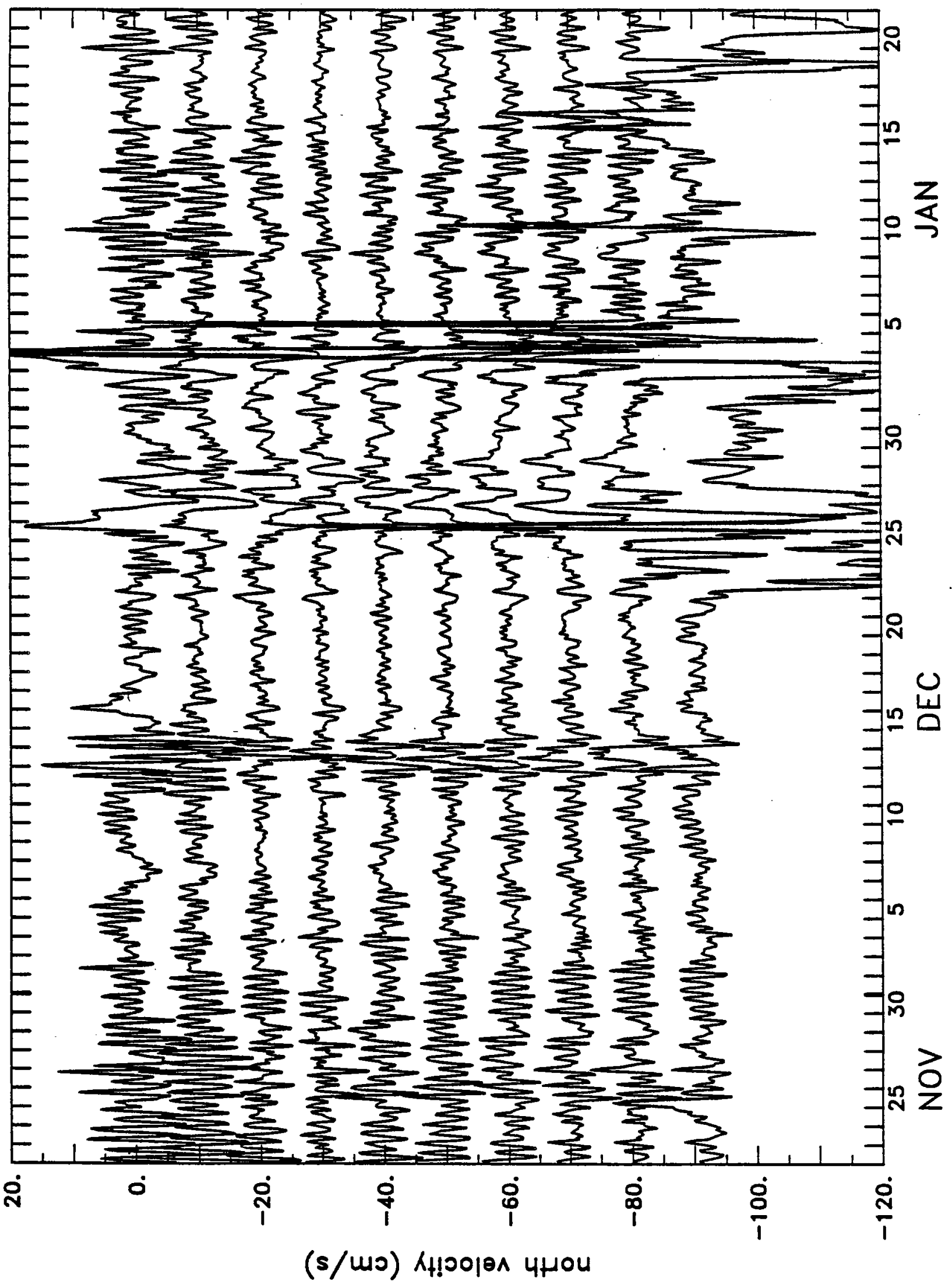


Figure 27d

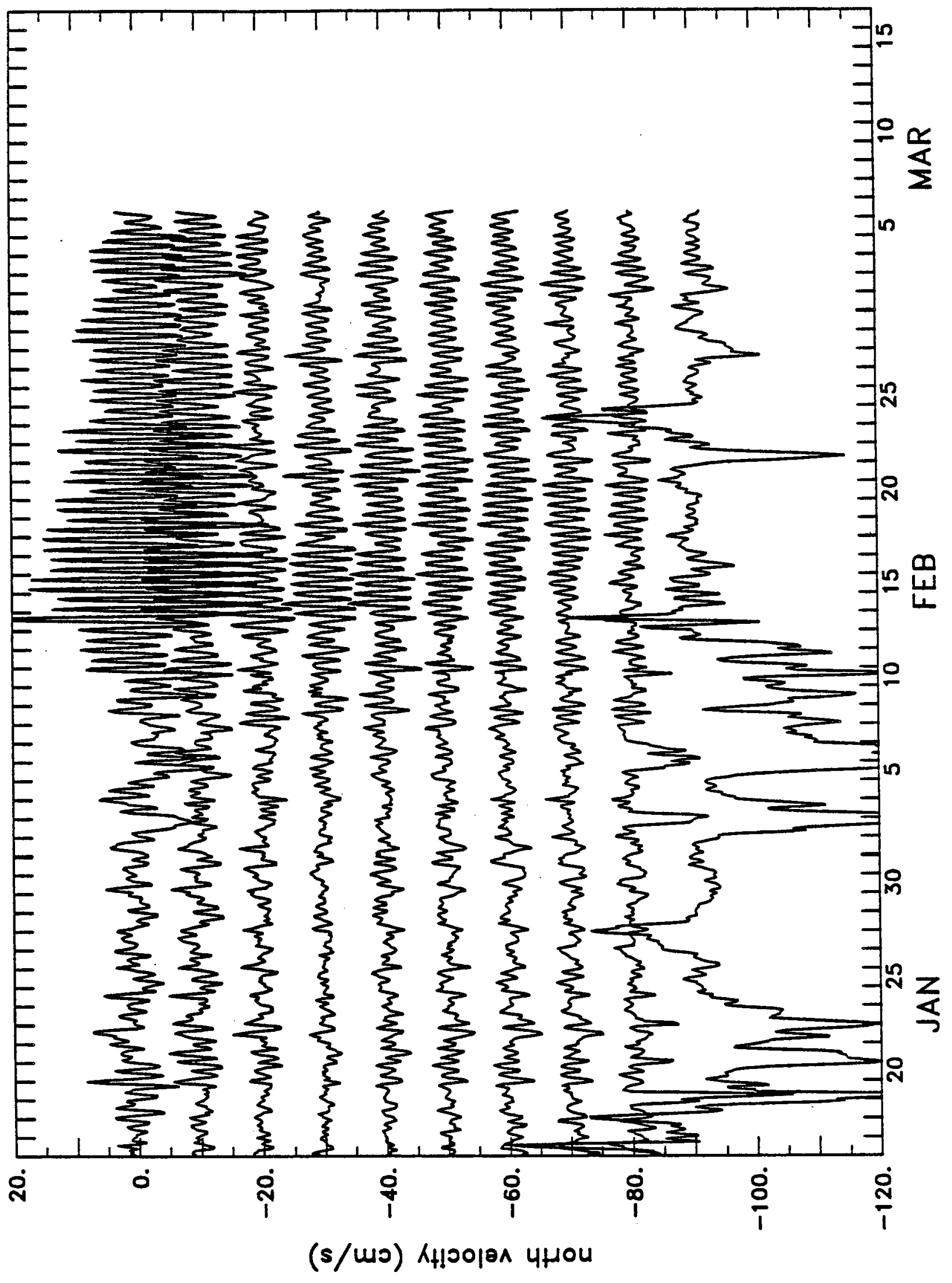


Fig. 28. ADCP vertical velocity time series: a) section 1, b) section 2 , c) section 3, d) section 4. The vertical scale is correct for the uppermost time series which is centered at a depth of $40 \mathrm{~m}$. Each successive time series is offset by -5.0 $\mathrm{cm} / \mathrm{s}$ on the vertical scale and, since these data are averaged over 2 depth bins, each successive line is $32 \mathrm{~m}$ deeper. Velocity time series at each depth were averaged over 4 hours and decimated by 2 hours prior to plotting.

A record containing radial velocities for the 20 range bins of each of the four ADCP beams is recorded every half hour. For the downward facing ADCP deployed on the AEDB, the data from the 20 range bins of each beam form a vertical profile of velocity. The raw ADCP records represent an average of 40 profiles separated by one second in time. Bad points in the raw records were identified by computing the statistics of the first difference of the data with time. Records were de-spiked by eliminating points where the first difference was greater than three times the standard deviation of the first difference. The four radial beam velocities are combined to form estimates of horizontal and vertical velocities in the instrument coordinate system. These velocities are then transformed to geographic coordinates using output from the tilt and heading sensors in the instrument. 
Figure 28a

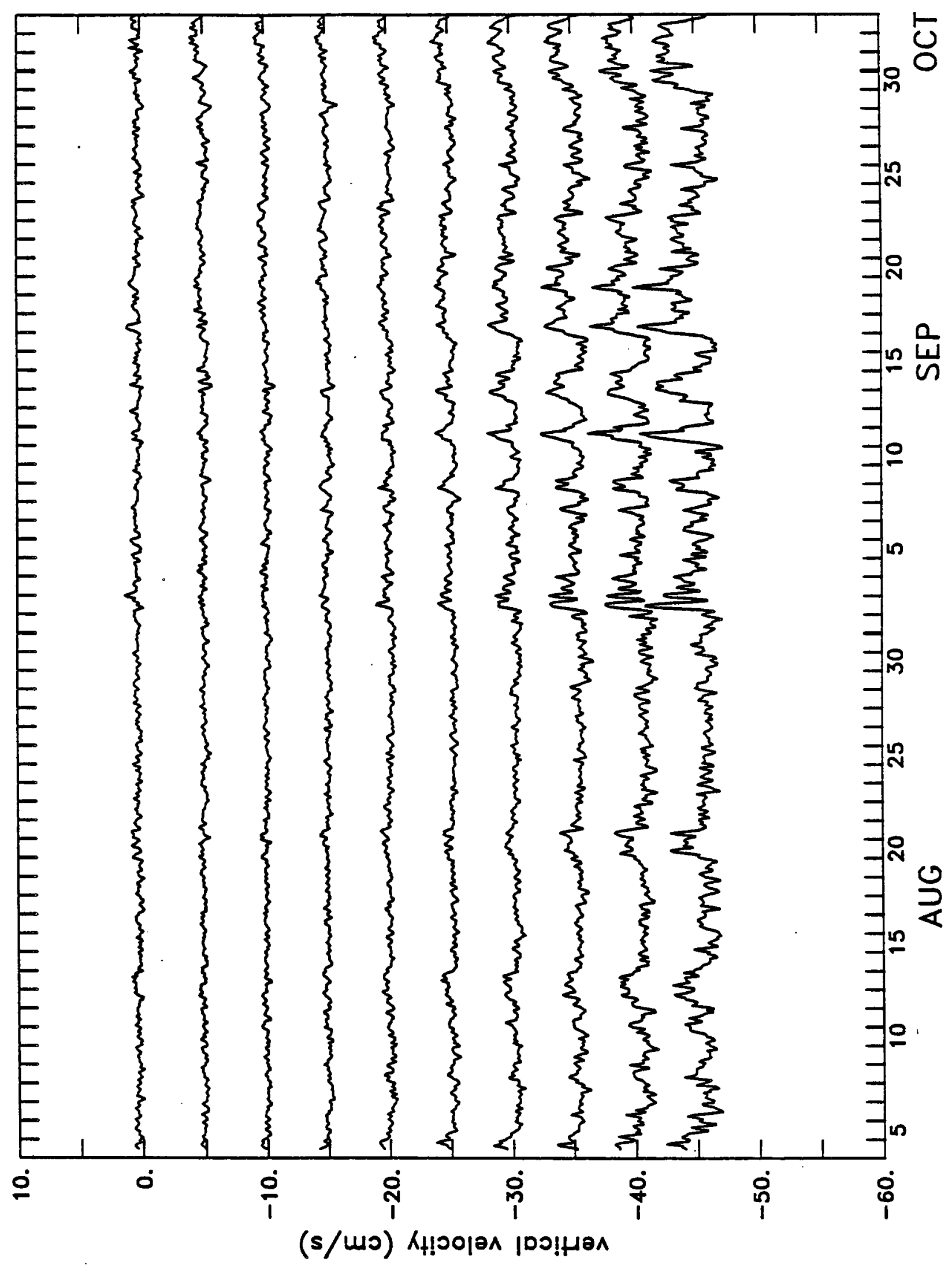


Figure 28b

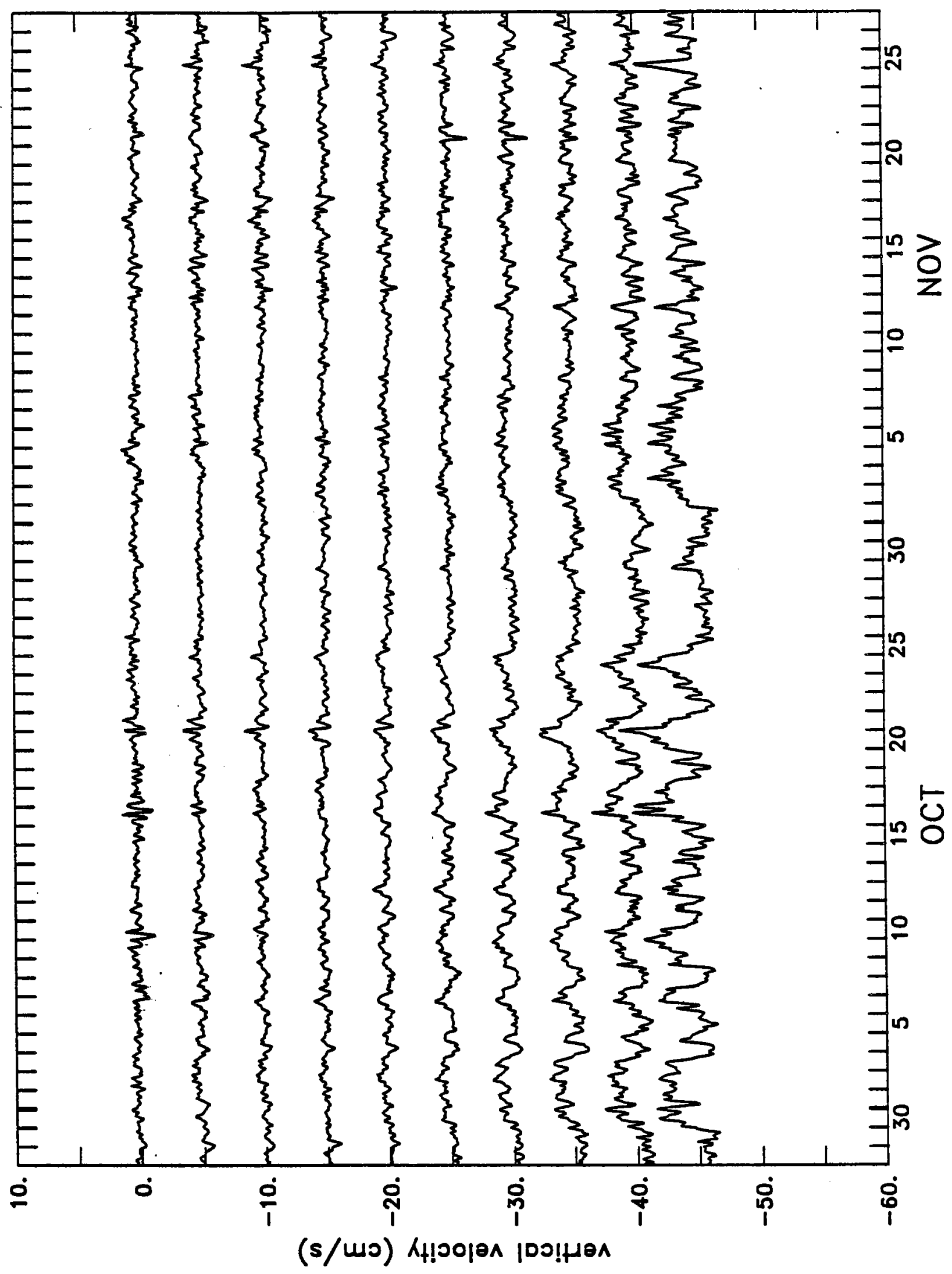


Figure 28c

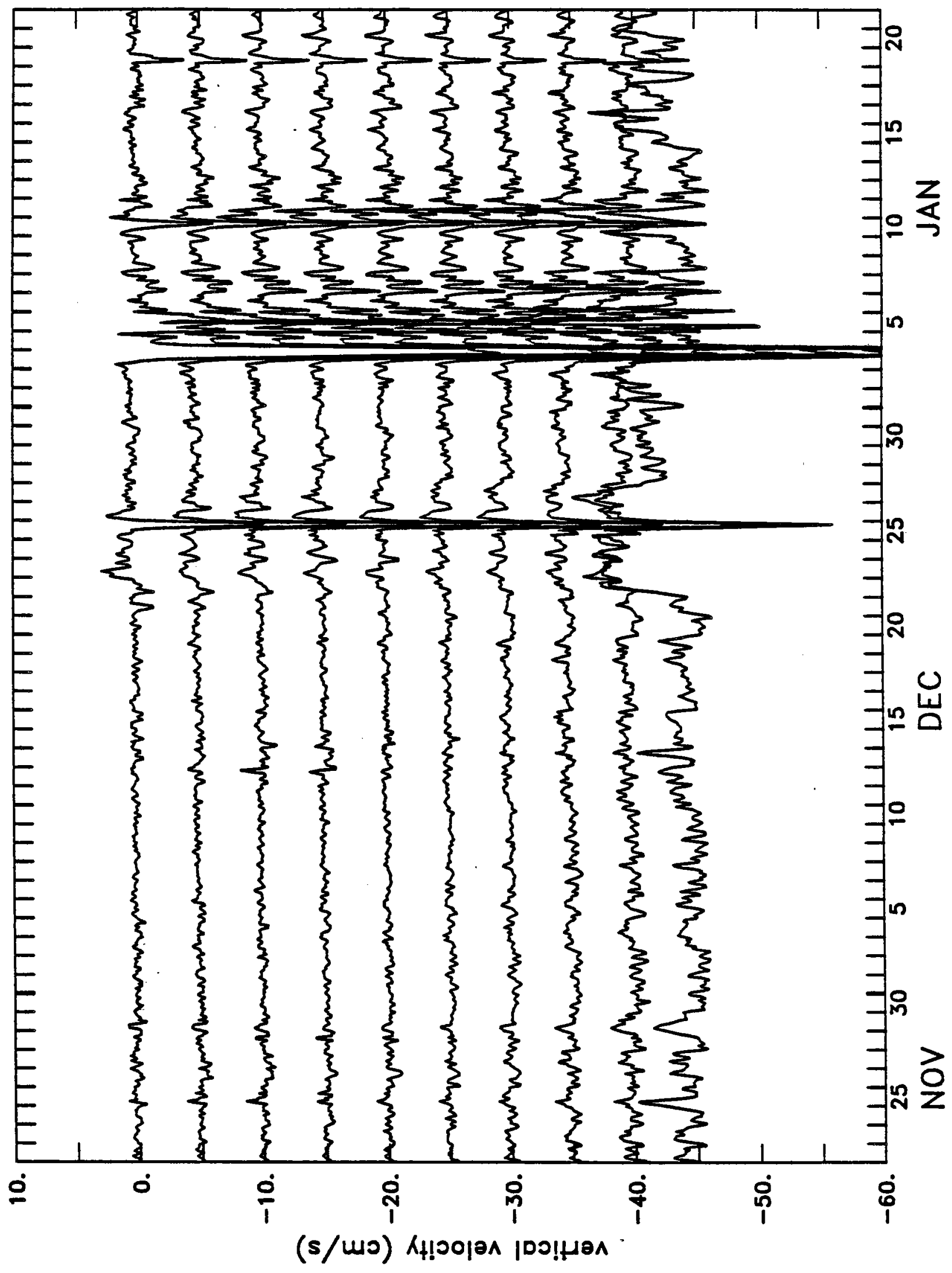


Figure 28d

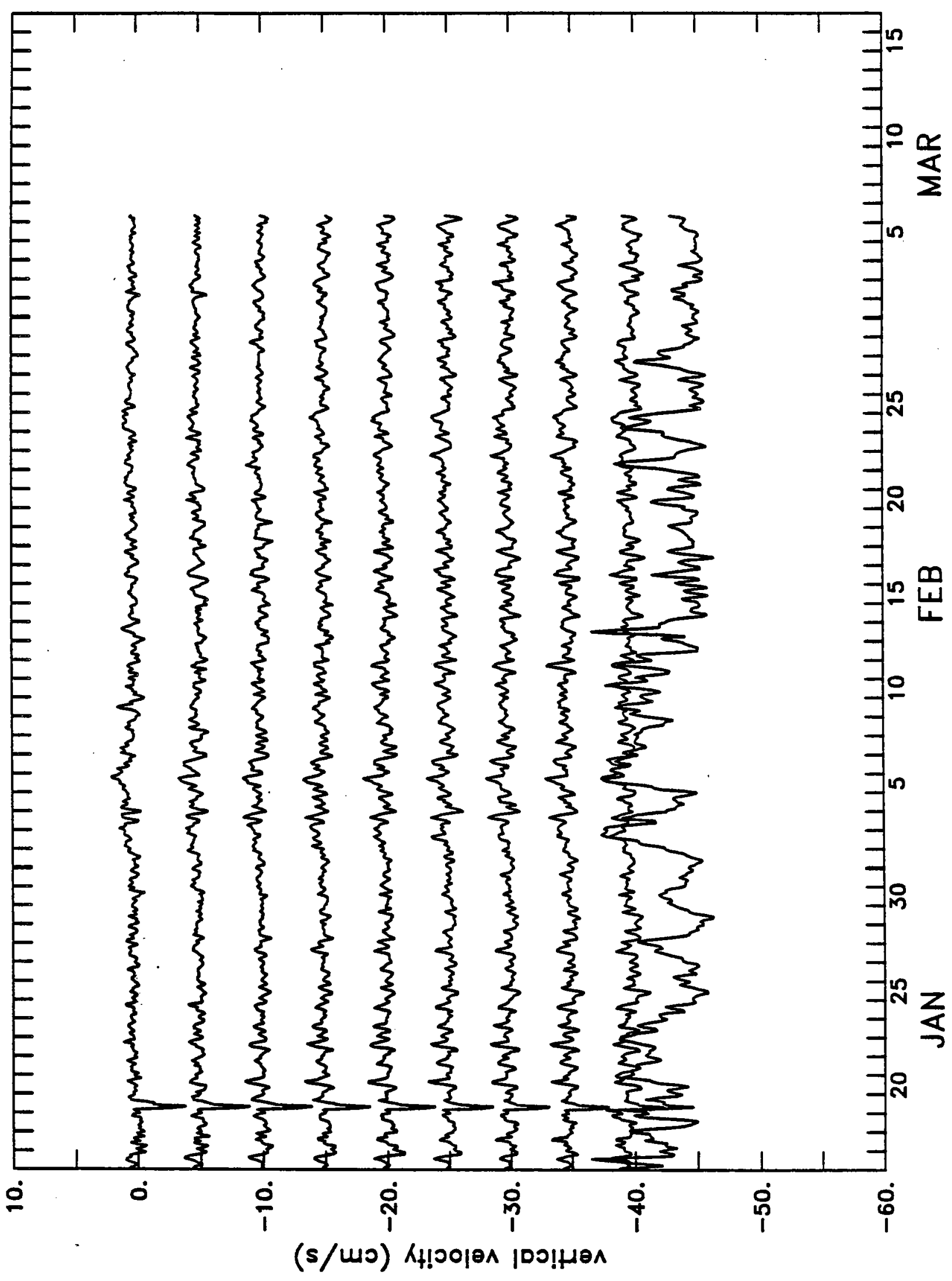




\section{Appendix A: Campbell data logger program}

*1

$01: 5400.0$

01: $\quad$ P89

01:0001

02: 04

03: 3.000

$04: 30$

02: $\mathrm{P} 32$

$01: 0001$

03: $\mathrm{P} 86$

01:00

04 : P94

05: $\mathrm{P} 30$

$01: 0.000$

02:0001

06 : $\mathrm{P} 10$

01:0002

07: $\quad$ P89

01:0002

02: 04

03: 9.7000

04:00

08: $\mathrm{P} 20$

01:01

02: 01

09: P87

01:00

02: 0032

10: P22

01:01

02: 0001

03: 0000

04: 5000.0

11: P05

01:01

02: 14

03: 01

04: 02

05: 0500

06: $0002 \mathrm{C}$

07: 1.000

08: 0.000

12: P95

13: P20

01:00

02: 01

14: P05

01:03

02: 14

03: 02

$04: 03$

05: 0500
Program Table 1

1.5 hour table execution interval

If $X$ compared to $F$ (to sample at 6 hour rate) Location \#1 for $X$

If $X<F$

$F=3.000$

Then Do

Increment input location

Destination location \#1

Do

Else

Goto end of program table

Load fixed data

$F=0.000$

Destination location \#1

Store battery voltage

Destination location \#2

If $X$ compared to $F$ (to end if battery is low) Location \#2 for $X$

If $X<F$

$F=9.7000$

Goto end of program table

Set port (to enable AM32)

Set high (5 V)

Loop

Digital control port 1

No delay

32 iterations

Excitation with delay (clock)

Excitation channel 1

Excite for .01 seconds

No delay after excitation

Excitation $=5000.0 \mathrm{mV}$

Measure AC conductivity (thermistors 1 to 32 ) 1 repetition $500 \mathrm{mV}$ full scale; fast integration time

Single ended channel 1

Excitation channel 2

Excitation $=500 \mathrm{mV}$

Starting destination location \#2 (indexed)

Multiplier *1

Zero offset

End loop

Set port (reset AM32)

Set low (OV)

Digital control port 1

Measure AC conductivity (thermistors 33 to 35 ) 3 repetitions

$500 \mathrm{mV}$ full scale; fast integration time

Start at single ended channel 2

Excitation channel 3

Excitation $=500 \mathrm{mV}$ 
06: 0034

07: 1.000

08: 0.000

15: P59

02: 0002

03: 1.0000

16 : P59

01:01

02: 0034

03: 1.0040

17: P59

01:01

02: 0035

03:.9830

18: P59

01:01

02: 0036

03:.9940

19: P86

20: P77

01:0110

21: P70

01: 35

02: 0002

22: P95

*4

01: 01

02: 02

* 5

05: 87

05: XXXX

05: HH:MM

$\underline{*}$

*A

01: 0036

$02: 0036$

03: 19280

04: 0809

*B

01: 1664.0

02 : 33080

03 : 52865
Starting destination location \#34

Multiplier*1

Zero offset

Compute block resistances $[x /(1-x)]$ for 1 to 32

01: 3535 repetitions

Starting destination location \#2

Multiplier ${ }^{*} 1.0000$ ohm Vishay

Compute resistance for 33

1 repetition

Destination location \#34

Multiplier * 1.0040 ohm resistor

Compute resistance for 34

1 repetition

Starting destination location \#2

Multiplier * $.9830 \mathrm{ohm}$ resistor

Compute resistance for 35

1 repetition

Starting destination location \#2

Multiplier *.9940 ohm resistor

Do (to enable output)

Real time

Set flag 10

Store day, hour-minute

Sample (to store data in SM64)

35 repetitions

Starting location \#2

End table execution

Output options

SM64 enabled

9600 baud

Set/display time

Year

Julian day

Hours:Minutes

Log data

Memory Allocation

Input storage locations

Intermediate storage locations

Final storage locations in $21 \mathrm{X}$

Remaining program memory (bytes)

Signatures

Program memory

EPROM No. 1

EPROM No. 2 


\section{Appendix B: Fluorometer and data logger tests}

Prior to deployment, laboratory tests were conducted on the fluorometer and data logger packages in order to determine the validity of the data that would be recorded. Using air as a constant fluorescent medium, hourly sampling was conducted using 1 and $3 \mathrm{~s}$ time constant settings in the fluorometer, while varying the warmup and averaging parameters in the data logger. These tests showed that a 32 sample average after $11 \mathrm{~s}$ warmup with $1 \mathrm{~s}$ time constant was comparable to an 8 sample average after a $20 \mathrm{~s}$ warmup with a $3 \mathrm{~s}$ time constant, as expected. In both cases, the standard deviation of recorded voltage was less than $0.005 \mathrm{~V}$; within the resolution of the fluorometer at the high sensitivity setting. As a result, precision could be maintained while reducing the battery requirements, since the fluorometer needs to be provided with power for a shorter duration using the $1 \mathrm{~s}$ time constant (17 versus $24 \mathrm{~s}$ ).

One test simultaneously determined the linearities of both the fluorometer and data logger in a single package. With the fluorometer immersed in one liter of ordinary filtered seawater, a solution containing a phytoplankton culture was added to the seawater in discrete microliter increments while the data logger recorded the voltage output of the fluorometer. Concurrently, readings were being manually recorded from a DVM connected in parallel to the data logger. Four multipoint comparisons (two per fluorometer package) of the amount of added chlorophyll solution to fluorometer voltage outputs (as indicated by the DVM) produced a straight line relationship with a correlation factor of 0.9997 . Similar comparisons between the DVM reading and data logger values correlated to 0.9999 . However, due to a slight mismatching of impedances between the fluorometers and data loggers, the latter comparison also indicated positive bias shifts in the voltage value recorded in the loggers' memory of $66 \mathrm{mV}$ in one unit and $130 \mathrm{mV}$ in the other. These offsets were subtracted from the raw data when converting the retrieved records in the data loggers to fluorometer voltages.

The fluorometers were roughly calibrated to a known concentration of chlorophyll $a$, composed of a solution of dried spinach and $100 \mathrm{ml}$ of acetone, using the manner described by Strickland and Parsons (1972). Readings obtained by the fluorometer package were compared to the calculated chlorophyll values. Due to the biases in the data loggers and possible slight imperfections in the optical components of the fluorometers, the shallow and deep fluorometers displayed different full scale values. The shallow package attained full scale at $3.9 \mathrm{ug} / \mathrm{l}$ chlorophyll a, while the deeper unit reached full scale at $5.1 \mathrm{ug} / \mathrm{l}$. 
Appendix C: Schedules for sediment trap and micro-filter pump

\begin{tabular}{|c|c|c|c|c|c|}
\hline & ment Trap & & & Micro-filter Pump & \\
\hline Sample & Date & Time & Filter & $\begin{array}{l}\text { Date } \\
\end{array}$ & Time \\
\hline test & 4 Aug 87 & $7: 50$ & test & & $7: 10$ \\
\hline start & 4 Aug & $18: 00$ & 1 & 4 Aug & $18: 00$ \\
\hline 1 & 24 Aug & $18: 00$ & & rengy & \\
\hline 2 & 13 Sept & $18: 00$ & 3 & 3 sepl & 10.00 \\
\hline 3 & 3 Oct & $18: 00$ & $\begin{array}{l}4 \\
5\end{array}$ & $\begin{array}{l}18 \text { Sept } \\
3 \mathrm{Oct}\end{array}$ & $\begin{array}{l}18: 00 \\
18: 00\end{array}$ \\
\hline 4 & 23 Oct & $18: 00$ & 0 & $100 \mathrm{cl}$ & \\
\hline 5 & $12 \mathrm{Nov}$ & $18: 00$ & $\gamma$ & 2 Nov & 18:00 \\
\hline 6 & $1 \mathrm{Dec}$ & $18: 00$ & $\begin{array}{r}8 \\
9 \\
10\end{array}$ & $\begin{array}{r}17 \mathrm{Nov} \\
2 \mathrm{Dec} \\
17 \mathrm{Dec}\end{array}$ & $\begin{array}{l}18: 00 \\
18: 00 \\
18: 00\end{array}$ \\
\hline 7 & 22 Dec & $18: 00$ & 11 & 1 lan 98 & 18.00 \\
\hline 8 & 11 Jan & $18: 00$ & & & \\
\hline 9 & 31 Jan & $18: 00$ & $\begin{array}{l}13 \\
14\end{array}$ & 31 Jan & $\begin{array}{l}18: 00 \\
18: 00\end{array}$ \\
\hline 10 & $20 \mathrm{Feb}$ & $18: 00$ & 15 & 1 Mar & $18: 00$ \\
\hline 11 & $11 \mathrm{Mar}$ & $18: 00$ & 16 & 16 Mar & $18 \cdot 00$ \\
\hline 12 & $31 \mathrm{Mar}$ & $18: 00$ & $\begin{array}{l}17 \\
18\end{array}$ & $\begin{array}{l}31 \mathrm{Mar} \\
15 \mathrm{Apr}\end{array}$ & $\begin{array}{l}18: 00 \\
18: 00\end{array}$ \\
\hline 13 & 20 & $18: 00$ & 19 & $30 \mathrm{Apr}$ & $18: 00$ \\
\hline
\end{tabular}




\section{References}

Aagaard, K., A synthesis of the Arctic Ocean circulation, Rapp. P.-v. Réun. Cons. int. Explor. Mer, 188, 11-22, 1989.

Andrews, J.T., Climatic evolution of the eastern Canadian Arctic and Baffin Bay during the past three million years, Philosophical Transactions of the Royal Society of London, Series B: Biological Sciences, 318, 645-660, 1988.

Augstein, E., coordinator, ARKTIS IV (1-3) gemeinsam mit dem Forschungsflugzeug POLAR 2, Expeditionsprogramm Nr. 10, Alfed Wegener Institute for Polar and Marine Research, 54 pp., 1987.

Colony, R., Nansen's Luck, J. Geophys. Res., in press, 1990.

Gorshkov, S.G., ed., Arctic Ocean, Vol. 3 of World Ocean Atlas, Pergamon Press, Oxford, 189 pp., 1983.

Hibler, W.D., and J.E. Walsh, On modeling seasonal and interannual fluctuations of Arctic sea ice, J. Phys. Oceanogr., 12, 1514-1523, 1982.

Honjo, S., Particle Fluxes and Modern Sedimentation in the Polar Oceans, Chapter 12 in Polar Oceanography (W.O. Smith, Jr., ed.), Academic Press, New York, in press, 1990.

Johannessen, O.M., W.D. Hibler, P. Wadhams, W.J. Campbell, K. Hasselmann, I. Dyer, and M. Dunbar, MIZEX, A Program for Mesoscale Air-Ice-Ocean Interaction Experiments in Arctic Marginal lce Zones: II. A Science Plan for a Summer Marginal lce Zone Experiment in the Fram Strait/Greenland Sea: 1984, Cold Regions Research and Engineering Laboratory Special Report 83-12, Hanover, New Hampshire, 47 pp., 1983.

Jones, E.P., D. Nelson and P. Treguer, Chemical Oceanography, Chapter 7 in Polar Oceanography (W.O. Smith, Jr., ed.), Academic Press, New York, in press, 1990. 
Krause, G., J. Meinke, and J. Thiede, Scientific Cruise Reports of Arctic Expeditions ARK IV/1, 2 \& 3, Reports on Polar Research 56, Alfed Wegener Institute for Polar and Marine Research, 150 pp, 1989.

Maykut, G.A., Large-scale heat exchange and ice production in the central Arctic, J. Geophys. Res., 87, 7971-7984, 1982.

Nansen, F., Farthest North, Vol. I, Westminster, Archibald Constable and Company, 1897.

Öslund, H.G., and G. Hut, Arctic Ocean Water Mass Balance from Isotope Data, J. Geophys. Res., 89, 6373-6381, 1984.

Perovich, D.K., W.B. Tucker III, and R.A. Krishfield, Oceanic heat flux in the Fram Strait measured by a drifting buoy. Geophys. Res. Let., 16, 995-998, 1989.

Strickland, J.D.H. and T.R. Parsons, A Practical Handbook of Seawater Analysis, Bulletin 167, 2nd edition, Fisheries Research Board of Canada, Ottawa, $310 \mathrm{pp}, 1972$.

Thorndike, A.S., and R. Colony, Arctic Ocean Buoy Program Data Report 19 January 1979 - 31 December 1979, Polar Science Center, University of Washington, Seattle, 131 pp., 1980.

Tucker, W.B. III and J.W. Govoni, A Portable Hot Water Ice Drill. Cold Regions Science and Tech., 14, 57-64, 1987.

Untersteiner, N., The Geophysics of Ice, Plenum Press, New York, 1196 pp., 1986.

Untersteiner, N., and A.S. Thorndike, Arctic data buoy program, Polar Record, 21, 127-135, 1982.

Vinje, T. and O. Finnekasa, The Ice Transport through the Fram Strait, Skrifter Nr. 186, Norsk Polarinstitutt, Oslo, 39 pp., 1986. 
Wadhams, P., The Ice Cover, Chapter 2 in The Nordic Seas (B.G. Hurdle, ed.), Springer-Verlag, Berlin, 777 pp., 1986.

Weeks, W.F., and S.F. Ackely, The growth, structure, and properties of sea ice, CRREL Monograph 82-1, Cold Regions Research and Engineering Laboratory, Hanover, New Hampshire, 130 pp., 1982. 
January 17, 1990

\section{Distribution List for Technical Report Exchange}

Attn: Stella Sanchez-Wade

Documents Section

Scripps Institution of Oceanography

Library, Mail Code C-075C

La Jolla, CA 92093

Hancock Library of Biology \& Oceanography

Alan Hancock Laboratory

University of Southern California

University Park

Los Angeles, CA 90089-0371

Gifts \& Exchanges

Library

Bedford Institute of Oceanography

P.O. Box 1006

Dartmouth, NS, B2Y 4A2, CANADA

Office of the International

Ice Patrol

c/o Coast Guard R \& D Center

Avery Point

Groton, CT 06340

NOAA/EDIS Miami Library Center

4301 Rickenbacker Causeway

Miami, FL 33149

\section{Library}

Skidaway Institute of Oceanography

P.O. Box 13687

Savannah, GA 31416

Institute of Geophysics

University of Hawaii

Library Room 252

2525 Correa Road

Honolulu, HI 96822

Marine Resources Information Center

Building E38-320

MIT

Cambridge, MA 02139

Library

Lamont-Doherty Geological Observatory

Colombia University

Palisades, NY 10964

Library

Serials Department

Oregon State University

Corvallis, OR 97331
Pell Marine Science Library

University of Rhode Island

Narragansett Bay Campus

Narragansett, RI 02882

Working Collection

Texas A\&M University

Dept. of Oceanography

College Station, TX 77843

Library

Virginia Institute of Marine Science

Gloucester Point, VA 23062

Fisheries-Oceanography Library

151 Oceanography Teaching Bldg.

University of Washington

Seattle, WA 98195

Library

R.S.M.A.S.

University of Miami

4600 Rickenbacker Causeway

Miami, FL 33149

Maury Oceanographic Library

Naval Oceanographic Office

Bay St. Louis

NSTL, MS 39522-5001

Marine Sciences Collection

Mayaguez Campus Library

University of Puerto Rico

Mayagues, Puerto Rico 00708

Library

Institute of Oceanographic Sciences

Deacon Laboratory

Wormley, Godalming

Surrey GU8 5UB

UNITED KINGDOM

The Librarian

CSIRO Marine Laboratories

G.P.O. Box 1538

Hobart, Tasmania

AUSTRALIA 7001

Library

Proudman Oceanographic Laboratory

Bidston Observatory

Birkenhead

Merseyside L43 7 RA

UNITED KINGDOM 


\begin{tabular}{|c|c|c|c|}
\hline $\begin{array}{l}\text { REPORT DOCUMENTATION } \\
\text { PAGE }\end{array}$ & $\begin{array}{l}\text { 1. REPORT NO. } \\
\text { WHOI-90-02 }\end{array}$ & 2. & 3. Recipient's Accession No. \\
\hline \multirow{2}{*}{\multicolumn{2}{|c|}{$\begin{array}{l}\text { 4. Title and Subtitie } \\
\text { The Arctic Environmental Drifting Buoy (AEDB) } \\
\text { Report of Field Operations and Results } \\
\text { August, } 1987 \text { - April } 1988\end{array}$}} & & $\begin{array}{l}\text { 5. Report Date } \\
\text { January, } 1990\end{array}$ \\
\hline & & & 6. \\
\hline \multicolumn{3}{|c|}{$\begin{array}{l}\text { 7. Author(s) } \\
\text { Susumu Honjo, Richard Krishfield, Albert Plueddemann }\end{array}$} & $\begin{array}{l}\text { 8. Performing Organization Rept. No. } \\
\text { WHOI } 90-02\end{array}$ \\
\hline \multirow{2}{*}{\multicolumn{2}{|c|}{$\begin{array}{l}\text { 9. Performing Organization Name and Address } \\
\text { The Woods Hole Oceanographic Institution } \\
\text { Woods Hole, Massachusetts } 02543\end{array}$}} & & 10. Project/Task/Work Unit No. \\
\hline & & & $\begin{array}{l}\text { 11. Contract(C) or Grant(G) No. } \\
\text { (C) ONR Number NO0014-87, } 88 \text {, } \\
\text { (G) } 89, J-1288\end{array}$ \\
\hline \multirow{2}{*}{\multicolumn{2}{|c|}{$\begin{array}{l}\text { 12. Sponsoring Organization Name and Address } \\
\text { Funding was provided by the Office of Naval Research }\end{array}$}} & & $\begin{array}{l}\text { 13. Type of Report \& Period Covered } \\
\text { Technical Report }\end{array}$ \\
\hline & & & 14. \\
\hline
\end{tabular}

15. Supplementary Notes

This report should be cited as: Woods Hole Oceanog. Inst. Tech. Rept., WHOI-90-02.

16. Abstract (L/mit: 200 words)

There are strong reasons to gather data on polar oceanography and climatology in real time using fully automated, unattended instrumentation systems for long periods; particularly during the inaccessible winter months when moving ice is extremely hazardous. We deployed an Arctic Environmental Drifting Buoy (AEDB) on 4 August 1987 at $86^{\circ} 7^{\prime}$ N, $22^{\circ} 3^{\prime}$ E off of the FS Polarstern on a large $3.7 \mathrm{~m}$ thick ice island. The AEDB consisted of 2 major components: a $147 \mathrm{~cm}$ diameter surface float housing ARGOS transmitters and a data logger for ice-profiling thermistors, and a $125 \mathrm{~m}$ long mooring line attached to the sphere and fed through a $1 \mathrm{~m}$ diameter ice hole. Along the mooring were deployed 2 fluorometers, conductivity and temperature loggers, an Acoustic Doppler Current Profiler (ADCP), a current meter, and a time-series sediment trap/micro-filter pump/transmissometer unit. The AEDB proceeded southwesterly with the Transpolar Drift at an average speed of $15.3 \mathrm{~km} /$ day, with a maximum speed of $88.8 \mathrm{~km} /$ day. On 2 January 1988 , the AEDB dropped into the water while passing through the Fram Strait and for the remaining drift period was either free-floating on the water surface or underneath the sea ice. Throughout this period, the transmitters onboard successfully transmitted position, temperature, and strain caused by ice on the sphere. Although the sediment trap package was lost during the drift, valuable data was collected by the other instruments throughout the experiment. The ice thermistor data was used to determine oceanic heat flux, while continuous ADCP observations over the Yermak Plateau provided a wealth of information for understanding internal waves in the ice-covered ocean. The buoy was recovered 'by the Icelandic ship R/S Arni Fridriksson on 15 April 1988 at $65^{\circ} 17^{\prime} \mathrm{N}, 31^{\circ} 38^{\prime} \mathrm{W}$, off southeastern Greenland, completing $3,900 \mathrm{~km}$ of drift in 255 days. We are in the process of constructing the next automated stations which are planned for deployment in both the north and south polar regions in 1991-92.

17. Document Anaiysis a. Descriptors

1. transpolar drift

2. ice ocean environment

3. ADCP

b. Identiflers/Open-Ended Terms

c. COSATI Field/Group

18. Availability Statement

Approved for publication; distribution unlimited.

19. Security Class (This Report) UNCLASSIFIED

20. Security Class (This Page)
21. No. of Pages 128

22. Price 